\title{
Workplace Investigation of Increased Diagnosis of Malignant Melanoma Among Employees of Lawrence Livermore National Laboratory
}

Dan H. Moore II, Ph.D., H. Wade Patterson, B.A., Fred Hatch, M.D., Ph.D., David Discher, M.D., Jeffrey S. Schneider, M.D., Deborah Bennett, M.A.

August 1994

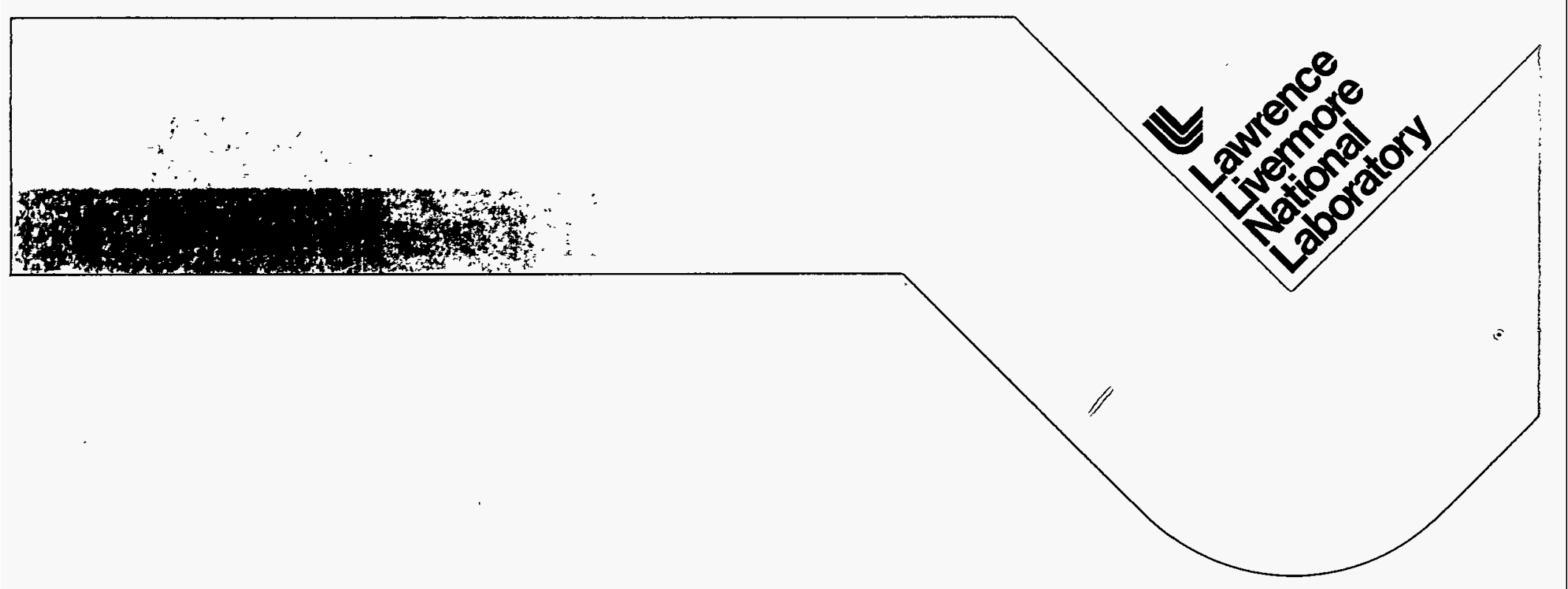




\section{DISCLAIMER}

This document was prepared as an account of work sponsored by an agency of the United States Govemment. Neither the United States Government nor the University of California nor any of their employees, makes any warranty, express or implied, or assumes any legal liability or responsibility for the accuracy, completeness, or usefulness of any information, apparatus, product, or process disclosed, or represents that its use would not infringe privately owned rights. Reference herein to any specific commercial product, process, or service by trade name, trademark, manufacturer, or otherwise, does not necessarily constitute or imply its endorsement, recommendation, or favoring by the United States Government or the University of California. The views and opinions of authors expressed herein do not necessarily state or reflect those of the United States Government or the University of California, and shall not be used for advertising or product endorsement purposes.

This report has been reproduced directly from the best available copy.

Available to DOE and DOE contractors from the Office of Scientific and Technical Information P.O. Box 62, Oak Ridge, TN 37831

Prices available from (615) 576-8401, FTS 626-8401

Available to the public from the

National Technical Information Service

U.S. Department of Commerce

5285 Port Royal Rd.

Springfield, VA 22161

Workperformed under the auspices of the U.S. Department of Energy by Lawrence Livermore National Laboratory under Contract W-7405-Eng-48. 


\section{DISCLAIMER}

Portions of this document may be illegible in electronic image products. Images are produced from the best available original document. 
UCRL-LR-106723

Distribution Category UC-908

Workplace Investigation of Increased Diagnosis of Malignant Melanoma Among Employees of Lawrence Livermore National Laboratory

Dan H. Moore II, Ph.D., H. Wade Patterson, B.A., Fred Hatch, M.D., Ph.D., David Discher, M.D., Jeffrey S. Schneider, M.D., Deborah Bennett, M.A.

August 1994

\section{LAWRENCE LIVERMORE NATIONAL LABORATORY}

University of California - Livermore, California • 94551

DISTRIBUTION OF THIS DOCUMENT IS UNLIMITED 


\section{Acknowledgments}

We wish to thank the many people who made this effort possible. In particular, we would like to acknowledge the following people for their diligent and conscientious support during this project. Robert Grabske developed and ran the programs used to compare the frequency of words used by the controls and cases in the interviews and in the narrative summary prepared from each interview. Pamela Harris managed our melanoma databases. Pamela entered and maintained data, archived historical melanoma data, and generated statistical reports and files. She also designed several melanoma databases and built new databases as required to support our study. Susan Johnson performed the administrative work for the investigation. Susan created and maintained a confidential medical file for each individual and scheduled appointments for interviews and examinations. She also routed copies of the interviews and the narrative summaries to the participants, the investigators, and the reviewers. She did all this with unfailing good humor coupled with the necessary degree of persistence. Karen Martin, a nurse in the LLNL Health Services Department, met with each of the participants and helped them through the questionnaire on the constitutional factors. She also assisted with the dermatological examinations, in particular the detailed mole counts. We also wish to thank James S. Johnson, David S. Myers, and William J. Silver for their careful and thoughtful reviews of the narrative summaries for completeness and scoring accuracy. A special appreciation goes to Margaret Sands who patiently and carefully edited this document. She skillfully combined the written contributions of the several authors into a smooth, coherent, and unified text. 


\section{Table of Contents}

Executive Summary ....................................................................................................................... 4

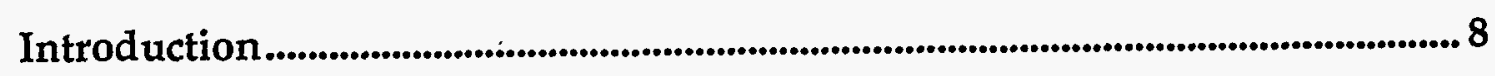

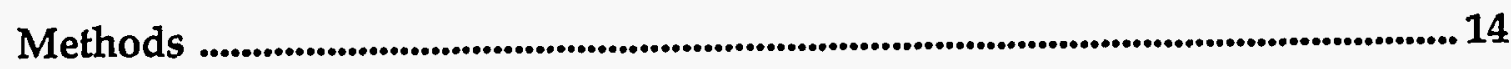

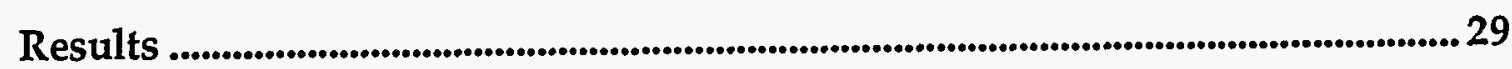

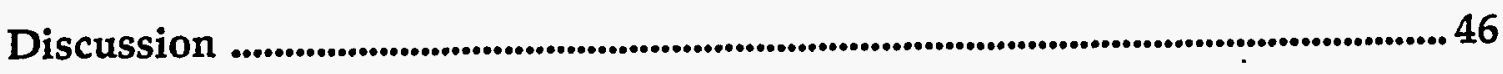

Conclusions and Recommendations .................................................................................... 52

References ............................................................................................................................ 54

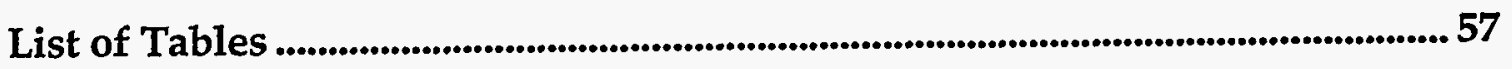

List of Figures ................................................................................................................ 59

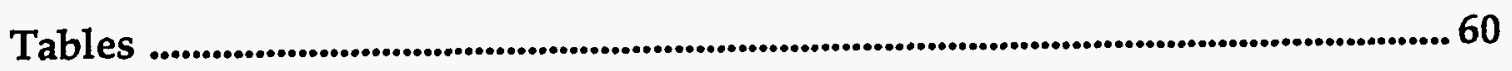

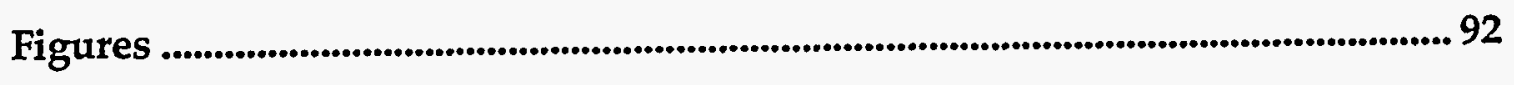

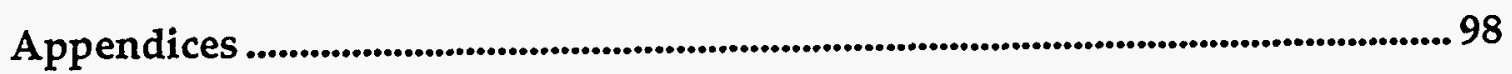




\section{Executive Summary}

Based on rates for the surrounding communities, the diagnosis rate of malignant melanoma for employees of Lawrence Livermore National Laboratory (LLNL) during 1972 to 1977 was three to four times higher than expected. ${ }^{1}$

In 1984 Austin and Reynolds concluded, as a result of a case-control study, that five occupational factors were "causally associated" with melanoma risk at LLNL. 2 These factors were: (1) exposure to radioactive materials, (2) work at Site 300, (3) exposure to volatile photographic chemicals, (4) presence at the Pacific Test Site, and (5) chemist duties.

Subsequent reviews of the Austin and Reynolds report concluded that the methods used were appropriate and correctly carried out.3,4 These reports did determine, however, that Austin and Reynolds' conclusion concerning a causal relationship between occupational factors and melanoma among employees was overstated. There is essentially no supporting evidence linking the occupational factors with melanoma from animal studies or human epidemiology. Our report summarizes the results of further investigation of potential occupational factors.

\section{Study Design}

Our case-control study matched one control to each case. All melanoma cases diagnosed among LLNL employees between January 1, 1969 (all cases prior to 1969 are deceased), and March 1, 1989 (the start of the study), were eligible. The study included 69 cases who were alive and willing to participate. A "bestmatch" control (an LLNL employee without melanoma) was selected according to five criteria: (1) sex, (2) age, (3) start date at LLNL, (4) years of education, and (5) years of tenure at LLNL.

Three methods were used to gather information from cases and controls. The first method was an occupational interview focusing on exposures to the Austin and Reynolds factors conducted by a former Hazards Control department head who had been associated with both LLNL and LBL (Lawrence Berkeley Laboratory) for over 40 years. Each interview was recorded by a certified shorthand reporter, and the transcript of the interview was used by a panel of 
three occupational exposure experts to assess exposures to suspected occupational agents. The second method was a questionnaire administered by a nurse to assess constitutional factors that included many known risk factors for melanoma such as ethnicity, hair and eye color, skin reaction to sunlight, and episodes of sunburn. The third method was a thorough examination by a dermatologist for each case and each control. The dermatologist also counted all moles larger than $2 \mathrm{~mm}$ in diameter.

\section{Results}

We did not find any occupational factors that were significant for melanoma risk. Controls had greater exposure than cases to four of the Austin and Reynolds factors: ionizing radiation, presence at the Pacific Test Site, volatile photographic chemicals, and chemist duties. Cases had greater exposure than controls to one factor: Site 300. None of these differences were statistically significant. Furthermore, a computerized review of the words used by cases and controls during the occupational interview did not reveal significant differences in word frequencies for those words associated with any of the Austin and Reynolds factors. These findings fail to support those reported by Austin and Reynolds. There are, however, several differences between the two studies that may account for the differences in the findings.

In our study, controls were matched to cases for two important characteristics that were not used as matching criteria in the Austin and Reynolds study. These two characteristics were years of education and start date of employment at LLNL. Although Austin and Reynolds have reported (as have several other melanoma studies) that years of education is a significant risk factor for melanoma, it is not known how this risk factor operates. ${ }^{5}$ One hypothesis is that income increases with years of education and increased income leads to increased leisure activities in sunny areas. (In fact, based on data from studies in Australia, it appears that exposure to intense UV during early teenage years is the most significant solar risk factor.) It is believed that those with increased years of education are likely to have come from families of higher socioeconomic status who could afford sunny vacations and college educations for their offspring. Thus, by failing to match for years of education, the Austin and Reynolds study confounded this risk factor with occupational factors. 
For example, chemist duties require advanced education, therefore the risk factor for a chemist may be, in part, explained by educational background.

Over the years, the LLNL workforce has seen a decrease in exposure to both chemicals and ionizing radiation. Thus, employees with earlier start dates were likely to have higher exposures than those with later start dates. We can demonstrate that this was true for all of the 138 members in our case-control study. Therefore, by failing to match for start date, Austin and Reynolds introduced a possible confounding of exposure factors. For example, if a case who began working at LLNL in the 1960s was matched to a control who began in the 1970s, their exposures to chemicals and ionizing radiation would be expected to differ. On the other hand, when controls were matched to cases with respect to start date, we could better determine whether specific exposures increased the risk of melanoma.

We found the usual associations between non-occupational factors and melanoma risk. Cases were more likely to burn rather than tan, they tended to have more moles than the controls, and had less sun exposure prior to diagnosis. We also found that tanning ability and the total number of moles larger than $2 \mathrm{~mm}$ in diameter, as assessed by the dermatologist, could correctly identify 49 cases in the 69 case-control pairs ( $71 \%$ correct classification). If we restricted the classification to case-control pairs where the case had invasive melanoma, 33 out of $39(85 \%)$ could be correctly identified by these two factors. Only one invasive case was misclassified since the remaining five case-control pairs were indistinguishable with respect to these two factors.

The results of the responses to the questionnaire were also good for classifying all case-control pairs based on the following four factors: tanning ability, amount of sunbathing between the ages of 15 and 25 , sun avoidance during the 10 years preceding diagnosis, and hiking as a pastime. These responses correctly identified cases in 56 out of 69 pairs ( $81 \%$ of all types of melanoma). The same four factors, with a measure of UV exposure based on residential history in place of sunbathing during the ages of 15 to 25 , correctly identified cases in 35 out of 39 pairs $(90 \%)$ in which the case had invasive melanoma. Four invasive cases were misclassified by these four factors. 


\section{Conclusions}

During the course of this study, we found no evidence to suggest that there were any occupational factors at LLNL that contributed to the increased melanoma diagnosis among employees. A simple model that used the ability of the skin to tan after repeated exposure to sunlight and the number of moles larger than $2 \mathrm{~mm}$ in diameter to classify subjects, resulted in $71 \%$ correct classifications. Thus, we conclude that the major risk factors for melanoma among LLNL employees are constitutional. Such factors, plus a heightened awareness among employees and the medical staff, adequately explain the increased rate of diagnosis. After reaching a peak in the 1980s, the rate of diagnosis of invasive melanoma among employees has declined and is currently no higher than expected based on rates for the surrounding communities (Alameda and Contra Costa counties). 


\section{Introduction}

\section{Laboratory Programs}

LLNL is located approximately 65 kilometers east of San Francisco and occupies about 260 hectares in the Livermore Valley. This site, formerly used by the Navy as a primary flight-training base, is located just east of Livermore. Livermore has an approximate population of 50,000. LLNL and Sandia Laboratory, located immediately to the south, are the largest employers in the area with approximately 8000 and 3000 employees respectively.

In 1950, with the encouragement of Ernest Lawrence, California Research \& Development Corporation began the design and construction of the Materials Testing Accelerator. The Radiation Laboratory at Berkeley (now known as Lawrence Berkeley Laboratory) and the University of California supplied research and consulting assistance under a contract with the Atomic Energy Commission. In 1952, when the Atomic Energy Commission decided to create a second nuclear weapons laboratory under Lawrence's guidance, it was naturally located at this site. All staff and services were initially provided by the Radiation Laboratory and the University. Most employees spent portions of their time at both the Berkeley and Livermore sites.

The primary mission of LINL since its inception has been the design and engineering of nuclear explosives. A complete unit containing both highexplosive and nuclear material is never assembled at the site, although LLNL does produce and fabricate these materials. The quantities of materials that are used are sufficient for non-nuclear testing and evaluation.

Related nuclear energy programs conducted by LLNL have involved accelerators, lasers, magnetic fields, and nuclear reactors. Other non-nuclear programs conducted by LLNL include energy, environmental, and biomedical research.

Many of these non-nuclear programs were conducted off site, but only nuclear explosive testing employed large numbers of people off site over a long period of 
time. Early atmospheric tests were conducted in the Pacific and in Nevada. Underground testing has been conducted almost exclusively in Nevada.

The Experimental Test Site, Site 300, is located about 24 kilometers to the east of LLNL in the sparsely populated hills of the Diablo Range. Site 300 is primarily an explosives test facility that occupies about 10 times the area of the Livermore site. It began operation in 1955 to support the research, development, and non-nuclear testing associated with the design of nuclear weapons. The work there involves processing, assembly, and testing of explosive components.

Each explosives firing facility consists of a bunker for personnel protection and a gravel covered area (often referred to as a firing table). Tested explosives assemblies have contained uranium, beryllium, and sometimes thorium and tritium. The debris from these tests contain trace amounts of these materials, but monitoring data has shown that the majority of the materials are confined to the immediate vicinity of the firing table. The debris from the explosives tests and the gravel covering the firing table are periodically removed and until 1989 were placed in monitored landfills on site. Since 1989 the removed gravel and debris have been placed in approved waste collection containers.

Over the years, the residential population at Site 300 has averaged around 150 people, with perhaps 600 or 700 additional people assigned there on a part-time or intermittent basis. The climatic record shows slightly higher and lower temperatures than the LINL site with similar precipitation. All water comes from on-site wells, and there is an on-site waste treatment facility and wastewater pond.

LLNL is structured as a matrix organization. This system allows scientific, technical, and support staff to work in different programs simultaneously. For this reason, a person's job title in no way describes their actual working environment. Even payroll records are of little use in tracking job history. The use of many buildings has also changed completely over time. For example, a building that is used as a chemistry lab today might be an office tomorrow. Thus, an interview format was chosen for our study as the way to determine and quantify potential exposures. Figure 1 shows how these programs have changed over time. 
The LLNL workforce is relatively stable in comparison to other industries; however, turnover rates average about six percent per year. This leads to significant numbers of former employees and retirees who are of epidemiological concern. During the period when melanoma incidence at LLNL was initially rising above the community rate, there were approximately 5000 employees. Women and minorities were underrepresented early in the period reviewed, but their numbers have increased substantially.

The nature of research and development activities at LLNL has often required the frequent use of unusual materials, advanced equipment, and many one-of-a-kind processes. This is especially true when compared with other local employers engaged in research and development efforts. Interestingly, some interviewees spoke of the exotic work and materials that are found at LLNL. However, when viewed from the context of the workplace setting, the potential health hazards at LLNL are much the same as other DOE contractor sites. Similarly, our employees are much like employees at other DOE sites.

Although there are health hazards present at LLNL, safety awareness and prevention have always had a very high organizational priority and are an integral and well-funded part of all activities. Additionally, LLNL maintains a large professional staff devoted to safety issues. Safety records show that almost all accidents and lost-time injuries are due to ordinary industrial causes, while the few fatalities that have occurred have been due to transportation accidents.

\section{The LLNL Environment}

The suburban communities of Dublin and Pleasanton are located 10 kilometers west of LLNL. The land between these two communities is devoted to a mixture of agriculture, light industry, and residential developments. The land adjacent to LLNL is used for pasture, field crops, and grape harvesting. There are housing and apartment complexes just west of LLNL.

The Livermore Valley soil composition is alluvium and the terrain at LLNL slopes gently downward to the north. The slope is sufficient so that standing water does not remain after rainfall. The climate in the Livermore Valley is 
Mediterranean, with warm, dry summers and cooler damp winters. Annual rainfall is about 50 centimeters and occurs mostly between October and April. Snow in the area is rare. The annual windrose for LLNL is symmetric, but when temperatures are warm in the Central Valley and cool along the coast, the prevailing winds are westerly.

Jogging, swimming, hiking, bicycling, and other outdoor sports are popular in the Livermore Valley. LLNL encourages these and similar activities and maintains a large swimming pool for employees and their families.

Buildings at LLNL are of conventional construction and are anywhere from one to seven stories high. Central air conditioning is used throughout most of the site, and trailer complexes house many employees. Some older buildings are actually barracks remaining from Navy days, and others that are slightly newer have asbestos-containing exterior panels and interior ceiling tiles. Sampling has confirmed that health hazards from asbestos are not present in the buildings. Over the years, the grounds have been extensively landscaped with lawns and trees.

Water, both domestic and industrial, usually comes from the Hetch-Hetchy aqueduct that also supplies the city of San Francisco. Additionally, water from local wells (Zone 7) is connected to the LLNL system and is used when needed. Zone 7 water is also used domestically in nearby residential areas. Waste water and sewage are piped to the Livermore municipal treatment plant and can be diverted, if necessary, to a holding pond. The plant and holding pond are located several kilometers west of LLNL. A more complete description of the LLNL programs and environment can be found in the LLNL Environmental Impact Statement and Environmental Report. 6

\section{Cutaneous Melanoma Epidemiology}

Worldwide, the incidence of cutaneous melanoma has been doubling every decade for the past 30 years. ${ }^{7}$ In the U.S., the incidence of cutaneous melanoma is increasing more rapidly among Caucasian men than any other cancer. In Caucasian women, the rate of increase is second only to lung cancer. The estimated incidence of melanoma in the U.S. for 1991 was 32,000 invasive cases 
(about $2.9 \%$ of the total cancer incidence) and 6000 in situ cases. The mortality in 1991 was estimated to be 8500 . The death rate for men with melanoma was substantially higher than the death rate for women. Between 1985 and 1987, the U.S. incidence rates appear to have reached a plateau, although the incidence rate in 1987 was about $25 \%$ higher for men than for women. ${ }^{8}$

In the metropolitan San Francisco-Oakland statistical area, the plateau of recent incidence rates has been confirmed by Horn-Ross. ${ }^{9}$ However, the Bay Area rate for men exceeds the national SEER (Surveillance, Epidemiology, and End Results) Program rate by about $25 \%$. The excess for women is about $28 \%$ (estimated from Figure 1 of Horn-Ross). ${ }^{9}$

\section{Recognition of Melanoma Increase at LLNL}

Up until 1960, when one case was diagnosed, there had been no known cases of cutaneous melanoma at LLNL (see Figure 2). Single cases occurred in 1963 and 1964. Beginning in 1968, one case per year was diagnosed until 1972 when a cluster of four cases occurred. Although there were no cases in 1973, four cases were diagnosed in both 1974 and 1975. Two cases were diagnosed in 1976, and six cases in 1977. The total number of cases from 1960 to 1976 was 21 . However, only 15 of these cases were known to the medical department.

Dr. Max Biggs, the LLNL Medical Director at the time, and several physicians in the area became concerned about the increased diagnosis rate at LLNL. In February of 1977, with LLNL funding, Dr. Biggs requested assistance from Dr. Donald Austin at the Resource for Cancer Epidemiology, California Department of Health Services. This department maintains the Tumor Registry for the San Francisco Bay Area.

Dr. Austin and Dr. Reynolds (his associate) compared the number of melanoma cases observed among LLNL employees from 1972 to 1977 with the expected number. This number was based on age, race, sex, and census tract rates in two adjacent counties where most LLNL employees lived. The results were released in April 1980 as Report No. 1 and later published in Lancet. ${ }^{1}$ 
The incidence rate of 19 cases of melanoma among LLNL employees during this period was determined to be three to four times higher than the expected incidence rate. Also, a retrospective analysis of six-year cumulative data showed that the LLNL incidence rate began to exceed that of the adjacent counties in approximately 1971. (A comprehensive history of melanoma studies at LLNL is the subject of a separate report. $)^{10}$ 


\section{Methods}

This section describes the investigative methods that were developed for this study. We could not find an existing investigative method that exactly suited our requirements for this particular study. Therefore, we devised our own method for the exposure assessment process. After our interviews were completed, we did find a similar interview approach that had been developed by Siemiatycki for application to community case-control studies. 11,12 We based our constitutional factors questionnaire on the Australian experience of Holman. ${ }^{13}$ The methods we used for each phase of the study are discussed in detail below.

\section{Identifying the Cases}

We began by establishing the criteria for the melanoma cases to be included in the study. The first criterion was that an individual must have been an employee when the diagnosis occurred. This excluded U.C. Berkeley and LBL employees, contract employees, and others not employed by LLNL at the time of diagnosis. We further required that all of our cases have their melanoma diagnosis confirmed by pathologists at the U.C. San Francisco Melanoma Clinic. This criterion was established because there are often differing interpretations of melanoma. Finally, the diagnosis must have occurred between January 1, 1969, and March 1, 1989. Using these criteria, we were able to identify 86 melanoma cases.

Of the 86 people identified, seven people refused to participate, nine people died before the study began, and one we could not locate. When we obtained their informed consents, 14 of the remaining 69 participants had retired from LLNL. During the course of our study, other LLNL employees retired, but all of them continued to participate in the study.

\section{Selecting the Controls}

Shortly after receiving consents from the 69 cases, we accessed the LLNL master personnel file to obtain, through use of an algorithm, a candidate list of matched controls. The algorithm calculation of the best, second-best, and third-best matches served as a basis for inviting individuals to participate. This algorithm calculation could not be made solely on data in the master personnel file because 
of certain omissions and inaccuracies. In addition, we found it necessary to personally contact those people whose preliminary algorithm scores were close to that of a case. If they agreed to participate, we obtained their informed consent and then scheduled data acquisition following the same procedure used for the cases. (A copy of the consent form is provided in the appendices of this report.) We made a concerted effort to follow the same procedure thereafter for both groups.

\section{Algorithm for Identifying Matched Pairs}

It was the judgment of the principal investigators and the Melanoma Investigation Task Group that any difference in sex should be weighed most heavily followed by differences in start date and education. Thus, the algorithm for identifying matched pairs contained five weighted elements. These elements were: difference in age ( $A$, in years), difference in sex $(S, 0$ or 1$)$, difference in start date ( $D$, in years), difference in tenure ( $T$, in years, adjusted for leave of absence), and difference in post-high-school education ( $E$, in years). The differences were squared and given relative weighting factors, yielding the equation:

$$
\frac{\mathrm{A}^{2}+4 \mathrm{~S}^{2}+2 \mathrm{D}^{2}+\mathrm{T}^{2}+2 \mathrm{E}^{2}}{10}
$$

The following is a hypothetical example of the results of the matching algorithm. Joseph Case was 52 years old, with a start date of January 1969, tenure of 21 years, and 9 years of post-high-school education. His best match was John Control, who was 53 years old, with a start date of November 1969, tenure of 20 years, and 7 years of education. These values were substituted in the algorithm as shown below:

$$
\begin{gathered}
\frac{(53-52)^{2}+4(0)^{2}+2\left(\frac{11-1}{12}\right)^{2}+(20-21)^{2}+2(7-9)^{2}}{10} \\
=\frac{1+0+1.39+1+8}{10}=1.139 .
\end{gathered}
$$


As noted above, the data used for this algorithm came from a master file of all personnel who had been employed by LLiNL. This file contained data on approximately 16,000 people. The algorithm was used to calculate a best, secondbest, and third-best match to the cases, including matching retiree-to-retiree. In only two cases were we unable to arrange for the participation of the best matched control and therefore used the second-best match.

To protect the privacy of the cases and controls in this study, the data presented in Table 1 cannot be used to identify individuals. Of the 69 matches, only 11 were not matched for sex. The results of the matching for age, start date, years of education, and years of tenure are shown in Tables 2 through 5. These tables show that the matching obtained for each matching factor was quite close. Table 6 shows the distribution of overall match scores, as defined above. The pair with the largest match score (equal to 6.15), i.e., the poorest match, were of the same sex (both male), and differed by one year in age. They both had matching start dates and tenure within one month, but differed in education by 5.5 years. All other pairs had lower matching scores, so the matching appeared to be very close. Later we compared these matched controls with those selected by Austin \& Reynolds in their case-control study. Finally, we note that we have retained complete documentation in a confidential file on the selection of each case and of each control.

\section{Pilot Study}

We considered our first 11 cases to be a pilot study group, and as such, we used the experience gained from them to improve, modify, and expand our procedure. We thus refined the control-selection algorithm, the occupational factors interview, the constitutional factors questionnaire, and the dermatological exam. These 11 cases were then reinterviewed and reexamined using the modified techniques to supplement and normalize the information we had first obtained from them. 


\section{The Occupational Factors Interview}

To ensure that the occupational factors interview was as effective as possible, a principal investigator met with each interviewee before the interview and explained the nature and extent of the investigation process. He discussed the forthcoming interview, the administration of the constitutional factors questionnaire, and the dermatological examination. During this initial meeting, the interviewee signed the necessary health information release forms and two request-for-information forms. One request was sent to the LLNL Security Department to obtain a copy of the individual's personnel security questionnaire (PSQ). (This document contains information about past residences and employment.) The other request was sent to the Hazards Control Department for the individual's radiation dosimetry record.

The principal investigator also gave the interviewee an exposure checklist and explained how it should be used to organize his (or her) thinking and to help recall past events. The principal investigator also asked the interviewee to prepare for the interview by re-reading and checking the items a day or so before it took place. The checklist was extensive and contained more than approximately 400 items and workplace situations. A portion of the exposure checklist is presented in the appendices of this report. An outline of the checklist is shown below:

1. Possible exposures. (Chemical, physical, biologic, and other unusual types of exposures.)

2. Programs, projects, and enterprises at LLNL and elsewhere.

3. LLNL work history. (Including locations, building and room numbers, names of supervisors and coworkers, etc.)

4. Appendices A-D attached to the checklist. (These appendices list carcinogens, photographic chemicals, explosives, and materials used for stemming the drill holes to underground placement cavities at the Nevada Test Site.) 
The principal investigator then answered any questions that the interviewee had and made an appointment for the occupational factors interview. The dermatologic examination and the session with the occupational health nurse to administer the constitutional factors questionnaire were also scheduled at that time. The occupational factors interview, the examination, and the questionnaire took approximately four hours to complete. In addition, just before the interview, the interviewee was reminded with a phone call.

\section{The Interview Setting}

One of two noteworthy elements in the interview was the setting. All interviews took place in a small room with comfortable chairs, a circular table, and a window with an outside view. This conveyed an atmosphere of openness and neutrality. The room itself was outside the security area of LLNL so that uncleared people could come and go without being checked by a guard. We believe that this relaxed setting encouraged the interviewees to speak freely about their history and experiences. For example, it was not uncommon for the interviewee to say, "I'd forgotten about that. I'm glad you reminded me." Or perhaps, "I hadn't thought about that for years." The second noteworthy element of the interview was the presence of a certified shorthand reporter. The purpose of using a reporter to transcribe the interview was to eliminate the necessity of taking notes and deciphering audiotapes. In addition, the presence of the reporter emphasized that the interview was a serious matter to LLNL. The interviewer was a male of retirement age with a 40-year history of association with LLNL and LBL programs and projects. Although he was not a professional interviewer, nor completely informed about every pertinent LLNL or LBL activity, he was conversant about nearly every topic that arose during the interview.

Given this setting and assurances, only one interviewee declined to continue to participate in the study after the interview. With this single exception, the interviewees' level of participation, cooperation, and enthusiastic interest in the interview process as well as the entire investigation were remarkable. 


\section{Interview Description}

The interviewee was told at the beginning of the interview that the exposure checklist was only a partial listing and that they should discuss any pertinent material not on the list. The interviewer then explained the rating system that would be used. For example, he explained that any exposures would be rated and quantified, and he also explained the manner in which a narrative summary with ratings would be prepared. He also told the interviewee that they would have an opportunity to comment on the transcript and on the summary of their interview.

Usually during the first part of the interview, the interviewee's PSQ and radiation dosimetry record were discussed. This first part of the interview also covered, in somewhat chronological order, the residential, academic, and work history of the interviewee. It was appropriate, in a few cases, to assure the interviewees that the interview was not a legal hearing and they were not under oath. The interviewer always emphasized that the interviewee was the sole arbiter of the contents of the transcript. He urged them to change only the facts by adding, deleting, and modifying the text. He also emphasized that the only purpose of the transcript was to best reflect their memory of the topic or situation discussed.

The interviewee was sometimes told that should it be necessary to discuss classified information, the site of the discussion could be moved to a secure area. This happened only once during an inconsequential portion of a particular interview. Thus, each interview was fully transcribed. No classified information or any other type of information was omitted.

The second part of the interview concerned five suggested occupational links to melanoma. Dr. Donald Austin of the State of California Department of Public Heath listed these tentative links in his investigation reports of melanoma at LLNL. ${ }^{2}$ The interviewees were invited to comment on each link as it pertained to them personally. The links, using Dr. Austin's terms, were: 
1. Exposure to volatile photographic chemicals.

2. Exposure to radioactive materials.

3. Work at Site 300 .

4. Presence at the Pacific Test Site during a nuclear test.

5. Chemist duties.

We found that many interviewees believed that overexposure to sunlight is the primary cause of melanoma. Therefore, the interviewer discussed the constitutional factors linked to melanoma during the second part of each interview. The interviewer stated that these non-occupational factors would appear in their summary report, but would not need to be further discussed in the interview. The constitutional factors mentioned were:

1. Large moles or numerous moles.

2. A parental history of skin cancer.

3. A previous nonmelanoma skin cancer in the subject.

4. The tendency to burn rather than tan.

5. The acquisition of an advanced educational degree.

At the end of the interview, the interviewer repeated that the interviewees should edit their copy of the transcript only by adding or deleting factual matters, and that the transcript should reflect their best memory of matters discussed. The length of the interviews ranged from about one to five hours. (The five-hour interview was done in two sessions.) The shorthand reporter then took the exposure checklist, the PSQ, and the radiation dosimetry record to be copied and bound with each of three copies of the transcript. 
One copy of the transcript was mailed to the interviewee for editing. It is noteworthy that while none of the interviewees made substantial deletions, some did add useful information. Another copy of the transcript went to the interviewer to ensure that the interview had covered all topics of interest. The principal investigator also reviewed this copy at the time of mailing. It was important for the principal investigator and the interviewer to determine that the events that happened before the melanoma diagnosis were clearly separated for purposes of analysis from those that happened after the diagnosis.

\section{Interview Data}

After the editing and review process was complete, the panel prepared a narrative and scored summary of each interview using the interview transcript. In their summary, the panel assigned occupational factors a numerical rating as follows:

1. Exposure to ionizing radiation. Range 1 to 4.

2. Work at the Pacific Test Site. Range 1 to 3.

3. Work at the Nevada Test Site. Range 1 to 3.

4. Work at Site 300. Range 1 to 3.

5. Chemical exposure. Range 1 to 4 .

6. Photographic chemical exposure. Range 1 to 4.

7. Exposure to nonionizing radiation. Range 1 to 4 .

8. Assignment as a chemist. Range 1 to 3.

\section{Overall Workplace Exposures}

The method developed to score overall workplace exposures to chemicals, nonionizing radiation, and ionizing radiation was simple to understand and to apply. Also, the individuals in our study accepted it without objection. The 
method depended on the fact that most people agree on the broad meaning of general concepts. For example, nearly everyone will agree on a broadly defined concept of difference in size or magnitude. Thus, people can, without difficulty, rank the size of test objects when asked to compare them, e.g., a football field, a racetrack, or a square mile. Our method of ranking workplace exposures was based on this ability.

We explained and established the method during the occupational factors interview by stating that if there were exposures, they would be scored on a fourpoint subjective scale, defined as follows:

1. Inconsequential. (This implies normal or less than normal, normality being those exposures received routinely by all employees.)

2. Higher than normal, but within statutory limits or limits suggested by good engineering practice.

3. Alleged (by the interviewee) or presumed (by the investigator) to be higher than those limits, but not documented. (With documentation meaning the existence of a written record.)

4. Higher than those limits and documented.

The interviewee was then asked to comment on this system, and any questions were answered at the time.

When applying this scoring system to ionizing radiation for which we had a dosimetry record, we scored the accumulated whole-body dose. However, when applicable, the skin dose, the estimated internal emitter doses to specific organs by type of radiation, and the doses received during other employment were appended to this. We also noted when a person had unusual medical doses.

Since operations began in 1952, it has been the policy to issue a radiation dosimeter to all LLNL employees regardless of their work assignment. The specific type of radiation dosimeter issued has changed over the years to reflect state-of-the-art technology. From 1952 until 1969, film was used for personnel 
dosimetry. DuPont 508 and 519 Personnel Monitoring film were also used during this time period, and Kodak Type A nuclear emulsion film was used for neutron dosimetry. In 1969, LLNL was one of the first facilities to convert to thermoluminescent dosimeters (TLDs) for personnel dosimetry. The TLD crystals used in these dosimeters were lithium fluoride (Harshaw 100, 600, and 700) and calcium fluoride (Harshaw 200). The dosimeter packages were designed at LLNL and each contained three crystals that were selected for specific dosimetric applications. The original TLDs were used at LLNL from 1969 to 1985. In 1985, LLNL switched to a commercially produced Panasonic TLD containing four crystals that provide additional dosimetric information. LLNL calibrates its personnel dosimeters with radiation sources that are traceable to the National Institute of Standards (NIST).

The data on each person also included a list of all the specific agents that they discussed in the interview, e.g., carbon tetrachloride, plutonium 239, or magnetic flux at the 3-Gauss level. Generally, these data were not individually scored, but exposures to any of the photographic chemicals, assignments as a chemist, assignments to the Nevada Test Site, assignments to the Pacific Test Site, and work for LLNL at Site 300 were scored to enable us to evaluate the linkages suggested by Dr. Austin.

The narrative summary discussed specific exposures, situations, and elements in the person's history. It was then reviewed by the interviewer and by a threemember panel: a senior safety and health professional, a senior industrial hygienist, and a senior health physicist. These three individuals also had extensive experience in all LLNL activities, and their written comments, if any, were incorporated into the text of each summary. Any differences of opinion were resolved by the principal investigator after he had gathered further data and conferred with sources able to corroborate or clarify past exposure situations. These differences were rare, and their resolution was carried out confidentially and with the interviewee's full knowledge.

At the same time, summaries were circulated to the interviewees for their comments. Using their comments, the numerical values for each occupational factor were reviewed for completeness and accuracy. The values were then entered in a data base for correlation, comparison, and analysis. LLNL activities 
were segregated from non-LLNL activities. Exposure of both cases and controls were assigned to time periods determined by the date of the case diagnosis. Time Period A was 10 or more years prior to the date of diagnosis. Time Period B covered from 10 years prior to the date of diagnosis up to the date of diagnosis.

\section{The Constitutional Factors Questionnaire}

The constitutional factors questionnaire (see the appendices section of this report) was administered to all participants by the same person, a registered nurse employed in the LLNL Health Services Department. This was done face-toface with the participant in a private room in the Health Services Department. The nurse read the questions to the participant and wrote down the answers. Most of the questionnaires were administered during the same half-day as the dermatological exam and lasted about 30 minutes.

Almost all of the questions involved some explanation and probing on the part of the nurse. A discussion about the intent of a question usually took place before the participant decided on an answer. For example, the first time the term "sunbathing" was used, the nurse explained that in the context of the questionnaire, "sunbathing" included any purposeful sun exposure where more than just the head and hands were exposed. It was not confined to "trying to get a tan." As a second example, one question pertained to the average sun exposure between the participant's 15th and 25th birthdays. Almost all of the participants had very different patterns of exposure during high school (ages 15 to 18) than they did during college or military service (ages 18 to 25). The nurse frequently divided the question into two parts and placed the average for the greatest sun exposure era in the answer box with a written explanation next to it. The nurse also noted that during this phase of the study, all of the participants were friendly and cooperative.

\section{The Dermatological Examination}

The dermatologist began each examination by reviewing the administered constitutional factors questionnaire and discussing any prior medical visits to the LLNL medical facility that pertained to skin conditions. The participant's family history was then elicited for the following information: 
1. Numerous moles in any family member.

2. Abnormal-looking moles in any family member.

3. Certified dysplastic moles in any family member.

4. Mole removal in any family member.

5. Melanoma in any family member.

6. Precancerous actinic keratosis in any family member.

7. Skin cancer (nonmelanoma) in any family member.

If a family member had any previous history of the skin conditions listed above, the relationship to the participant was noted.

The participant's own medical history was then discussed with respect to dysplastic moles, mole removal, melanoma pathology, actinic keratosis, and nonmelanoma skin cancer. The participant's skin type was established from the response to two questions: (1) the type of skin reaction (none, pink, red, tender, or blistering) from one hour of noon sun on previously unexposed skin early in the summer, and (2) how dark after the summer (no tan, very little tan, lighter than average, average, darker than average, or very dark) the participant's arms became compared to that of friends who had equal sun exposure. Hair color was rated red, blond, light brown, brown, dark brown, or black. If the participant had gray hair, their recollection of hair color at age 20 was used. Eye color was compared to a standard eye color chart.

Two whole-body skin examinations were conducted. The first was identical to the LLNL Spot Check screening examination. However, instead of being a selfexamination, it was performed by a dermatologist who enumerated the total number of moles for each body location. The number of freckles and lentigines were estimated as follows: few (covering or limited to a single body part, e.g., a shoulder), moderate (two body areas), or many (more than two body areas). The clinical likelihood of any dysplastic lesion was then assessed as possible, 
probable, or definite. The total number of these dysplastic lesions were estimated as few (1 to 5), moderate (6 to 10), or many (>10). The size of the largest dysplastic mole was measured and recorded as small (less than $6 \mathrm{~mm}$ ), medium ( 6 to $11 \mathrm{~mm}$ ), large (12 to $20 \mathrm{~mm})$, and very large $(>20 \mathrm{~mm})$. Both the predominant locations and the secondary locations of moles were noted. Separate mole counts were made for the scalp, head and neck, upper back, low back, buttocks, chest, abdomen, upper extremity, lower extremity, palms, and the soles of the feet. The employee was then reexamined and the exact number of moles greater than $2 \mathrm{~mm}$, greater than $5 \mathrm{~mm}$, and dysplastic moles were recorded for each body region.

\section{Scoring of the Dermatological Exam}

Responses to the questionnaire and the results of the dermatological exam were coded into scores with a range of 1 to 4 . A " 1 " indicated a low melanoma risk and $a$ " 4 " indicated a high melanoma risk. For example, the skin examination findings were coded based on eye color, hair color, skin typing, and mole count findings. Blue or green eyes, and red or blond hair were all Code 4 categories. In contrast, brown eyes and dark brown or black hair were coded as 1. Skin typing was done by a combination of direct skin appearance and responses to two questions about skin reactivity. Fair-skinned people with a pink or red-flare response to an hour of noonday sun and little "end-of-summer tan" were coded as 4. Typically, darker skinned individuals were coded as 1 because these people failed to respond at all, or very slightly, to such acute exposure, but showed summer tanning on repeated solar exposure. Intermediate skin appearance and solar response was graded by burning and tanning proclivity. This skin type coding was a modification of a method described by Fitzpatrick. ${ }^{14}$ Detailed descriptions of the scoring scheme for each questionnaire item and each factor from the dermatological exam are presented in the Results section of this report. 


\section{Statistical Analyses}

For each constitutional and occupational factor, we calculated the average scores for cases and controls as well as the average difference between the scores of matched case and control pairs (case scores minus control scores). We also counted the number of pairs where the case score exceeded the control score and the number of pairs where the control score exceeded the case score. These two numbers were expected to be equal when there was no difference between cases and controls. If a factor was associated with melanoma, cases tended to have higher scores than controls, and the number of pairs where cases had higher scores than controls would exceed the number of pairs where controls had higher scores than cases.

The statistical significance of the numbers of pairs can be tested by comparison to a binomial distribution. If $x$ equals the number of pairs where cases have higher scores than controls and $y$ equals the number of pairs where controls have higher scores than cases, then $x /(x+y)$ will have a binomial distribution with parameter 0.5 when there is no difference between cases and controls. This type of analysis, known as the sign test in the statistical literature, ignores the size of the differences between cases and controls.

To determine whether the risk of becoming a case became greater with increasing difference in scores, we used the paired-t statistic where:

$$
t=\sqrt{n} \frac{\bar{d}}{s_{d}}
$$

where:

$$
\begin{aligned}
& \bar{d}=\text { average difference in scores, case score-control score, } \\
& \mathrm{s}_{d}=\text { standard deviation of differences in scores. }
\end{aligned}
$$

The paired- $t$ statistic has a $t$ distribution with $n-1$ degrees of freedom under the hypothesis that there are no differences between cases and controls.

This analysis made use of the magnitude of the differences between cases and controls. It can be shown that the paired- $t$ statistic is mathematically equivalent to the test for a linear trend in the log relative risks given by Breslow and Day. ${ }^{15}$ 
Because it was easier to compute the paired- $t$ statistic, we used it in place of the Breslow and Day statistic.

In addition, we used a conditional logistic regression model to analyze multiple factors simultaneously. This model assumes that the risk associated with two or more factors is equal to the product of the risks of the individual factors. A computer program was used to carry out this analysis. ${ }^{15} \mathrm{We}$ used this program stepwise, adding factors one at a time and first choosing among constitutional factors. After finding the best subset of constitutional factors, occupational factors were tested one at a time in the presence of the best subset of constitutional factors. Occupational factors were added until there was no further improvement in the ability of the program to predict melanoma in the casecontrol pairs. Improvement was measured by the log-likelihood, a statistical method for assessing the accuracy of the fit of a model to the data.

The results of these analyses can be summarized visually in a frequency histogram where the difference in scores (case score - control score) is on the $x$-axis and the number of pairs with that score is on the $y$-axis. We showed the improvement in the fit of the model to the data, as measured by log-likelihood, as a function of the number of factors in the model in a summary plot for the conditional logistic regression results.

\section{Summary of Methods}

In summary, 69 cases and 69 controls participated in the occupational factors interview. They were also given a constitutional factors questionnaire, and each one was examined by a dermatologist. After we completed these steps, the exposures of each case and each control were scored, and a narrative summary of the scoring was prepared. The panel and the study participant then reviewed it and approved the contents. Finally, we conducted a statistical analysis on the consensus results. 


\section{Results}

\section{Questionnaire Results}

Table 7 shows the distribution of case and control responses to questions concerning ethnic origin (Questions 3 and 4 on the questionnaire). An ethnicity score for each person was determined by assigning a subscore to the response for each grandparent and then summing the subscores. The subscores were assigned as follows:

1.0-British or Northern European

0.8-Eastern or Southern European

0.3-Hispanic

0.2-Native American or Asian

0.1 -Black

When the ethnicity of a grandparent was not stated or was unknown, we assigned a subscore equal to the average subscore for the known grandparent's ethnicity for each person. The subscores, although somewhat arbitrary, reflect melanoma incidence for people of that ethnic origin. For example, people with Northern European or British ancestry had the highest risk of melanoma as reflected by the subscore of 1.0. This is in contrast to people with black ancestry who had a subscore of 0.1 . (This reflects the approximately one-tenth melanoma incidence rate among blacks compared to Northern European whites.)

Table 8 summarizes the distribution of the overall scores for cases and controls. These scores were compared pair-wise by using the paired- $t$ test. None of the differences were significant; therefore, ethnic origin did not appear to be a factor that could explain the differences between cases and controls in our study.

\section{Marital Status}

Table 9 shows that the distribution of cases and controls was the same with respect to marital status. However, it is interesting to note that cases were less willing than controls to reveal their marital status ( $10^{\circ}$ cases vs 0 controls). It is significant to note that this question refers to their marital status at the time that the questionnaire was administered rather than at the diagnosis date of the case. 


\section{Education}

Cases and controls were matched for education so it is not surprising that there was no significant difference between cases and controls for this factor.

\section{Residences}

Question 7 required each person to list all residences starting from birth. The information included the city, state, country, and dates of residence and was recorded in a database. We then used a formula given by Scotto to convert this information into a "dose" of UV based on the location of the interviewee's residence and the time spent living there. ${ }^{16}$ We obtained an electronic file of populated places from the USGS Geographic Name Information System from Hoyt Walker at the LLNL Atmospheric Release Advisory Center (ARAC). This resource allowed us to determine the latitude and elevation for each U.S. residence listed. Latitude and elevation for overseas locations were obtained, when possible, from an Internet database maintained by the University of Michigan. For locations not listed in either database, we used an atlas to obtain the approximate latitude and elevation. Scotto's formula was then applied to determine a UV number for each place. The number was then multiplied by the number of years of residence to obtain a total UV score. The total UV score was then broken down into 5-year age periods for each person. A sample calculation for one subject is shown below. 
Example UV Calculation

\begin{tabular}{|c|c|c|c|c|c|c|c|c|}
\hline \% & $y$ & State & 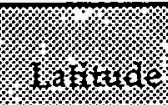 & א. & (yine & \% & rove & (1) \\
\hline 1941-'59 & Houston & TX & $294547 N$ & 38 & 18 & 1.75 & 31.6 & 31.6 \\
\hline 1959-64 & Austin & TX & $301601 N$ & 501 & 5 & 1.78 & 8.9 & 40.4 \\
\hline $1964-66$ & Urbana & IL & $400638 N$ & 725 & 2 & 1.31 & 2.6 & 43.1 \\
\hline $1966-70$ & East Lansing & MI & $424357 \mathrm{~N}$ & 828 & 3 & 1.19 & 3.6 & 46.6 \\
\hline $1970-83$ & Livermore & $\mathrm{CA}$ & $374055 \mathrm{~N}$ & 482 & 13 & 1.40 & 18.3 & 64.9 \\
\hline
\end{tabular}

1 Based on formula: UV $=1.50-0.05$ (Latitude -37.9$)+0.000105$ (Elev. $-500 \mathrm{ft}$.)

For the subject shown in the table, the cumulative UV dose from ages 10 to 24 is $\frac{8}{18}(31.6)+8.9+2.6=25.5$. This calculation is based on summing the $\mathrm{UV} / \mathrm{yr}$. over the years 1951 to 1966 , corresponding to when the subject was age 10 (1951) to age 25 (1966). The fraction $\frac{8}{18}$ represents the subject's age range 10 to 18,8 years, divided by the total, 18 years, for the first residence. A computer program was written to perform the calculations for each subject.

Table 11 summarizes the results of these pair-wise calculations for all cases and controls. The paired-t test was used to compare differences in accumulated UV (cases minus controls) in each age group. Statistical significance was achieved for UV accumulated during ages 20 to 24 . For invasive cases, the accumulation from ages 10 to 24 was also significant. In both comparisons, UV exposure was greater for controls than cases. No differences were significant for the in situ case-control pairs.

\section{Eye and Hair Color}

The distribution of eye and hair color among cases and controls is shown in Tables 12 and 13. There was no significant difference in eye color (Table 12), while the difference in hair color was of marginal statistical significance $(p=0.03$ ). (See Table 13.) When the data were broken down into invasive and in situ cases, the corresponding paired- $t$ statistics for hair color differences were 1.39 and 1.74 with $(p=0.17)$ and $(p=0.09)$, respectively. 


\section{Skin Reaction to Sunlight}

Previous studies of melanoma risk factors have found that sunlight, particularly sunlight on skin that tends to burn, is a major risk factor for melanoma. Thus, several questions on the questionnaire focused on the subject's skin reaction to sunlight.

Questions 10 and 11 in the questionnaire were identical to those used by Austin and Reynolds in their case-control study. ${ }^{2}$ The questions measured skin reaction following one half-hour of summer noonday sun. One question concerned skin reaction with no previous exposure (Question 10) and the other (Question 11) concerned skin reaction following a few days' prior exposure. The distribution of case and control answers to these questions is shown in Tables 14 and 15. The pooled, relative risks were for those who burn with little or no tanning compared to those who burn with tanning, or tan without burning. This allowed us to directly compare our results with Austin and Reynolds' risk ratios since they were calculated the same way.

We found, as did Austin and Reynolds, that Question 11 was a better predictor of melanoma risk than Question 10. However, our relative risks were larger than those found by Austin and Reynolds. For skin reaction with no previous exposure, both the relative risk for all case-control pairs and invasive pairs (2.91 and 4.07) were larger than that reported by Austin and Reynolds (1.9). For skin reaction following previous exposure, our relative risks were 3.56 and 7.27 for all case-control pairs and invasive pairs. This compared to Austin and Reynolds' value of 2.5. The explanation for the difference in risk ratios lies in the distribution of controls. For Question $10,62 \%$ of our cases burned with little or no tanning compared to $61 \%$ for Austin and Reynolds. However, in our study, only $36 \%$ of the controls fell into this combined category compared to $47 \%$ for Austin and Reynolds. Similarly, for reaction following previous exposure, $21 \%$ of our cases burned with little or no tanning, compared to $35 \%$ for Austin and Reynolds. However, only $7 \%$ of our controls, compared to $19 \%$ of Austin and Reynolds' controls, fell into the category. The explanation for the discrepancy in control percentages could have been due to the fact that our controls were matched to our cases by education while Austin and Reynolds' controls were 
not. This matching requirement apparently led to selection of controls who were less likely to burn than Austin and Reynolds' controls.

Similar results were found when Questions 10 and 11 were asked in a slightly different way. Questions 24 and 25 in our questionnaire were taken from Holman's dissertation. ${ }^{13}$ The questions concerned a longer exposure, one hour vs one-half hour in the Austin and Reynolds study. The response selection also differed with the more sensitive responses requiring blistering or pain in the Holman questions in contrast to the Austin and Reynolds responses, which only required burning rather than tanning. In our questionnaire, the Austin and Reynolds questions were asked at the beginning of the section pertaining to sun exposure. The Holman questions appeared after three and one-half pages of questions concerning sunbathing habits and painful sunburn experiences. This seems to have boosted the percentage of both cases and controls in responding as "sunburners" rather than tanners. In the Austin and Reynolds early question, $21 \%$ of the cases and $7 \%$ of the controls responded "burn with little or no tanning." In contrast, $39 \%$ of the cases and $21 \%$ of the controls admitted to blistering or painful sunburn in response to the Holman question. Thus, the location of the question concerning skin reaction to sun following previous exposures seems to have had an effect on the response in our questionnaire.

\section{Sun Exposure Habits}

Our questionnaire also included questions concerning sunbathing habits. During the year prior to diagnosis, cases tended to avoid exposing themselves to the sun; a smaller percentage kept a tan year round (Table 18) and significantly fewer sunbathed (Table 19). In the past, cases had also tended to sunbathe less frequently than controls (Table 20). There was no difference in the age when cases or controls began sunbathing (Figure 3). The mean age at which sunbathing began was 12 (median $=14$ ) for the 50 cases who had sunbathed, and 13 (median $=13$ ) for the 63 controls who had sunbathed.

For those case-control pairs who had sunbathed, we measured their sunbathing frequency during two time periods: (1) the number of hours per week spent sunbathing during the 10 years preceding diagnosis of the case, and (2) the number of days per year during the ages of 15 to 25 . Table 21 summarizes these 
results. The distributions were highly skewed. Most subjects had small values and a few had very large values (indicating extensive sunbathing activity). Sunbathing frequencies were categorized as shown in the table. The cutpoints for the categories of sun exposure were selected to make the number of controls in each category roughly equal to $25 \%$. The categories were then scored on a scale of 1 to 4 and the paired-t statistic for each type of sun exposure was then calculated.

We found highly significant differences for both measures of sun exposure for all case-control pairs and for the invasive pairs. The difference corresponds to cases that had sunbathed significantly less frequently. This result, coupled with the result in Table 20 (where it was shown that significantly fewer cases had ever sunbathed) reinforced our finding that our melanoma cases voluntarily experienced much less sun exposure while they were growing up than did their matched controls.

Cases and controls were also asked whether or not they had visited a tanning salon prior to the diagnosis date of the case. Only four subjects (all cases) responded that they had and the difference was not statistically significant ( $p=0.06$ by Fisher's exact test). Table 22 shows the distribution of the results. There was also no difference between cases and controls who took tablets to improve skin tanning (Table 23).

Each case and control was asked to list outdoor pastimes by selecting from a card with a selection of activities. They were also asked to give the ages they were when they did the activities, the season of the year, and the frequency, in times per week, month, or year that they took part in the activity. Table 24 summarizes the results in terms of (1) numbers of case-control pairs where the case performed the activity while the matched control did not (labeled \#\{Case>Control\} in the table) and (2) the numbers of case-control pairs where the control performed the activity while the case did not (labeled \#\{Control>Case\} in the table). The sign test was used to determine the statistical significance of the result. For all cases, only hiking ( $p=0.003)$ and soccer $(p=0.01)$ were statistically significant. In 23 case-control pairs, the case had spent time hiking while the matched control did not. This is in contrast to four pairs where the control had spent time hiking and the case did not. (In the remaining pairs, either both case and control had hiked, or neither had hiked.) Only hiking activities were significant in the subgroup of 
invasive case-control pairs, while both hiking and soccer activities were significant in the in situ subgroup.

\section{Sunburn Episodes}

Tables 25 and 26 show the distribution of the number of times cases and controls were blistered (Table 25) and had painful sunburns (Table 26) during four age groups. These tables again reflected the tendency of cases to avoid the sun compared to controls. During young adulthood (defined as ages 18 through 29) invasive cases tended to have fewer sun blistering episodes (Table 25) and fewer sunburns with pain (Table 26) than their matched controls. It is interesting to note that with respect to painful sunburn episodes (Table 26), invasive casecontrol pairs differed little when they were children (elementary school age), but by the time they were in high school, cases had fewer episodes than controls. This difference became significant in young adulthood but disappeared later. The change seems to have been due to the behavior of the controls, rather than the cases.

Cases and controls were also asked about particularly severe sunburn episodes. This included sunburn with pieces of dead skin that could be peeled off, sunburn with large blisters, and sunburn with pain for two or more days (Table 27). Only one significant difference was found in the case-control paired responses; a greater number of controls in the in situ subgroup of case-control pairs had sunburn with large blisters (Table 27). There were no differences between cases and controls with respect to freckling (Table 28).

\section{Prior Skin Cancer and Mole Removal}

Cases and controls were asked whether or not they had any skin cancers or moles removed prior to the date of diagnosis of the case. Unfortunately we could not use the responses to these questions because it was evident that there was confusion about the time period during which these procedures occurred. Many cases included the removals that had led to their diagnosis. 


\section{Multifactor Results}

As explained in the Methods section of this report, we used conditional logistic regression to determine the set of factors that best enabled us to discriminate between cases and controls. First we coded responses to questions from the questionnaire into a 0 to 3 scale, where 0 represented low risk and 3 represented the highest risk. We used the distribution of the responses among the controls to determine three cutpoints so that approximately $25 \%$ of the controls received each score ( 0 to 3 ). For example, the range of $U V$ exposure based on residential history during ages 20 to 24 (Table 11) was coded as follows:

\begin{tabular}{lc}
\multicolumn{1}{c}{$\begin{array}{c}\text { Range of UV } \\
\text { Exposure }\end{array}$} & Score \\
\hline 0 to 6.52 units & 3 \\
6.52 to 7.10 units & 2 \\
7.10 to 7.89 units & 1 \\
Greater than 7.89 units & 0
\end{tabular}

The scoring reflected the fact that cases tended to have lower exposures to UV during ages 20 to 24 than controls; thus, low UV exposure leads to high risk for melanoma. We included eleven factors in the stepwise selection process:

1. UV exposure based on residential history during ages 20 to 24 .

2. Hair color.

3. Sunbathing frequency during the year prior to diagnosis.

4. Outdoor recreation habits during the year prior to diagnosis.

5. Sunbathing frequency during the 10 years preceding diagnosis.

6. Sunbathing frequency during the ages of 15 to 25 .

7. Skin reaction after one-half hour of sun exposure with no prior exposure.

8. Skin reaction after one-half hour of sun exposure with prior exposure.

9. Skin reaction after one hour of sun exposure with no prior exposure.

10. Skin reaction after one hour of sun exposure with prior exposure.

11. Hiking as a pastime. 
These factors were selected from the questionnaire responses because the univariate analysis indicated that they were significant (or borderline significant) risk factors. The program was free to choose any combination of these factors to make the discrimination between cases and controls.

When classifying all cases, the program selected four factors as significant:

1. Sunbathing frequency during the 10 years prior to diagnosis.

2. Sunbathing frequency during ages 15 to 25 .

3. Skin reaction after one hour of sun exposure with prior exposure.

4. Hiking as a pastime.

Based on these four coded factors, we could correctly identify 56 cases (81\%) in the case-control pairs. We misclassified 12 cases, and one case-control pair had identical scores.

When classifying invasive cases, four factors were selected as significant:

1. UV exposure based on residential history during ages 20 to 24 .

2. Sunbathing frequency during the 10 years prior to diagnosis.

3. Skin reaction after one hour of sun exposure with prior exposure.

4. Hiking as a pastime.

Based on these four coded factors we could correctly identify 35 cases (90\%).

Four were misclassified.

When classifying in situ cases, only hiking as a pastime was selected as statistically significant. Based on this factor, 12 out of 30 case-control pairs were correctly identified. There were 14 pairs with identical scores and two were misclassified (i.e., the control, but not the case, hiked).

\section{Dermatological Examination Results}

\section{Mole Counts}

Mole counts were taken by the dermatologist for three types of moles: moles $\geq 2 \mathrm{~mm}$ in diameter; moles $\geq 5 \mathrm{~mm}$ in diameter; and dysplastic (atypical) moles. Figures 4 through 6 show that the distribution of these mole counts was highly skewed in both cases and controls. It is also apparent that the total counts, 
summed over all body sites, tended to be greater in cases than in controls. Tables 29 through 31 show summary statistics for the different types of moles and different body sites.

The sign test indicated that the total count of $2 \mathrm{~mm}$ moles was greater among all cases than in controls $(p=0.005$, Table 29). The body sites that contributed significantly to this difference include: the chest $(p=0.007)$, the lower back $(p=0.007)$, the thighs $(p=0.001)$, and the lower legs $(p<0.001)$. Interestingly, the body site percentage distribution of the $2 \mathrm{~mm}$ moles did not differ among cases and controls. The proportion of moles on the most common site, the upper back, was the same in cases and controls ( $20 \%$ vs $23 \%$ ).

The total count for $\geq 5 \mathrm{~mm}$ moles did not differ significantly among all casecontrol pairs ( $p=0.088$ by sign test, Table 29 ), even though the average count for cases was over three times that of controls (12.2 vs 3.8). Significant differences in mole counts of $\geq 5 \mathrm{~mm}$ were found in the sign test for the upper arms ( $p=0.006$ ), the abdomen $(p=0.002)$, and the lower legs $(p=0.003)$.

Total dysplastic mole counts differed among case-control pairs $(\mathrm{p}<0.001)$. Significant differences were found for the upper arms $(p=0.008)$, the abdomen $(p=0.002)$, the upper back $(p=0.006)$, and the lower back $(p=0.001)$.

Statistically significant differences in counts of $\geq 2 \mathrm{~mm}$ moles were found in invasive cases-control pairs for the thighs ( $p=0.001$, Table 30) and for the lower legs ( $p=0.007)$. For $\geq 5-\mathrm{mm}$ moles, invasive cases had greater counts than controls for the abdomen $(p<0.001)$, the upper back $(p=0.006)$, the lower back $(p=0.006)$, and the lower legs $(p=0.008)$. Significant differences were also found in dysplastic mole counts for several body sites (see Table 30) as well as overall counts $(p<0.001)$. No significant difference in mole counts were found for any type of moles in the in situ case-control pairs (Table 31).

Table 32 summarizes the result of applying univariate methods outlined in Breslow \& Day for matched data to categorized mole counts. ${ }^{15}$ These analyses show that there was a statistically significant linear trend for increasing melanoma risk for each type of mole count. The strongest trend was for dysplastic moles, and those with two or more dysplastic moles were estimated to 
have 22 times greater risk of melanoma compared to those who had no dysplastic moles.

The different types of mole counts were highly correlated (Table 33).

Interestingly, the correlations were significantly higher among cases than among controls. Thus, we expected that when multiple conditional logistic regression was applied to these data, only the strongest predictor of case-control status (i.e., total count of dysplastic moles) would emerge as an independent risk factor for melanoma.

\section{Personal and Family History}

As previously mentioned, a personal and family medical history relating to moles and skin cancer for each case and control was elicited as part of the dermatological physical examination. The results in terms of the number of positive responses (where a positive response meant that the examinee had one or more family members with the condition) are summarized in Table 34. The sign test was used to determine whether there were significant differences in the case-control pairs for each condition. Factors that appeared to be related to melanoma status included: a family history of numerous moles, a family history of abnormal moles, and a personal history of dysplastic moles. Cases were more likely to have had a previous mole excision, while controls were more likely to have had a precancerous (nonmelanoma) lesion removed. These factors were statistically significant when all cases and controls were considered as a group. For invasive case-control pairs, only the personal history factor of dysplastic moles was statistically significant (at $\mathrm{p}<0.01$ ). For in situ pairs, a family history of numerous moles, a family history of nonmelanoma pre-cancer, and a personal history of dysplastic moles were statistically significant (at $p<0.01$ ). It is interesting to note that in invasive pairs, a family history of nonmelanoma precancer was more common among the controls in contrast to the in situ pairs.

\section{Skin Type and Skin Reactivity}

The dermatologist also evaluated each examinee's likelihood of burning (or tanning) based on the response to specific questions. (See the Methods section of this report.) Skin reactivity was also determined by the Fitzpatrick scale. ${ }^{14}$ The distribution of these ratings among cases and controls and the results of pair- 
wise comparisons based on the paired-t test are summarized in Table 35. The results indicate that the type of tan, as determined by the dermatologist, was the most significant factor separating cases from controls, particularly in the invasive pairs. Interestingly, there was little difference between cases and controls with respect to the type of $\tan$ in the in situ pairs. Skin type also differed significantly in case-control pairs for all cases and for the invasive cases subgroup. The burn type did not differ significantly.

\section{Hair and Eye Color}

Hair and eye color were determined for each case and control by the dermatologist. Table 36 and Figures 7 and 8 show the distribution of hair and eye color in cases and controls and the results of the paired- $t$ test. Case-control pairs differed significantly with respect to hair color; cases tended to have lightercolored hair. The difference was significant for both invasive and in situ subgroupings. No significant differences could be established for eye color, which reflected the near similarity of the distributions in cases and controls.

\section{Multivariate Results for All Exam Factors}

Conditional logistic regression, as described in the Methods section of this report, was used to determine which combination of factors were most important for separating cases from controls. The results are summarized in Table 37 . When we considered all case-control pairs, two factors emerged: the ability to tan and the number of $\geq 2 \mathrm{~mm}$ moles (categorized into four risk groups). Classification based on these two factors correctly distinguished cases in 49 pairs (71\%) while misclassifying 11 pairs. There were nine tied pairs with identical tan and $\geq 2 \mathrm{~mm}$ mole scores.

For invasive case-control pairs, tanning ability and the number of dysplastic moles were statistically significant. These two factors correctly identified cases in 33 of the 39 pairs (85\%) and only one pair was incorrectly classified. There were five tied pairs. For in situ case-control pairs, a family history of moles and hair color was used to correctly identify 21 of the 30 pairs (70\%). There were five tied pairs and four pairs were misclassified. 
Combining the separate results for invasive and in situ case-control pairs led to 54 correct identifications, 5 incorrect identifications, and 9 tied identifications. Thus, the dermatological examination could be used to correctly identify $78 \%$ of the case-control pairs.

\section{Occupational Interview Results}

A description of how the overall ratings for occupational factors were assigned is provided in the Methods section of this report. The results of statistical analysis of these scores are presented in Table 38. For each exposure factor, the means for all cases and for all controls are shown as well as the p-value for the statistical significance of that difference. In total, there are $120 \mathrm{p}$-values displayed in the table. Only three $\mathrm{p}$-values were below the $5 \%$ level of significance. (If the tests had been independent we would have expected six to have p-values below $5 \%$ by chance alone.) Two are associated with the Nevada Test Site and one with Site 300. Controls tended to have greater scores than cases for ionizing radiation and for chemical-related factors (including exposure to chemicals, duties as a chemist, and exposure to photographic chemicals).

A closer look at the Nevada Test Site factor revealed that cases had higher scores than their matched control in 11 of the 39 invasive case-control pairs. This was compared to only four pairs where controls had higher scores than cases. The remaining 24 pairs had equal scores for the Nevada Test Site factor. This dichotomy had a $\mathrm{p}$-value 0.06 by the sign test. This factor was not significant in the in situ case-control pairs. When consideration was restricted to LLNL employment, 18 cases had higher scores for the Nevada Test Site than their matched controls. This was compared to nine pairs where the control had a higher score. This dichotomy also had a p-value equal to 0.06 by the sign test.

The low p-value for in situ cases with respect to Site 300 during time period $\mathrm{A}$ was most likely a statistical artifact since this factor never approached statistical significance in any other subgrouping of case-control pairs or employment periods. 


\section{Word Count Analysis}

In our study, we interviewed 69 matched case-control pairs. Of the 138 individual interviews, 58 pairs had digitized records that were suitable for this analysis. These digitized records, in the form of ASCII text files, were first given an identifying label and then sequenced so that the text of each case was immediately followed by the text of its matched control.

Each ASCII file was then computer processed, first by a filter routine and then by an analysis routine. Both routines were written in Pascal. The filter routine identified and counted all words. It also had several other options. One option rejected words that we designated as "trivial," such as prepositions, conjunctions, and articles. Another option rejected words that we determined were not potentially associated with melanoma in our population and included words such as "car" and "telephone." Another option was to select words uttered only by the interviewee. We combined alternate spellings of the same word to make a single word. For example, "allergic," "allergies," and "allergy" were combined. We also grouped words into a composite category associated with a particular LLNL program or project. For example, "febatron," "fxr," and "flash $\mathrm{x}$-ray" were combined. This progressive sequence of selection left us with a list of 601 words and categories which we then analyzed for their potential association with melanoma.

The analysis routine was structured to take each listed word and determine whether it occurred in either one or both matched pairs of interviews and then accumulate findings for all 58 pairs in order. Each word, "lithography" for example, was then coded by the routine as "both," if both members of the pair used the word or the interviewer used the word in their interviews. A code, "case only" was assigned if either the case or the interviewer used the word, and "control only" was assigned if only the control or the interviewer used the word. Finally, the analysis resulted in a "neither" code if neither one of a given pair used the word "lithography." Thus, for each matched pair there was a single coded result for each of the 601 selected words. This tabulation was accumulated for all 58 matched pairs. 
The tabulation of all selected words was focused on the discordance ratio of "case only" to "control only." This is the maximum likelihood estimate of the odds ratio. ${ }^{15}$ The degree of discordance was evaluated by the sign test based on 2-sided p-values in order to find those words for which the discordance was greatest. We also determined $99 \%$ confidence limits for the risk ratio as an aid in assessing its significance. ${ }^{15}$

Word use for our 601 selected words and categories ranged from one person to 115 out of a total maximum possible of 116 for the 58 case-control pairs. A majority of words were used by fewer than 10 interviewees; only 240 words appeared in the transcripts of 10 or more subjects. Table 39 summarizes the results of this analysis for the 34 words appearing in 10 or more transcripts and with sign test 2 -sided $p<0.05$. It is noteworthy that 27 of the 34 "significant" discordances involve words that appeared in more control than case transcripts. There are only seven words that appeared in more case transcripts than in control transcripts. These words were "lithography," "booties," "herbicide," "antenna," "electron," "ionizing," and "monitor."

Two of the words, "booties" and "ionizing," were possibly associated with working with radioactive materials while two others, "herbicide" and "lithography," could have been associated with chemical exposures. Both types of exposures were covered in depth by the expert panel when they assigned . overall exposure ratings (for radiation and for chemicals) to each case and control. In addition, "lithography" was found to be a nonsignificant word when the context in which it was used was examined. In seven of the transcripts it was first introduced by the interviewer with subsequent denial of exposure or use by the interviewee. In one of the remaining four instances, the context was that lithography was done in an adjoining room. Thus, the 11 "case only" instances of the word were reduced to three actual possible exposures that were not statistically significant.

\section{Itemized Exposures}

When the transcripts were read, any agent that was mentioned by the subject as a possible exposure was added to a list containing all exposures for each case and each control. (An agent is any entity that we subjectively believed could be 
associated with melanoma.) This list contained 459 agents. Each agent was assigned a unique code according to a classification system devised by Siemiatycki. ${ }^{11,12}$ Agents were also classified as radioactive or nonradioactive. Table 40 shows the results for both types of exposures. Overall, 54 of the 69 pairs (78\%) mentioned work with radioactive agents during the interview. There were 15 case-control pairs where only the case worked with these agents, and there were 17 pairs where only the control worked with these agents. Similarly, 64 of the 69 pairs (93\%) mentioned exposure to nonradioactive agents. Again, there was no significant difference between the number of pairs where only the case mentioned exposure compared to pairs where only the control was exposed. Some subjects mentioned more than one agent exposure. Tables 41 and 42 show the number of radioactive agents and nonradioactive agents mentioned by both cases and controls. There appears to be no difference in either distribution of the numbers of agents, although the average number of nonradioactive agents mentioned by controls was slightly higher than the number mentioned by cases.

We also looked at case-control exposures to each of the 459 different agents. There were few cases or controls exposed to any agents. In Table 43, we show the distribution of case-control pairs with respect to exposure to all of the agents that were mentioned by a least 10 case-control pairs. The distribution was obtained from the same computer program used for the word count analysis. One-sided $\mathrm{p}$-values based on the sign test are shown in the last column. Interpretation must take into account that there were 29 possibly significant agents. Only two agents had p-values below 0.05 . This is only slightly more than the theoretical 1.45 (equal to $29 \times 0.05$ ) that was expected by chance.

The 459 agents were then grouped into 65 general exposure groupings. For example, the two separate entries, trichlorethylene (TCE) and carbon tetrachloride shown in Table 43 were combined into a general grouping of chlorinated hydrocarbons shown in Table 43a. Thus, subjects exposed to either (or both) of these chemicals would be counted as exposed to the general grouping of chlorinated hydrocarbons. Table 43a summarizes the exposures to 39 groupings where 10 or more case-control pairs were exposed. Only one agent group had a p-value less than 0.05 . With 39 candidates, we expected that $1.95 \mathrm{p}$-values would be less than 0.05 . 
Table 44 summarizes the number of different agents mentioned by cases and controls. There was very little difference between the two distributions; therefore, we concluded that cases and controls mentioned approximately equal numbers of agents during the interview. A t-test of the means revealed that cases did not differ from controls.

The transcripts were also searched for indications that the subjects had skin exposure to chemicals. Subjects were classified by whether or not there had been skin exposure to any chemical. Subjects were also classified by their exposure to skin-irritating chemicals. A subject could receive a positive rating for exposure to a skin-irritating chemical regardless of whether or not that exposure was to the skin. The outcome of the statistical testing of these types of exposures is summarized in Table 45. Again, we saw that more controls than cases experienced skin exposures and exposures to skin-irritating chemicals.

\section{Analysis of Ionizing Radiation Dosimetry}

We obtained records of each subject's exposure to ionizing radiation from the LLNL's Hazards Control Department. These records are for five types of exposures: gamma, neutron, tritium, skin, and hand. Dosimetry records also include recorded doses of ionizing radiation received by employees prior to employment at LLNL.

Tables 46 through 50 summarize the distribution of the doses of radiation recorded in the dosimetry files for different types of radiation. For both cases and controls, the distribution was highly skewed. Statistical tests, based on coding the doses on a scale of 0 to 5 to remove the effects of skewing, confirmed that there were no differences between cases and controls. 


\section{Discussion}

Our study used three sources to gather information concerning the association between risk factors and melanoma. Two of the sources of information were standard: a personal history questionnaire and a dermatological exam. The third source of information was an occupational interview. Two aspects of the occupational interview were noteworthy. First, we used a certified court reporter to record and transcribe the interviews. Each interview was then read by both the interviewer and the interviewee for accuracy and completeness. The second noteworthy aspect of the interview was that, because most interviews existed as an ASCII file, we were able to perform a computer search for the occurrence of words associated with melanoma. We did not find any words that were used by our cases and not by our controls. We believe this computer search enhanced the likelihood that there is no association between melanoma and working conditions at LLNL. Also, as far as we are aware, these aspects of our study were unique.

Our findings, based on statistical analysis of the results from the questionnaire and the dermatological exam, suggest that the constitutional risk factors for our melanoma cases were no different from those reported in the extensive literature on melanoma. Our findings based on statistical analysis of the results from the occupational interview do differ from those reported by Austin and Reynolds. The possible reasons for the difference in findings are discussed below.

\section{Comparisons with Austin and Reynolds}

Austin and Reynolds concluded that five occupational factors led to the increased melanoma incidence among LLNL employees. Their study was a matched casecontrol design with approximately four controls matched to each of 31 cases (those diagnosed between January of 1969 and June of 1980). ${ }^{2}$ This study covers 69 cases diagnosed between January of 1969 and April of 1989, with one control matched per case. The matching criteria for Austin and Reynolds were:

1. Control employed during year that case was diagnosed.

2. Control same sex as case.

3. Control same race as case. 
4. Control within five years in age of the case.

It is important to note that there was no requirement for controls to be employed at LLNL as long as the cases. Austin and Reynolds also did not require that controls match the cases with respect to years of education.

The results for Austin and Reynolds' five occupational factors are summarized in Table 51 along with comparable summary results from this study. For radioactive materials, our rating score gave $14 \%$ of the cases and $20 \%$ of the controls scores greater than zero. Both of these percentages are lower than those reported by Austin and Reynolds for responses to the radioactive material question. By analyzing all agents mentioned in the interviews, we found that 37 cases (54\%) and 39 controls (57\%) were exposed, to some degree, to radioactive agents (Table 40). These percentages lie between those reported by Austin and Reynolds ( $33 \%$ for controls and $65 \%$ for cases). However, in contrast to Austin and Reynolds, we found no differences between cases and controls. For Site 300, we found that both cases and controls had similar exposures (39\% for cases and $36 \%$ for controls). These percentages were similar to the percentages for the Austin and Reynolds controls who had visited the site one or more times. We found a greater percentages of cases and controls with exposures to photographic chemicals. Forty-five percent of our cases and $51 \%$ of our controls were rated as having "higher than normal" occupational exposures to photographic chemicals, and $51 \%$ of the cases and $52 \%$ of the controls mentioned photographic chemicals in their interview. All of these percentages were higher than those reported by Austin and Reynolds (35\% for cases and 15\% for controls). Again, in contrast to Austin and Reynolds, we found no differences between cases and controls. We found that $12 \%$ of the cases and $16 \%$ of the controls had exposure to the Pacific Test Site. These percentages were similar for those found for the Austin and Reynolds cases (13\%). Our case-control difference was not significant. We rated $22 \%$ of our cases and $26 \%$ of our controls as having chemist duties. Both percentages were greater than those reported by Austin and Reynolds, which were based on job classifications ( $13 \%$ for cases and $2 \%$ for controls). Again, the difference in our percentages was not statistically significant. 
We have noted previously that Austin and Reynolds did not require that controls match cases with regard to tenure at LLNL or years of education. Table 52 summarizes the results of regressing the five factors found to be significant by Austin and Reynolds against start date and years of education for our cases and controls. These results support the hypothesis that these two factors-start date and years of education-could have acted as confounders in the Austin and Reynolds study. Since occupational factor scores decrease with start date (as evidenced by negative coefficients in the table), it is likely that controls who were not matched for these variables would have lower exposures to these factors simply because they began employment at LLNL after the cases. Similarly, because occupational factor scores increase with education (as evidenced by positive coefficients in the table), it is probable that controls with less education than cases would be less likely to engage in the type of activities that led to higher exposures. We had no way of testing for these effects in the Austin and Reynolds dataset since we did not know which controls were matched to each of the Austin and Reynolds cases. (This was done intentionally to protect the privacy of those who participated in the Austin and Reynolds study.)

A second possible explanation for the difference in study findings is that the study sample sizes were not the same. The Austin and Reynolds study design called for a 4 to 1 match. For example, four controls were matched to each case, although their results were based on fewer controls because some controls refused to participate in their study. Our study sample had only one control matched to each case. However, where as Austin and Reynolds had only 31 cases, we had 69 total cases, including 39 invasive cases. Statistical power (defined as the ability to detect a risk factor as significant) for case-control studies can be calculated using formulas given by Oliphant and McHugh. ${ }^{17}$ Table 53 summarizes the results of these calculations for comparing the study designs. Our study design, based on a 1 to 1 matching with all 69 case-control pairs, proved to be slightly more powerful than the Austin and Reynolds design. Even with only 39 invasive case-control pairs, our study had $80 \%$ of the Austin and Reynold's power for detecting four out of the five Austin and Reynolds factors. Thus, it is unlikely that the difference in study sample sizes accounted for the difference in the findings. 
Another factor that may have led to differences in the results of the two studies was the difference in the subjects interviewed. The effect of this factor was studied by subdividing our case-control pairs into two subgroups. The first subgroup consisted of the 22 pairs in which the case was interviewed both by Austin and Reynolds and ourselves. We named this subgroup the Austin and Reynolds case-control pairs. The second subgroup consisted of the 47 casecontrol pairs whom we interviewed but who were not interviewed by Austin and Reynolds. If the Austin and Reynolds factors applied only to the 22 Austin and Reynolds case-control pairs, then a separate analysis of these should have resulted in differences greater than those in the remaining 47 pairs. The results, summarized in Table 54, offer mixed support for this explanation of the differences between the studies. The paired- $t$ statistic showed increased risk for exposures to ionizing radiation and photographic chemicals for the Austin and Reynolds subset compared to the others. This is shown in the table where the paired- $t$ for ionizing radiation is 0.00 for the Austin and Reynolds subset. This is more positive than the paired- $t$ equal to -1.53 for the subset of others. The other three Austin and Reynolds factors, visits to the Pacific Test Site, presence at Site 300 , and chemist duties all have more positive paired- $t$ statistics for the subset of others. None of the differences in paired- $t$ statistics were statistically significant. Thus, we concluded that subdividing our cases into two subsets made no difference to the overall results.

We rematched our cases and controls to determine whether the less rigorous matching criteria of the Austin and Reynolds study would explain the difference in results. We could only rematch 58 of the 69 case-control pairs since the Austin and Reynolds criteria required that the controls be of the same sex as the cases. This time, applying the Austin and Reynolds criteria shifted all five paired- $t$ statistics to a more positive direction. (See Table 55.) Even though none of the differences were statistically significant, these results support the hypothesis that the Austin and Reynolds study found significant differences because the start date and years of education factors were confounded with occupational exposures.

Finally, we checked the effect of mismatching for sex in our study. (Note that 11 case-control pairs were mismatched for sex-10 pairs in which the case was female and the control was male were mismatched, and a single pair in which 
the case was male and the control was female was mismatched. Refer to Table 1.) We entered all of the matching variables (sex, age, starting year at LLNL, years of tenure at LLNL, and years of post-high-school education) into a conditional logistic regression. The results showed that sex was a statistically significant factor in separating cases from controls $(p=0.038)$. This result was explained by the fact that when a case-control pair contains one female and one male, it is more likely that the case will be the female. (This occurred in 10 of the 11 male-female pairs.) Thus, we re-ran the analysis of occupational factors, adding sex as a forced factor. The results are summarized in Table 56 and show the odds ratios for the risk factors identified by Austin and Reynolds with and without adjustment for sex. The adjustment increased the odds ratios slightly for four of the five factors-radioactive materials, Site 300, Pacific Test Site, and chemist duties. The adjustment decreased the odds ratio for photographic chemicals. Thus, even though the sex factor was statistically significant as a predictor of case-control status, it had little effect on the estimates for the effects of occupational factors.

\section{Comparisons with Other Occupational Studies}

A 1982 study conducted by the Los Alamos National Laboratory (LANL) found no significant increase in melanoma incidence among its employees. ${ }^{18}$ This finding makes it difficult to explain the increase at LLNL in terms of occupational activities since the two laboratories have nearly identical research activities and their employees are potentially exposed to similar chemicals and radiation. A second LANL study found that the most significant risk factor for melanoma was level of education. ${ }^{19}$ People with college degrees had a two fold risk, while those with graduate degrees experienced a three fold risk compared to those without college degrees. These findings support ours with regard to occupational factors and the importance of matching for years of education.

A search of the MEDLINE database in December of $1993^{20}$ using the keywords "melanoma" and "occupation" produced the following reports: 
- A case-control study of 140 cases in The Netherlands found that there was no increased risk of melanoma among workers in the chemical industry.

- A New Zealand male cancer mortality study by occupation found that there was an increased risk of melanoma among clerical workers but no increased risk among any other groups.

- A British Columbian male cancer patient study by occupation found predominant melanoma excesses among indoor workers.

- An occupational study based on cancer registries for England, Wales, and Sweden found increased melanoma incidence among professional workers of both sexes in all three countries. The highest excesses were found among airline pilots, finance and insurance brokers, professional accountants, dentists, transportation inspectors and supervisors, pharmacists, judges, doctors, university teachers, and chemists. There was no adjustment for years of education in this study.

- A cancer-by-industry survey based on state cancer registries in the U.S. found that there were excess melanomas among rubber and plastic product workers.

These surveys confirm that people who work primarily indoors and whose occupations require college or higher level degrees have an increased risk of melanoma compared to the general population. There are no reports of increased melanoma among radiation workers or those exposed to high levels of radiation in the extensive literature on the health effects of radiation. 


\section{Conclusions and Recommendations}

The results reported here represent our best effort to find factors that were unique among LLNL employees and led to an excess diagnosis of cutaneous malignant melanoma. Based on our findings we drew the following conclusions:

- None of the occupational factors identified in the Austin and Reynolds casecontrol study have been implicated or even established as biologically plausible.

- No other occupational factor identified in the interviews, either by inspection or by word-count analysis, was found to be implicated.

- The LLNL cases exhibited the same personal and familial characteristics as cases elsewhere.

- The LLNL workforce has a generally high level of education. This is an established risk factor for melanoma and may contribute, in part, to the rate elevation at LLNL compared to that of the community.

- The true cause of the elevated incidence of melanoma at LLNL cannot be determined. Some hypothetical mechanisms are: (1) an as yet unidentified occupational exposure, probably more prevalent in the early years of LLNL operations, cannot be ruled out; (2) unexplained clusters of cancer, including melanoma, have been recognized in other populations and remain a possibility at LLNL; and (3) a combination of generally high education and specific aspects of lifestyle coupled with aggressive surveillance probably is the best explanation for the excess rates.

- An increased awareness and understanding of melanoma by Lab employees and their physicians has resulted in increased diagnosis of thin lesions. It has been found that thin lesions have a good prognosis after treatment.

- Enhanced surveillance probably leads to prevention of life-threatening forms of melanoma. 
We offer the following recommendations:

- Continue the Spot Check education and onsite clinic programs for the next four years so that important data may be secured on mortality trend and precursor lesion life history. The most important objective is to obtain evidence about whether or not an aggressive program of education and surveillance can decrease mortality from melanoma.

- If changes do not occur that disturb the current trend toward disappearance of excess melanoma incidence at LLNL, we see no further need for investigation of possible workplace factors. Research and publication of clinical and epidemiologic data should continue, however. 


\section{References}

1. D. Austin et al., "Malignant Melanoma Among Employees of Lawrence Livermore National Laboratory," Lancet (October. 3,1991) pp. 712-716.

2. D. Austin and P. Reynolds, A Case-Control Study of Malignant Melanoma Among Lawrence Livermore National Laboratory Employees-Report \# 3, Lawrence Livermore National Laboratory, Livermore, CA UCRL-15629 (1984).

3. D. Shy et al., Malignant Melanoma at a Scientific Laboratory: A Synthesis of Reviewer's Comments on the Austin and Reynolds Study at LLNL, Lawrence Livermore National Laboratory, Livermore, CA UCRL-15737 (1985).

4. L. Kupper et al., A Case-Control Study of Malignant Melanoma Among LLNL Employees: A Critical Evaluation, Lawrence Livermore National Laboratory, Livermore, CA UCRL-15928 (1987).

5. C. D. Holman, B. K. Armstrong, and P. J. Heenan, "Relationship of Cutaneous Malignant Melanoma to Individual Sunlight Exposure Habits," J. Nat. Cancer Institute 76 (1986), pp. 403-414.

6. U.S. Department of Energy and University of California, Final Environmental Impact Statement and Environmental Impact Report for Continued Operation of Lawrence Livermore National Laboratory and Sandin National Laboratories, DOE EIS0157 (August 1992).

7. B. A. Miller et al., Cancer Statistics Review: 1973-1989, National Cancer Institute, NIH Pub. No. 92-2789 (1992).

8. American Cancer Society, Cancer Facts and Figures, San Francisco, CA (1991).

9. P. L. Horn-Ross et al., "Temporal Trends in the Incidence of Cutaneous Malignant Melanoma Among Caucasians in the San Francisco-Oakland MSA," Cancer Causes and Control 2 (1991) pp. 299-305. 
10. D. H. Moore and F. Hatch, Historical Summary and Recommendations on Melanoma in the Lawrence Livermore National Laboratory Workforce, Lawrence Livermore National Laboratory, Livermore, CA UCRL-UR-116044 (1994).

11. J. Siemiatycki et al., "Discovering Carcinogens in the Occupational Environment: A Novel Epidemiological Approach," J. Nat. Cancer Institute 66 (1981) p. 217.

12. J. Siemiatycki, Ed., Risk Factors for Cancer in the Workplace, CRC Press, Inc., Boca Raton, Florida (1991).

13. C. D. J. Holman, Risk Factors in the Causation of Human Malignant Melanoma of the Skin, Ph.D. thesis, University of Western Australia, Perth, Australia (1982).

14. T. B. Fitzpatrick et al., "Preventive Treatment of Sunburn, Dermatoheliosis, and Skin Cancer with Sun Protective Agents," in Dermatalogy in General Medicine, Third Edition (1991 pp. 1507-1519.

15. N. E. Breslow and N.E. Day, "Statistical Methods in Cancer Research, Vol. 1The Analysis of Case-Control Studies," IARC Scientific Publication, No. 32, Lyon, France (1980).

16. J. Scotto et al., Measurements of Ultraviolet Radiation in the United States and Comparisons with Skin Cancer Data, U.S. Dept. of Health, Education, and Welfare, Public Health Service, National Institutes of Health, National Cancer Institute, Division of Cancer Cause and Prevention, Bethesda, MD (1976).

17. T. H. Oliphant and R. B. McHugh, "Least Significant Relative Risk Determination in the Case of Unequal Sample Sizes," American J. of Epidemiology, 113 (1981) pp. 711-715.

18. J. F. Acqavella et al., "Malignant Melanoma Incidence at the Los Alamos National Laboratory," Lancet (1982) p. 883.

19. J: F. Acqavella et al., "A Melanoma Case-Control Study at the Los Alamos National Laboratory," Health Physics 45 (1983), pp. 587-92. 
20. MEDLINE [database online]. Bethesda (MD): National Library of Medicine; 1969-. Updated weekly. Available from: National Library of Medicine; BRS Technologies, McLean, VA; DIALOG Information Services, Inc., Palo Alto, CA. 


\section{List of Tables}

1. Case-Control Matches by Sex

2. Case-Control Matches by Age

3. Case-Control Matches by Start Date

4. Case-Control Matches by Years of Education

5. Case-Control Matches by Years of Tenure

6. Distribution of Overall Match Scores

7. Ethnicity of Cases and Controls

8. Ethnicity Scores for Cases and Controls

9. Marital Status of Cases and Controls

10. Highest Educational Level of Cases and Controls

11. UV Exposures from Residences for Cases and Controls

12. Eye Color for Cases and Controls

13. Hair Color for Cases and Controls

14. Skin Reaction to One-Half Hour of Summer Noonday Sun with No Previous

15. Skin Reaction to One-Half Hour of Summer Noonday Sun with a Few Days

16. Skin Reaction to One Hour of Strong Summer Sunlight for the First Time

17. Skin Reaction after Repeated and Prolonged Exposure to Sunlight

18. Sun Exposure During Year Prior to Date of Diagnosis of Case

19. Number of Times Sunbathed During Year Prior to Diagnosis of Case

20. Sunbathing in the Past

21. Sunbathing Frequency in the Past

22. Use of Tanning Salon Prior to Diagnosis

23. Use of Tablets to Improve Skin Tanning

24. Outdoor Pastimes

25. Sunburn with Blistering Episodes

26. Painful Sunburn Episodes

27. Episodes of Sunburn Peeling, Large Blisters, and Pain

28. Freckles that Change with Sun Exposure

29. Mole Count Summary Statistics for All Cases and Matched Controls

30. Mole Count Summary Statistics for Invasive Cases and Matched Controls

31. Mole Count Summary Statistics for All In Situ Cases and Matched Controls

32. Results of Applying Methods of Breslow and Day to Mole Count Data

33. Correlations Among Mole Counts

34. Distribution of Family and Personal Medical History Examination Factors 
35. Distribution of Skin Types Among Cases and Controls

36. Summary of Results for Hair and Eye Color

37. Results of Conditional Logistic Regression on Exam Factors

38. Occupational Factors

39. Words Used by Case-Control Pairs with Sign Test 2-Sided p-Values $<0.05$

40. Occupational Exposures to Agents

41. Number of Radioactive Agents with Exposure

42. Number of Nonradioactive Agents with Exposure

43. Exposure to Most Frequently Mentioned Agents

43a. Exposure to Agent Groupings

44. Number of Agents Mentioned During Interview

45. Occupational Skin Exposures and Exposures to Skin Irritants

46. Distribution of Total Ionizing Radiation

47. Distribution of Whole Body Ionizing Radiation

48. Distribution of Whole Body Dose-Time Period A

49. Distribution of Whole Body Dose-Time Period B

50. Distribution of Total Dose-Time Period A

51. Comparison of Occupational Factors

52. Regression of Occupational Factors on Start Year and Years of Education

53. Power to Detect Significant Risk Factors

54. Comparison of Results for Subsets of Cases

55. Comparison of Results with Different Matching Criteria

56. Effect of Adjusting for Sex Mismatch in Case-Control Pairs. 


\section{List of Figures}

Figure 1. LLNL Staffing History

Figure 2. Cases By Year Chart

Figure 3. Cumulative Distribution of Cases and Controls for Sunbathing Start

Figure 4. Distribution of $\geq 2 \mathrm{~mm}$ Moles

Figure 5. Distribution of Counts of $\geq 5 \mathrm{~mm}$ Moles

Figure 6. Distribution of Counts of Dysplastic Moles

Figure 7. Distribution of Hair Color Among Cases and Controls

Figure 8. Distribution of Eye Color Among Cases and Controls 


\section{Tables}

Table 1. Case-Control Matches by Sex

\begin{tabular}{|c|c|c|}
\hline 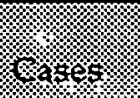 & 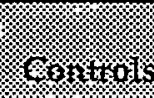 & (1) \\
\hline Male & Male & 53 \\
\hline Female & Female & 5 \\
\hline Female & Male & 10 \\
\hline Male & Female & 1 \\
\hline
\end{tabular}

Table 3. Case-Control Matches by Start Date

\begin{tabular}{|c|c|}
\hline 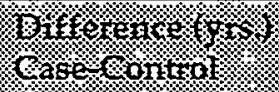 & 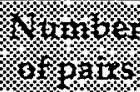 \\
\hline-3.5 to -2.5 & $\overline{1}$ \\
\hline-2.5 to -1.5 & 1 \\
\hline-1.5 to -0.5 & 3 \\
\hline-0.5 to 0.5 & 61 \\
\hline 0.5 to 1.5 & 2 \\
\hline 1.5 to 2.5 & 1 \\
\hline
\end{tabular}

Table 5. Case-Control Matches by Years of Tenure

\begin{tabular}{|c|c|}
\hline 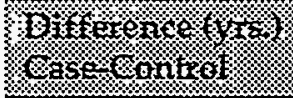 & Wringin \\
\hline-3.5 to -2.5 & 1 \\
\hline-2.5 to -1.5 & 1 \\
\hline-1.5 to -0.5 & 3 \\
\hline-0.5 to 0.5 & 59 \\
\hline 0.5 to 1.5 & 2 \\
\hline 1.5 to 2.5 & 1 \\
\hline 2.5 to 3.5 & 2 \\
\hline
\end{tabular}

Table 2. Case-Control Matches by Age

\begin{tabular}{|c|c|}
\hline 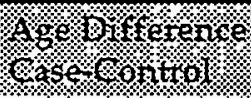 & \%riniver \\
\hline-4 & 2 \\
\hline-3 & 4 \\
\hline-2 & 3 \\
\hline-1 & 10 \\
\hline 0 & 26 \\
\hline 1 & 14 \\
\hline 2 & 4 \\
\hline 3 & 4 \\
\hline 4 & 1 \\
\hline 5 & 1 \\
\hline
\end{tabular}

Table 4. Case-Control Matches by Years of Education

\begin{tabular}{|c|c|}
\hline 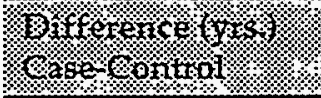 & Xininiver \\
\hline-5.5 to -4.5 & 1 \\
\hline-4.5 to -3.5 & 1 \\
\hline-3.5 to -2.5 & 0 \\
\hline-2.5 to -1.5 & 7 \\
\hline-1.5 to -0.5 & 18 \\
\hline-0.5 to 0.5 & 21 \\
\hline 0.5 to 1.5 & 12 \\
\hline 1.5 to 2.5 & 6 \\
\hline 2.5 to 3.5 & 3 \\
\hline
\end{tabular}

Table 6. Distribution of Overall Match Scores

\begin{tabular}{|c|c|}
\hline 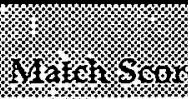 & \% \\
\hline 0 to 0.99 & 46 \\
\hline 1 to 1.99 & 14 \\
\hline 2 to 2.99 & 5 \\
\hline 3 to 3.99 & 1 \\
\hline 4 to 4.99 & 2 \\
\hline 5 to 5.99 & 0 \\
\hline 6 to 6.99 & 1 \\
\hline
\end{tabular}


Table 7. Ethnicity of Cases and Controls

\begin{tabular}{|c|c|c|}
\hline 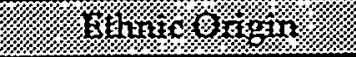 & Sasses & Ynonitar \\
\hline \multicolumn{3}{|l|}{ Maternal Grandfather } \\
\hline Great Britain or & 49 & 49 \\
\hline Northern European & & \\
\hline Eastern or Southern & 16 & 14 \\
\hline European & & \\
\hline Hispanic, Native & 1 & 4 \\
\hline American or Asian & & \\
\hline Black & $\mathbf{0}$ & 1 \\
\hline Unknown & 2 & 1 \\
\hline \multicolumn{3}{|l|}{ Maternal Grandmother } \\
\hline $\begin{array}{l}\text { Great Britain or } \\
\text { Northern European }\end{array}$ & 47 & 50 \\
\hline Eastern or Southern & 17 & 13 \\
\hline European & & \\
\hline Hispanic, Native & 2 & 4 \\
\hline American or Asian & & \\
\hline Black & $\mathbf{0}$ & 1 \\
\hline Unknown & 3 & 1 \\
\hline \multicolumn{3}{|l|}{ Paternal Grandfather } \\
\hline $\begin{array}{l}\text { Great Britain or } \\
\text { Northern European }\end{array}$ & 56 & 51 \\
\hline $\begin{array}{l}\text { Eastern or Southern } \\
\text { European }\end{array}$ & 10 & 9 \\
\hline Hispanic, Native & 2 & 5 \\
\hline \multicolumn{3}{|l|}{ American or Asian } \\
\hline Black & $\mathbf{0}$ & 1 \\
\hline Unknown & 1 & 3 \\
\hline \multicolumn{3}{|l|}{ Paternal Grandmother } \\
\hline $\begin{array}{l}\text { Great Britain or } \\
\text { Northern European }\end{array}$ & 54 & 48 \\
\hline $\begin{array}{l}\text { Eastern or Southern } \\
\text { European }\end{array}$ & 11 & 8 \\
\hline $\begin{array}{l}\text { European } \\
\text { Hispanic, Native }\end{array}$ & 1 & 5 \\
\hline American or Asian & & \\
\hline Black & 0 & 1 \\
\hline Unknown & 3 & 6 \\
\hline
\end{tabular}


Table 8. Ethnicity Scores for Cases and Controls

\begin{tabular}{|c|c|c|c|c|}
\hline 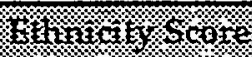 & (6) & soming & 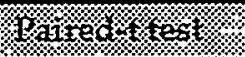 & (x) \\
\hline 4.0 & 41 & 47 & & \\
\hline $3-3.9$ & 26 & 16 & & \\
\hline $2-2.9$ & 1 & 1 & & \\
\hline $1-1.9$ & 0 & 1 & & \\
\hline $0-0.9$ & 1 & 4 & 1.00 & 0.321 \\
\hline \multicolumn{5}{|l|}{ Invasioe cases } \\
\hline 4.0 & 23 & 25 & & \\
\hline $3-3.9$ & 15 & 11 & & \\
\hline $2-2.9$ & 1 & 1 & & \\
\hline $1-1.9$ & 0 & 0 & & \\
\hline $0-0.9$ & 0 & 2 & 0.89 & 0.379 \\
\hline \multicolumn{5}{|l|}{ In situ cases } \\
\hline 4.0 & 18 & 22 & & \\
\hline $3-3.9$ & 11 & 5 & & \\
\hline $2-2.9$ & 0 & 0 & & \\
\hline $1-1.9$ & 0 & 1 & & \\
\hline $0-0.9$ & 1 & 2 & 0.55 & 0.584 \\
\hline
\end{tabular}

Table 9. Marital Status of Cases and Controls

\begin{tabular}{|c|c|c|c|c|c|}
\hline & ( & & & & \\
\hline (y) & (x) & 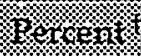 & m. & 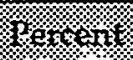 & 8) \\
\hline Married & 50 & $85 \%$ & 61 & $88 \%$ & \\
\hline Widowed & $\mathbf{0}$ & $0 \%$ & 1 & $1 \%$ & \\
\hline Divorced & 6 & $10 \%$ & 6 & $9 \%$ & \\
\hline Separated & 1 & $2 \%$ & 0 & $0 \%$ & \\
\hline Never married & 2 & $3 \%$ & 1 & $1 \%$ & \\
\hline Unknown & 10 & - & 0 & - & 0.0007 \\
\hline
\end{tabular}

t Percentage for cases based on 59 reponses excluding 10 "unknown"

* p-value based on Fisher's exact test for difference in percent unknown

Table 10. Highest Educational Grade of Cases and Controls

\begin{tabular}{|c|c|c|c|c|}
\hline 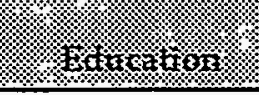 & (2). & (20ritious & (2): & 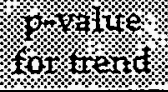 \\
\hline High School & 9 & 7 & & \\
\hline College & 24 & 26 & & \\
\hline Graduate work & 4 & 6 & & \\
\hline M.A.M.S. & 17 & 11 & & \\
\hline Ph.D.M.D. & 15 & 19 & 0.12 & 0.905 \\
\hline
\end{tabular}


Table 11. UV Exposures from Residences for Cases and Controls

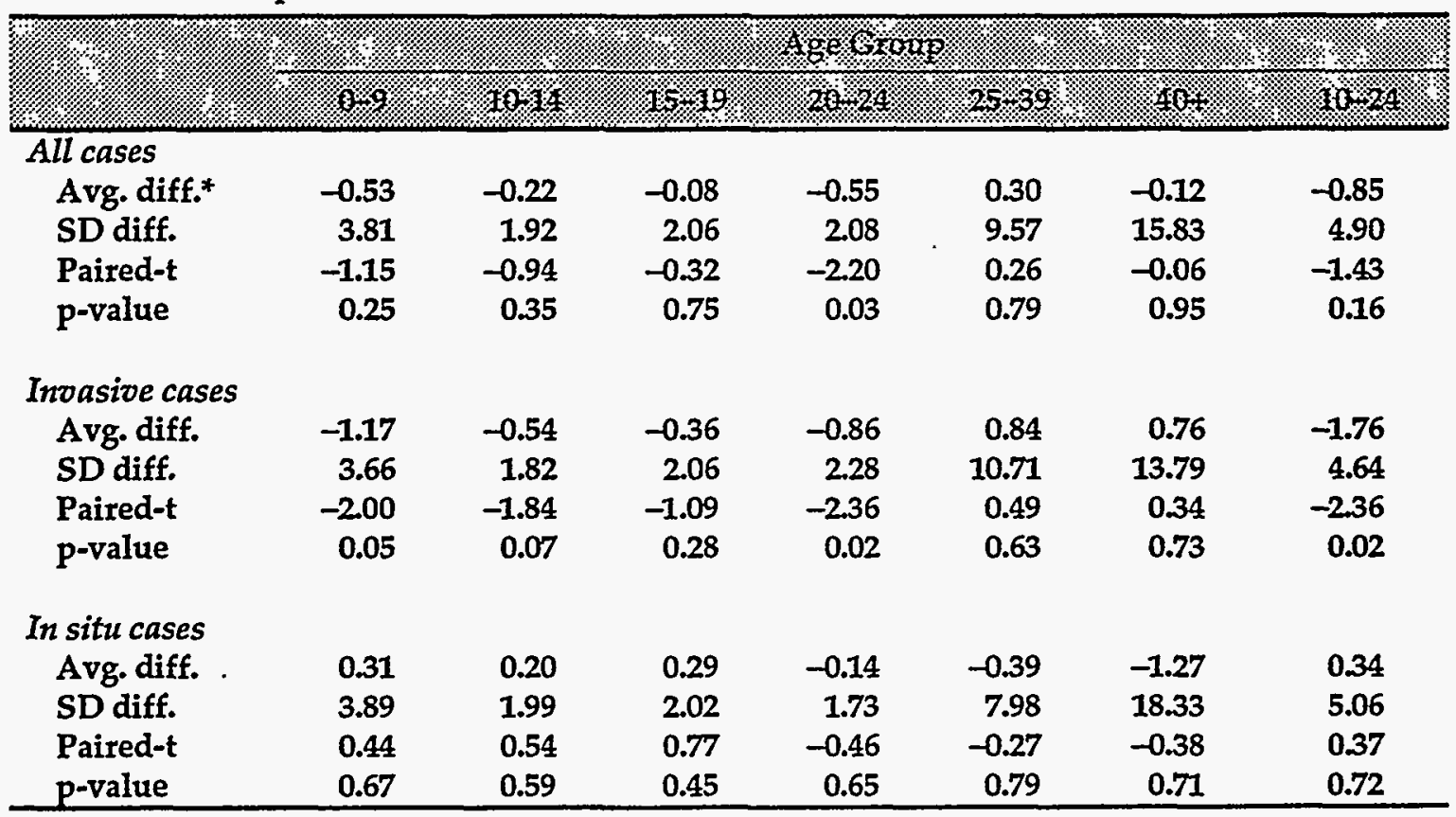

* Difference $=$ case-control

Table 12. Eye Color for Cases and Controls

\begin{tabular}{|c|c|c|c|c|}
\hline $8 y 400101$ & rasses & 400106616 & 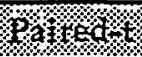 & $50161 \mathrm{y}$ \\
\hline Blue & 35 & 25 & & \\
\hline Green & 7 & 9 & & \\
\hline Gray & 0 & 2 & & \\
\hline Hazel & 17 & 19 & & \\
\hline Brown & 10 & 14 & 1.49 & 0.141 \\
\hline
\end{tabular}

Table 13. Hair Color for Cases and Controls

\begin{tabular}{|c|c|c|c|c|}
\hline 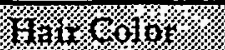 & 8 & 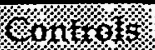 & 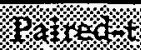 & prove \\
\hline Blond or Red & 27 & 14 & & \\
\hline Lt. Brown & 15 & 23 & & \\
\hline Brown & 26 & 26 & & \\
\hline Black & 1 & 6 & 2.21 & 0.03 \\
\hline
\end{tabular}


Table 14. Skin Reaction to One-Half-Hour of Summer Noonday Sun with No Previous Exposure

\begin{tabular}{|c|c|c|c|c|c|}
\hline 8) & easses & r. & 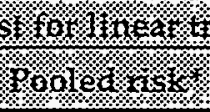 & 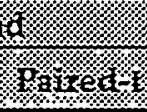 & ? \\
\hline \multicolumn{6}{|l|}{ All cases } \\
\hline Never burn or tan & 6 & 7 & & & \\
\hline Tan with no burning & 7 & 9 & & & \\
\hline Burn with tanning & 13 & 28 & & & \\
\hline Burn with little tanning & 30 & 16 & & & \\
\hline Burn with no tanning & 13 & 9 & 2.91 & 2.10 & 0.040 \\
\hline \multicolumn{6}{|l|}{ Inoasioe cases } \\
\hline Never burn or $\tan$ & 1 & 3 & & & \\
\hline Tan with no burning & 7 & 4 & & & \\
\hline Burn with tanning & 7 & 21 & & & \\
\hline Burn with little tanning & 16 & 9 & & & \\
\hline Burn with no tanning & 8 & 2 & 4.07 & 2.10 & 0.043 \\
\hline \multicolumn{6}{|l|}{ In situ cases } \\
\hline Never burn or tan & 5 & 4 & & & \\
\hline Tan with no burning & 0 & 5 & & & \\
\hline Burn with tanning & 6 & 7 & & & \\
\hline Burn with little tanning & 14 & 7 & & & \\
\hline Burn with no tanning & 5 & 7 & 1.97 & 0.84 & 0.41 \\
\hline
\end{tabular}

* Relative risk

Table 15. Skin Reaction to One Half Hour of Summer Noonday Sun with a Few Days Previous Exposure

\begin{tabular}{|c|c|c|c|c|c|}
\hline \multirow{2}{*}{ 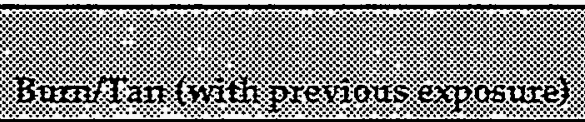 } & \multicolumn{5}{|c|}{ Hes/or, } \\
\hline & 1) & (13. & 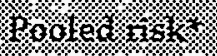 & 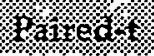 & x \\
\hline \multicolumn{6}{|l|}{ All cases } \\
\hline Never burn or tan & 14 & 12 & & & \\
\hline Tan with no burning & 30 & 44 & & & \\
\hline Burn with tanning & 10 & 8 & & & \\
\hline Burn with little tanning & 12 & 5 & & & \\
\hline Burn with no tanning & 3 & $\mathbf{0}$ & 3.56 & 2.62 & 0.011 \\
\hline \multicolumn{6}{|l|}{ Inoasioe cases } \\
\hline Never burn or tan & 6 & 4 & & & \\
\hline Tan with no burning & 16 & 29 & & & \\
\hline Burn with tanning & 6 & 4 & & & \\
\hline Burn with little tanning & 8 & 2 & & & \\
\hline Burn with no tanning & 3 & 0 & 7.27 & 2.94 & 0.005 \\
\hline \multicolumn{6}{|l|}{ In situ cases } \\
\hline Never bum or $\tan$ & 8 & 8 & & & \\
\hline Tan with no burning & 14 & 15 & & & \\
\hline Burn with tanning & 4 & 4 & & & \\
\hline Burn with little tanning & 4 & 3 & & & \\
\hline Burn with no tanning & $\mathbf{0}$ & 0 & 1.38 & 0.39 & 0.70 \\
\hline
\end{tabular}

* Relative risk 
Table 16. Skin Reaction to One Hour of Strong Summer Sunlight for the First Time

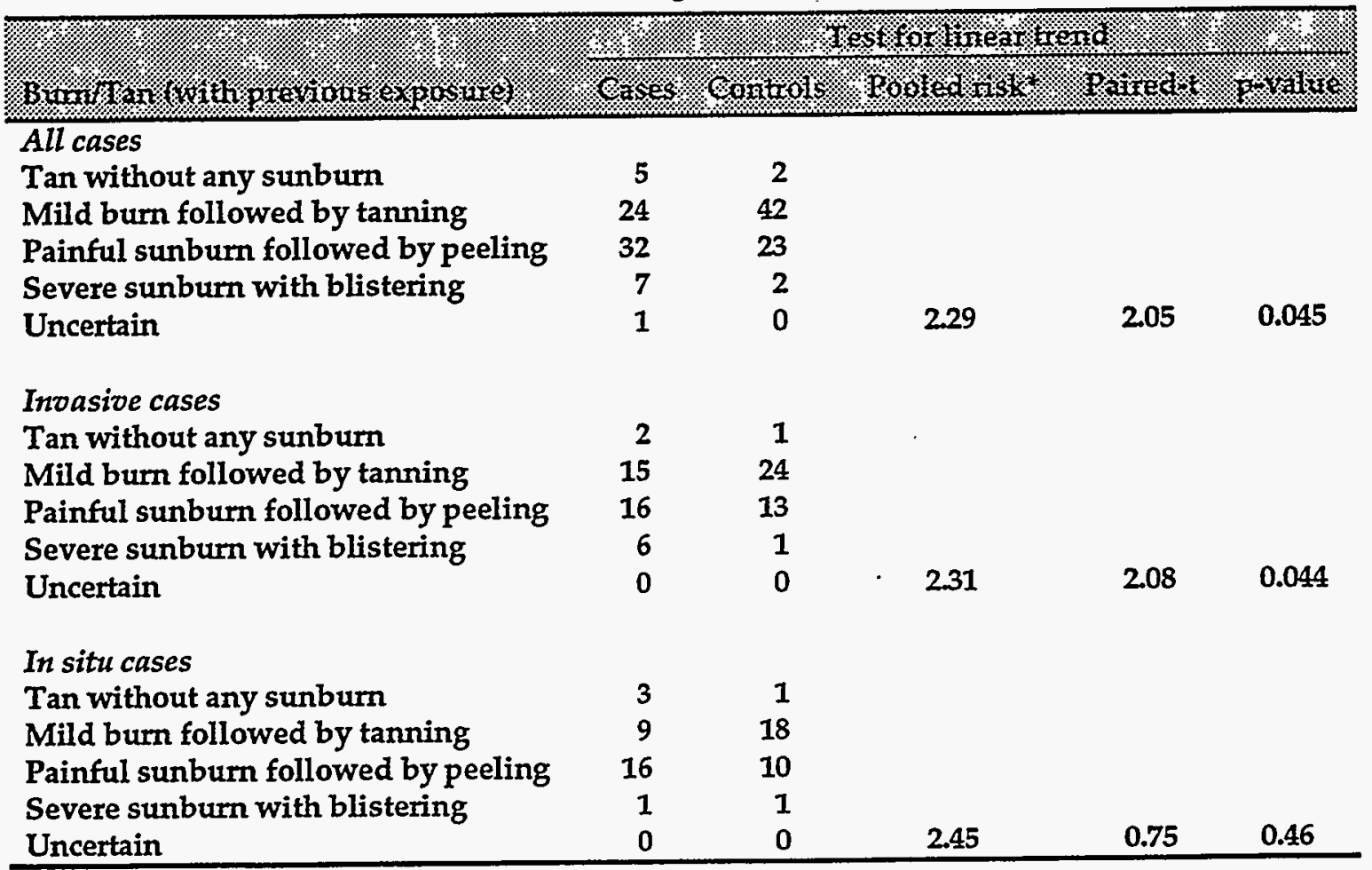

* Relative risk

Table 17. Skin Reaction after Repeated and Prolonged Exposure to Sunlight

\begin{tabular}{|c|c|c|c|c|c|}
\hline \% & (6.8. & 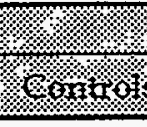 & Fingled, & (1) & 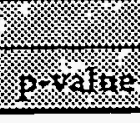 \\
\hline \multicolumn{6}{|l|}{ All cases } \\
\hline Deep $\tan$ & 7 & 17 & & & \\
\hline Moderate tan & 34 & 34 & & & \\
\hline Mild tan with peeling & 24 & 18 & & & \\
\hline Freckles or no suntan at all & 3 & 0 & & & \\
\hline Uncertain & 1 & 0 & 1.82 & 2.41 & 0.018 \\
\hline \multicolumn{6}{|l|}{ Inoasioe cases } \\
\hline Deep $\tan$ & 5 & 10 & & & \\
\hline Moderate tan & 16 & 24 & & & \\
\hline Mild tan with peeling & 15 & 5 & & & \\
\hline Freckles or no suntan at all & 3 & 0 & & & \\
\hline Uncertain & 0 & 0 & 5.83 & 3.00 & 0.005 \\
\hline \multicolumn{6}{|l|}{ In situ cases } \\
\hline Deep $\tan$ & 2 & 7 & & & \\
\hline Moderate $\tan$ & 18 & 10 & & & \\
\hline Mild $\tan$ with peeling & 9 & 13 & & & \\
\hline Freckles or no suntan at all & 0 & 0 & & & \\
\hline Uncertain & 1 & 0 & 0.56 & 0.00 & 1.00 \\
\hline
\end{tabular}

* Relative risk 
Table 18. Sun Exposure During Year Prior to Date of Diagnosis

\begin{tabular}{lrrrr}
\hline \\
Sun all year and kept a tan
\end{tabular}

Table 19. Number of Times Sunbathed During Year Prior to Diagnosis

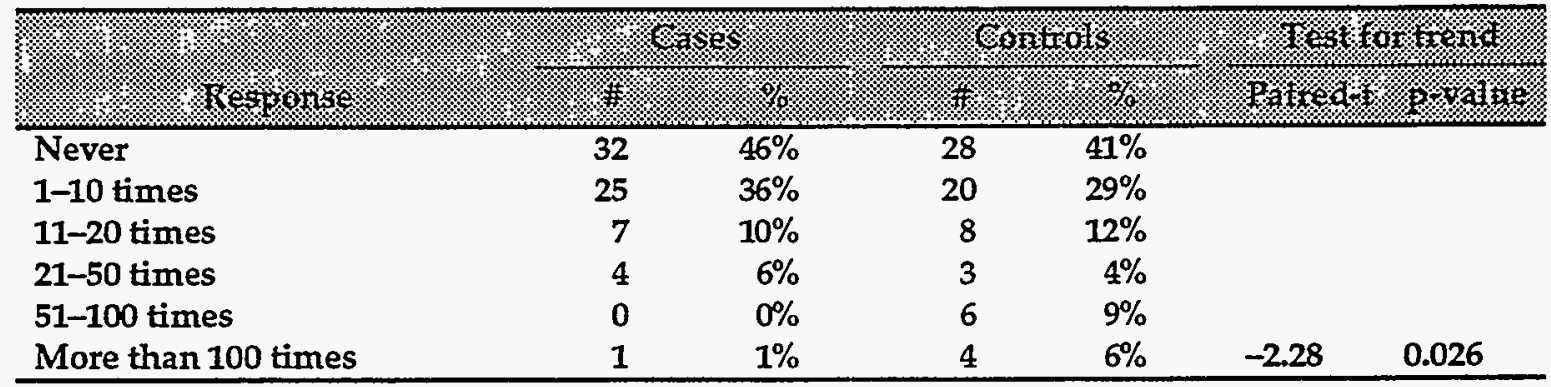

Table 20. Sunbathing in the Past

j:

Was there a time when

you sunbathed more

frequently?

$\begin{array}{lrrrrr}\text { Yes } & 62 & 90 \% & 69 & 100 \% & 0.013 \\ \text { No } & 6 & 9 \% & 0 & 0 \% & \end{array}$

Did you ever sunbathe?

\begin{tabular}{lrrrrr} 
Yes & 50 & $72 \%$ & 63 & $93 \%$ & 0.002 \\
No & 19 & $28 \%$ & 5 & $7 \%$ & \\
\hline
\end{tabular}


Table 21. Sunbathing Frequency in the Past

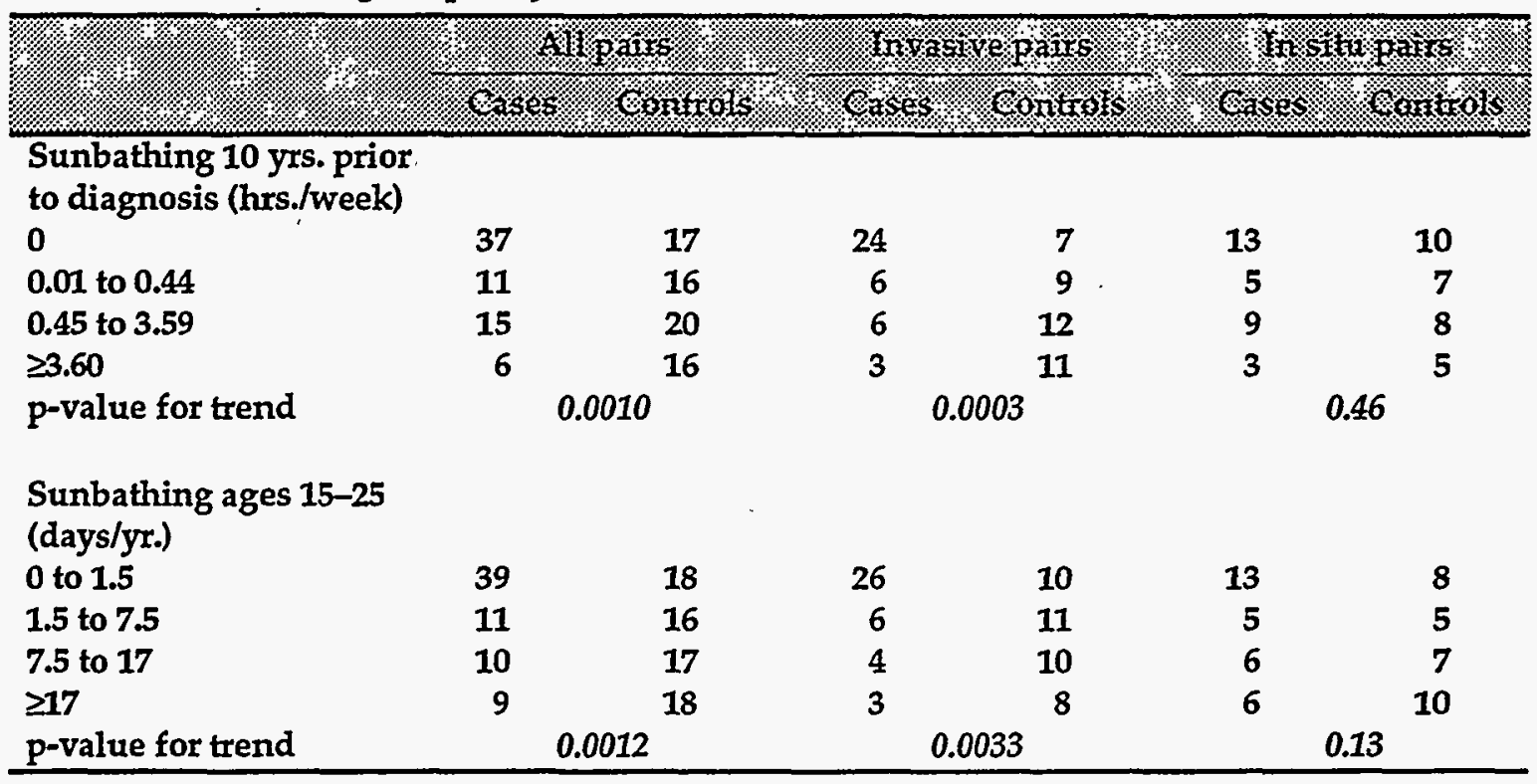

Table 22. Use of Tanning Salon Prior to Diagnosis

\begin{tabular}{lccc}
\hline Never & & & \\
Neves & 65 & 68 \\
$1-10$ times & 0 & 0 \\
$11-25$ times & 1 & 0 \\
$26-50$ times & 0 & 0 \\
$51-100$ times & 2 & 0 \\
$>100$ times & 1 & 0 \\
\hline 1 One control did not answer this \\
question.
\end{tabular}

Table 23. Tablets to Improve Skin Tanning

\begin{tabular}{|c|c|c|c|}
\hline (1) & 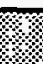 & পy & 4 \\
\hline \multicolumn{4}{|c|}{ All cases } \\
\hline Yes & & 5 & 6 \\
\hline No & & 63 & 63 \\
\hline \multicolumn{4}{|c|}{ Invasive. } \\
\hline Yes & & 3 & 3 \\
\hline No & & 36 & 36 \\
\hline \multicolumn{4}{|l|}{ In situ } \\
\hline Yes & & 2 & 3 \\
\hline No & & 27 & 27 \\
\hline
\end{tabular}


Table 24. Outdoor Pastimes

\begin{tabular}{|c|c|c|c|c|c|c|c|c|c|}
\hline t. & rerinta & 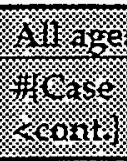 & 6ring & (1) & $\frac{4 g e x}{119}$ & 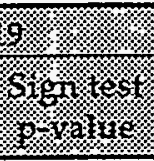 & \% & 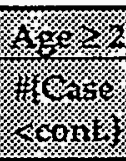 & 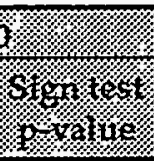 \\
\hline \multicolumn{10}{|l|}{ All cases } \\
\hline Swimming & 10 & 9 & 1.00 & 13 & 6 & 0.17 & 19 & 13 & 0.38 \\
\hline Walking/Jogging/ & 6 & 13 & 0.17 & 2 & 8 & 0.11 & 5 & 12 & 0.14 \\
\hline \multicolumn{10}{|l|}{ Running } \\
\hline Gardening & 15 & 13 & 0.85 & 14 & 12 & 0.85 & 17 & 13 & 0.58 \\
\hline Boating/Sailing & 21 & 14 & 0.31 & 9 & 4 & 0.27 & 16 & 15 & 1.00 \\
\hline Fishing & 18 & 19 & 1.00 & 13 & 12 & 1.00 & 18 & 16 & 0.86 \\
\hline Tennis & 12 & 17 & 0.46 & 10 & 14 & 0.54 & 11 & 14 & 0.69 \\
\hline Softball & 15 & 21 & 0.41 & 13 & 18 & 0.47 & 12 & 17 & 0.46 \\
\hline Golf & 10 & 14 & 0.54 & 5 & 5 & 1.00 & 9 & 13 & 0.52 \\
\hline Water Skiing & 11 & 16 & 0.44 & 8 & 7 & 1.00 & 10 & 14 & 0.54 \\
\hline Basketball & 6 & 7 & 1.00 & 6 & 6 & 1.00 & 2 & 2 & 1.00 \\
\hline Football & 16 & 12 & 0.57 & 15 & 12 & 0.70 & 6 & 4 & 0.75 \\
\hline Surfing & 5 & 8 & 0.58 & 6 & 6 & 1.00 & 2 & 4 & 0.69 \\
\hline Skin Diving/Scuba & 8 & 8 & 1.00 & 3 & 3 & 1.00 & 6 & 8 & 0.79 \\
\hline Snow Skiing & 17 & 20 & 0.74 & 10 & 8 & 0.81 & 16 & 19 & 0.74 \\
\hline Motorbiking/ & 5 & 8 & 0.58 & 2 & 2 & 1.00 & 5 & 7 & 0.77 \\
\hline \multicolumn{10}{|l|}{ Motorcycling } \\
\hline Biking/Cycling & 12 & 20 & 0.22 & 12 & 20 & 0.22 & 12 & 15 & 0.70 \\
\hline Horseback Riding & 10 & 7 & 0.63 & 6 & 7 & 1.00 & 9 & 3 & 0.15 \\
\hline Hang Gliding & 0 & 0 & 1.00 & 0 & 0 & 1.00 & 0 & $\mathbf{0}$ & 1.00 \\
\hline Soccer & 8 & 0 & 0.01 & 4 & 0 & 0.13 & 7 & $\mathbf{0}$ & 0.02 \\
\hline $\begin{array}{l}\text { Cricket/Rugby/ } \\
\text { Lawn Bowls }\end{array}$ & 1 & 0 & 1.00 & 1 & 0 & 1.00 & 1 & $\mathbf{0}$ & 1.00 \\
\hline Baseball & 8 & 3 & 0.23 & 6 & 1 & 0.13 & 5 & 2 & 0.45 \\
\hline Hiking & 23 & 4 & 0.0003 & 23 & 8 & 0.01 & 25 & 5 & 0.0003 \\
\hline Windsurfing & 2 & $\mathbf{0}$ & 0.50 & 0 & $\mathbf{0}$ & 1.00 & 1 & $\mathbf{0}$ & 1.00 \\
\hline Snorkeling & $\mathbf{0}$ & $\mathbf{0}$ & 1.00 & 0 & $\mathbf{0}$ & 1.00 & 0 & 0 & 1.00 \\
\hline Convertible Riding & 6 & 14 & 0.12 & 4 & 3 & 1.00 & 6 & 13 & 0.17 \\
\hline $\begin{array}{l}\text { Roller Skating/ } \\
\text { Rollerblading }\end{array}$ & 1 & 0 & 1.00 & 0 & 0 & 1.00 & 1 & $\mathbf{0}$ & 1.00 \\
\hline \multicolumn{10}{|l|}{ Inoasioe cases } \\
\hline Swimming & 7 & 4 & 0.55 & 9 & 3 & 0.15 & 13 & 7 & 0.26 \\
\hline $\begin{array}{l}\text { Walking/Jogging/ } \\
\text { Running }\end{array}$ & 4 & 6 & 0.75 & 1 & 2 & 1.00 & 2 & 6 & 0.29 \\
\hline Gardening & 8 & 8 & 1.00 & 7 & 7 & 1.00 & 9 & 9 & 1.00 \\
\hline Boating/Sailing & 11 & 9 & 0.82 & 6 & 2 & 0.29 & 8 & 10 & 0.81 \\
\hline Fishing & 10 & 11 & 1.00 & 7 & 8 & 1.00 & 11 & 10 & 1.00 \\
\hline Tennis & 8 & 9 & 1.00 & 7 & 8 & 1.00 & 9 & 8 & 1.00 \\
\hline Softball & 11 & 9 & 0.82 & 9 & 8 & 1.00 & 8 & 9 & 1.00 \\
\hline Golf & 3 & 8 & 0.23 & 3 & 3 & 1.00 & 3 & 8 & 0.23 \\
\hline Water Skiing & 8 & 8 & 1.00 & 6 & 4 & 0.75 & 8 & 7 & 1.00 \\
\hline Basketball & 2 & 4 & 0.69 & 2 & 4 & 0.69 & 2 & 1 & 1.00 \\
\hline Football & 8 & 8 & 1.00 & 8 & 8 & 1.00 & 5 & 3 & 0.73 \\
\hline Surfing & 4 & 5 & 1.00 & 5 & 4 & 1.00 & 1 & 2 & 1.00 \\
\hline Skin Diving/Scuba & 4 & 3 & 1.00 & 0 & 1 & 1.00 & 2 & 3 & 1.00 \\
\hline Snow Skiing & 10 & 10 & 1.00 & 5 & 4 & 1.00 & 9 & 10 & 1.00 \\
\hline
\end{tabular}


Table 24. Outdoor Pastimes (continued)

\begin{tabular}{|c|c|c|c|c|c|c|c|c|c|}
\hline 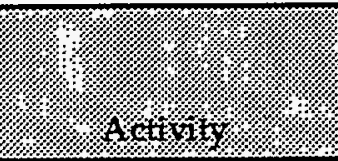 & $\frac{1.8}{1.6 .9}$ & 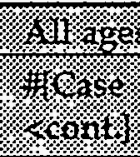 & 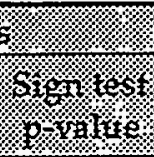 & 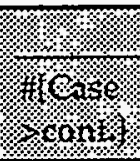 & 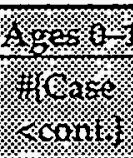 & 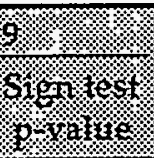 & 洋: & 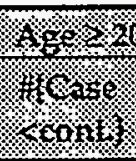 & (8) \\
\hline \multicolumn{10}{|l|}{ Invasive cases } \\
\hline $\begin{array}{l}\text { Motorbiking/ } \\
\text { Motorcycling }\end{array}$ & 2 & 3 & 1.00 & 1 & 1 & 1.00 & 2 & 3 & 1.00 \\
\hline Biking/Cycling & 7 & 11 & 0.48 & 7 & 13 & 0.26 & 7 & 10 & 0.63 \\
\hline Horseback Riding & 4 & 6 & 0.75 & 3 & 5 & 0.73 & 3 & 3 & 1.00 \\
\hline Hang Gliding & 0 & 0 & 1.00 & 0 & 0 & 1.00 & 0 & 0 & 1.00 \\
\hline Soccer & 2 & 0 & 0.50 & 2 & 0 & 0.50 & 1 & 0 & 1.00 \\
\hline $\begin{array}{l}\text { Cricket/Rugby/ } \\
\text { Lawn Bowls }\end{array}$ & 1 & 0 & 1.00 & 1 & 0 & 1.00 & 1 & 0 & 1.00 \\
\hline Baseball & 3 & 2 & 1.00 & 3 & 1 & 0.63 & 0 & 1 & 1.00 \\
\hline Hiking & 11 & 2 & 0.02 & 10 & 6 & 0.45 & 13 & 3 & 0.02 \\
\hline Windsurfing & 1 & 0 & 1.00 & 0 & 0 & 1.00 & 0 & 0 & 1.00 \\
\hline Snorkeling & 0 & 0 & 1.00 & 0 & 0 & 1.00 & 0 & 0 & 1.00 \\
\hline Convertible Riding & 4 & 9 & 0.27 & 4 & 1 & 0.38 & 3 & 9 & 0.15 \\
\hline $\begin{array}{l}\text { Roller Skating/ } \\
\text { Rollerblading }\end{array}$ & 0 & 0 & 1.00 & 0 & 0 & 1.00 & 0 & 0 & 1.00 \\
\hline In situ cases & & & & & & & & & \\
\hline Swimming & 3 & 5 & 0.73 & 4 & 3 & 1.00 & 6 & 6 & 1.00 \\
\hline $\begin{array}{l}\text { Walking/Jogging/ } \\
\text { Running }\end{array}$ & 2 & 7 & 0.18 & 1 & 6 & 0.13 & 3 & 6 & 0.51 \\
\hline Gardening - & 7 & 5 & 0.77 & 7 & 5 & 0.77 & 8 & 4 & 0.39 \\
\hline Boating/Sailing & 10 & 5 & 0.30 & 3 & 2 & 1.00 & 8 & 5 & 0.58 \\
\hline Fishing & 8 & 8 & 1.00 & 6 & 4 & 0.75 & 7 & 6 & 1.00 \\
\hline Tennis & 4 & 8 & 0.39 & 3 & 6 & 0.51 & 2 & 6 & 0.29 \\
\hline Softball & 4 & 12 & 0.08 & 4 & 10 & 0.18 & 4 & 8 & 0.39 \\
\hline Golf & 7 & 6 & 1.00, & 2 & 2 & 1.00 & 6 & 5 & 1.00 \\
\hline Water Skiing & 3 & 8 & 0.23 & 2 & 3 & 1.00 & 2 & 7 & 0.18 \\
\hline Basketball & 4 & 3 & 1.00 & 4 & 2 & 0.69 & $\mathbf{0}$ & 1 & 1.00 \\
\hline Football & 8 & 4 & 0.39 & 7 & 4 & 0.55 & 1 & 1 & 1.00 \\
\hline Surfing & 1 & 3 & 0.63 & 1 & 2 & 1.00 & 1 & 2 & 1.00 \\
\hline Skin Diving/Scuba & 4 & 5 & 1.00 & 3 & 2 & 1.00 & 4 & 5 & 1.00 \\
\hline Snow Skiing & 7 & 10 & 0.63 & 5 & 4 & 1.00 & 7 & 9 & 0.80 \\
\hline $\begin{array}{l}\text { Motorbiking/ } \\
\text { Motorcycling }\end{array}$ & 3 & 5 & 0.73 & 1 & 1 & 1.00 & 3 & 4 & 1.00 \\
\hline Biking/Cycling & 5 & 9 & 0.42 & 5 & 7 & 0.77 & 5 & 5 & 1.00 \\
\hline Horseback Riding & 6 & 1 & 0.13 & 3 & 2 & 1.00 & 6 & 0 & 0.03 \\
\hline Hang Gliding & 0 & 0 & 1.00 & 0 & 0 & 1.00 & $\mathbf{0}$ & 0 & 1.00 \\
\hline Soccer & 6 & 0 & 0.03 & 2 & 0 & 0.50 & 6 & 0 & 0.03 \\
\hline $\begin{array}{l}\text { Cricket/Rugby/ } \\
\text { Lawn Bowls }\end{array}$ & 0 & 0 & 1.00 & 0 & 0 & 1.00 & $\mathbf{0}$ & 0 & 1.00 \\
\hline Baseball & 5 & 1 & 0.22 & 3 & 0 & 0.25 & 5 & 1 & 0.22 \\
\hline Hiking & 12 & 2 & 0.01 & 13 & 2 & 0.01 & 12 & 2 & 0.01 \\
\hline Windsurfing & 1 & 0 & 1.00 & 0 & 0 & 1.00 & $\mathbf{I}$ & 0 & 1.00 \\
\hline Snorkeling & 0 & 0 & 1.00 & 0 & 0 & 1.00 & 0 & 0 & 1.00 \\
\hline Convertible Riding & 2 & 5 & 0.45 & 0 & 2 & 0.50 & 3 & 4 & 1.00 \\
\hline $\begin{array}{l}\text { Roller Skating/ } \\
\text { Rollerblading }\end{array}$ & 1 & 0 & 1.00 & 0 & 0 & 1.00 & 1 & $\mathbf{0}$ & 1.00 \\
\hline
\end{tabular}


Table 25. Sunburn with Blistering Episodes

\begin{tabular}{|c|c|c|c|c|c|c|c|c|c|c|c|c|}
\hline 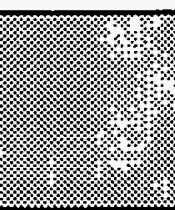 & 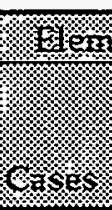 & int: & Solow & 6. & (r: & $\frac{104}{4}$ & $\frac{40173}{4}$ & $\frac{4 x}{4}$ & 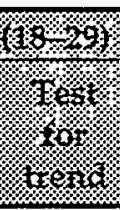 & \%: & : & 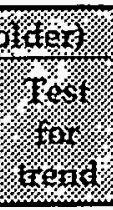 \\
\hline \multicolumn{13}{|l|}{ All cases } \\
\hline None & 43 & 49 & 0.38 & 38 & 45 & 0.80 & 44 & 45 & 0.16 & 59 & 59 & 0.00 \\
\hline $1-10$ & 23 & 17 & 0.71 & 31 & 22 & 0.43 & 25 & 24 & 0.87 & 10 & 9 & 1.0 \\
\hline $11-20$ & 3 & 1 & & 0 & 2 & & 0 & 0 & & 0 & 0 & \\
\hline $21-30$ & 0 & 1 & & 0 & 0 & & 0 & 0 & & $\mathbf{0}$ & 0 & \\
\hline$>30$ & 0 & 1 & & 0 & 0 & & 0 & 0 & & 0 & 0 & \\
\hline \multicolumn{13}{|c|}{ Inoasive cases } \\
\hline None & 23 & 26 & -0.14 & 24 & 23 & -0.40 & 28 & 15 & -2.82 & 33 & 30 & -0.90 \\
\hline $1-10$ & 14 & 10 & 0.89 & 15 & 15 & 0.69 & 11 & 24 & 0.01 & 6 & 8 & 0.37 \\
\hline $11-20$ & 2 & 1 & & 0 & 1 & & 0 & 0 & & 0 & 0 & \\
\hline $21-30$ & 0 & 1 & & 0 & 0 & & 0 & 0 & & $\mathbf{0}$ & 0 & \\
\hline$>30$ & 0 & 1 & & 0 & 0 & & 0 & 0 & & 0 & 0 & \\
\hline \multicolumn{13}{|c|}{ In situ cases } \\
\hline None & 20 & 23 & 0.13 & 14 & 22 & 1.88 & 16 & 30 & 5.04 & 26 & 29 & 1.36 \\
\hline $1-10$ & 9 & 7 & 0.33 & 16 & 7 & 0.07 & 14 & 0 & $<0.001$ & 4 & 1 & 0.18 \\
\hline $11-20$ & 1 & 0 & & 0 & 1 & & 0 & 0 & & 0 & 0 & \\
\hline $21-30$ & $\mathbf{0}$ & 0 & & 0 & 0 & & 0 & 0 & & 0 & 0 & \\
\hline$>30$ & 0 & 0 & & 0 & 0 & & 0 & 0 & & 0 & 0 & \\
\hline
\end{tabular}

1 Upper number is paired-t statistic; lower number is 2-sided p-value. 
IL

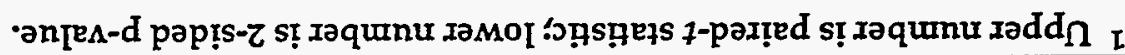

\begin{tabular}{|c|c|c|c|c|c|c|c|c|c|c|c|c|}
\hline & 0 & 0 & & 0 & $\bar{I}$ & & 0 & 0 & & 0 & $\overline{0}$ & $0 \varepsilon<$ \\
\hline & 0 & 0 & & 0 & 0 & & 0 & I & & 0 & $\mathbf{0}$ & $0 \varepsilon-I Z$ \\
\hline & $\mathbf{0}$ & 0 & & 0 & 0 & & 0 & 0 & & 0 & $\mathbf{0}$ & $0 Z-I I$ \\
\hline ELOO & $\tau I$ & $\mathbf{S}$ & $\varepsilon L^{\circ} 0$ & 五 & $6 I$ & $E S^{\circ} 0$ & $8 L$ & $8 T$ & $28^{\circ} 0$ & 玵 & SL & $0 \mathrm{~L}-\mathbf{L}$ \\
\hline$\varepsilon S^{\circ} \tau_{-}$ & 8I. & $\nexists z$ & 9S'L & 9I & OI & $29^{\circ} 0$ & $\tau I$ & II & $\varpi \tau^{\circ} 0$ & $9 \tau$ & \multicolumn{2}{|c|}{ saswo n?!s $u_{I}$} \\
\hline & 0 & $\mathbf{0}$ & & 0 & 0 & & 0 & 0 & & I & 0 & $0 \varepsilon<$ \\
\hline & 0 & 0 & & 0 & 0 & & 0 & 0 & & I & 0 & $0 \varepsilon-\tau z$ \\
\hline & 0 & 0 & & 0 & 0 & & 0 & 0 & & I & $\tau$ & $0 z-\tau \tau$ \\
\hline $0^{\circ} L$ & SI & SI & $200^{\circ} 0$ & $\tau \varepsilon$ & $\angle I$ & $\tau \tau^{*} 0$ & sz & $6 L$ & $59^{\circ} 0$ & $\Xi \tau$ & $\pi$ & $0 T-I$ \\
\hline \multirow[t]{4}{*}{$00^{\circ} 0$} & $\overline{\nabla Z}$ & 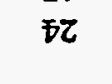 & $\angle \mathcal{S}^{\circ} \varepsilon-$ & $L$ & $z z$ & $\varepsilon Z^{\circ} I_{-}$ & EI & $0 z$ & $\mathbf{S E}^{\circ} 0$ & $\pi$ & \multicolumn{2}{|c|}{ sosvo วа!ุsvQuI } \\
\hline & 0 & $\mathbf{0}$ & & 0 & I & & 0 & 0 & & I & $\mathbf{0}$ & $0 \varepsilon<$ \\
\hline & 0 & 0 & & 0 & 0 & & 0 & I & & I & 0 & $0 \varepsilon-\tau \tau$ \\
\hline & 0 & 0 & & 0 & 0 & & 0 & 0 & & I & $z$ & $0 Z-I I$ \\
\hline$I \varepsilon^{*} 0$ & $L \tau$ & $0 z$ & 0 & 97 & $9 \varepsilon$ & $99^{\circ} 0$ & $\varepsilon \mp$ & $L \varepsilon$ & I9*0 & 82 & $\angle \varepsilon$ & OI-I \\
\hline E०'L- & $\tau \pi$ & 87 & $6 L^{\circ} 0-$ & $\varepsilon \tau$ & $\tau \varepsilon$ & 伍0- & 92 & IE & LS'0 & $8 \varepsilon$ & $0 \varepsilon$ & $\begin{array}{l}\text { ouoN } \\
\text { Sasvo } 11 \mathrm{~V}\end{array}$ \\
\hline 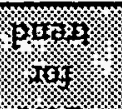 & 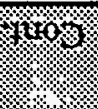 & & 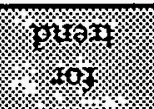 & 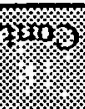 & ( & 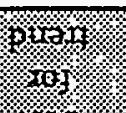 & 14. & 593 & \% & & (3. & \\
\hline $4 \%$ & 19. & 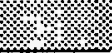 & & & & & & & 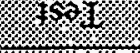 & \% & & \\
\hline Gop & 16 & $6 \%$ & $(6 \% 8,8)$ & $y_{y}$ & onnol & (6) & Fs? & & of & Mryiura & छखा & $2 \%$ \\
\hline
\end{tabular}

sopos!̣dG umquns [mu!ed $9 Z$ əIqRI 
Table 27. Episodes of Sunburn Peeling, Large Blisters, and Pain

\begin{tabular}{|c|c|c|c|c|c|c|c|c|c|}
\hline & \multicolumn{3}{|c|}{ r } & \multicolumn{3}{|c|}{ 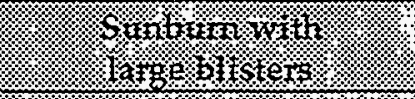 } & \multicolumn{3}{|c|}{ 19. } \\
\hline & (2) & Cenntrots & (1) & sersees & Q enturtorys & 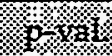 & 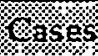 & 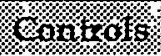 & 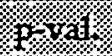 \\
\hline \multicolumn{10}{|c|}{ All cases } \\
\hline Yes & 2 & 3 & 0.50 & 41 & 48 & 0.18 & 32 & 33 & 0.74 \\
\hline No & 67 & 66 & & 28 & 20 & & 36 & 33 & \\
\hline \multicolumn{10}{|c|}{ Invasioe cases } \\
\hline Yes & 1 & 0 & 1.00 & 25 & 23 & 0.83 & 17 & 25 & 0.97 \\
\hline No & 38 & 39 & & 14 & 15 & & 21 & 14 & \\
\hline \multicolumn{10}{|c|}{ In situ cases } \\
\hline Yes & 1 & 3 & 0.25 & 16 & 25 & 0.01 & 15 & 8 & 0.15 \\
\hline No & 29 & 27 & & 14 & 5 & & 15 & 22 & \\
\hline
\end{tabular}

+ Peeling refers to pieces of dead skin that could be peeled off (not flaking).

$\mp$ p-value based on sign test

Table 28. Freckles That Change with Sun

Exposure

\begin{tabular}{llll}
\hline ill cases & & & \\
Yes & 32 & 24 & 0.17 \\
No & 35 & 45 & \\
& & & \\
Invasive cases & & & \\
$\quad$ Yes & 21 & 16 & 0.20 \\
No & 17 & 23 & \\
& & & \\
In situ cases & & & \\
Yes & 11 & 8 & 0.40 \\
No & 18 & 22 & \\
\hline
\end{tabular}

$\ddagger$ p-value based on sign test 
Table 29. Mole Count Summary Statistics for All Cases and Matched Controls

\begin{tabular}{|c|c|c|c|c|c|c|c|c|}
\hline \multirow{3}{*}{ 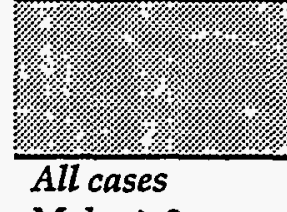 } & \multicolumn{2}{|c|}{$\sqrt{1}$} & \multicolumn{2}{|r|}{ (4) } & \multicolumn{3}{|c|}{ (2ass. } & \multirow[b]{2}{*}{6} \\
\hline & rantive & 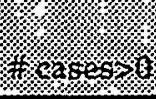 & courn. & 47. & (1) & 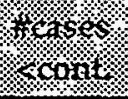 & titerense: & \\
\hline & & & & & & & & \\
\hline \multicolumn{9}{|l|}{ Moles $\geq 2 \mathrm{~mm}$} \\
\hline Total & 60.65 & 68 & 25.67 & 68 & 34.99 & 45 & 23 & $0.005 *$ \\
\hline Scalp & 0.54 & 20 & 0.30 & 13 & 0.23 & 16 & 8 & 0.076 \\
\hline Head \& neck & 3.57 & 55 & 2.17 & 44 & 1.39 & 36 & 23 & 0.059 \\
\hline Upper arms & 9.90 & 58 & 4.29 & 51 & 5.61 & 41 & 25 & 0.032 \\
\hline Lower arms & 3.29 & 44 & 2.03 & 33 & 1.26 & 33 & 21 & 0.067 \\
\hline Palms & 0.00 & 0 & 0.03 & 2 & -0.03 & 0 & 2 & 1.000 \\
\hline Chest & 7.25 & 57 & 3.43 & 48 & 3.81 & 40 & 20 & $0.007 *$ \\
\hline Abdomen & 5.19 & 43 & 1.65 & 45 & 3.54 & 35 & 22 & 0.056 \\
\hline Upper back & 12.13 & 60 & 5.99 & 59 & 6.14 & 38 & 25 & 0.065 \\
\hline Lower back & 5.61 & 53 & 1.87 & 40 & 3.74 & 37 & 18 & $0.007 *$ \\
\hline Buttocks & 1.39 & 36 & 0.55 & 29 & 0.84 & 26 & 14 & 0.040 \\
\hline Thighs & 6.54 & 51 & 1.96 & 42 & 4.58 & 41 & 17 & $0.001 *$ \\
\hline Lower legs & 4.94 & 48 & 1.26 & 28 & 3.68 & 40 & 13 & $0.000 *$ \\
\hline Soles of feet & 0.33 & 17 & 0.13 & 9 & 0.20 & 14 & 6 & 0.058 \\
\hline \multicolumn{9}{|l|}{ Moles $\geq 5 \mathrm{~mm}$} \\
\hline Total & 12.20 & 57 & 3.83 & 54 & 8.38 & 39 & 27 & 0.088 \\
\hline Scalp & 0.28 & 14 & 0.12 & 7 & 0.17 & 12 & 4 & 0.038 \\
\hline Head \& neck & 1.32 & 29 & 0.36 & 16 & 0.96 & 22 & 12 & 0.061 \\
\hline Upper arms & 0.29 & 9 & 0.17 & 8 & 0.12 & 26 & 10 & $0.006 *$ \\
\hline Lower arms & 0.00 & $\mathbf{0}$ & 0.00 & 0 & 0.00 & 9 & 8 & 0.500 \\
\hline Palms & 0.75 & 30 & 0.41 & 18 & 0.35 & $\mathbf{0}$ & 0 & 1.000 \\
\hline Chest & 1.93 & 33 & 0.68 & 24 & 1.25 & 27 & 15 & 0.044 \\
\hline Abdomen & 1.71 & 29 & 0.26 & 13 & 1.45 & 27 & 9 & $0.002 *$ \\
\hline Upper back & 3.30 & 41 & 1.06 & 30 & 2.25 & 30 & 19 & 0.076 \\
\hline Lower back & 1.38 & 30 & 0.46 & 18 & 0.91 & 27 & 12 & 0.012 \\
\hline Buttocks & 0.23 & 10 & 0.07 & 5 & 0.16 & 10 & 5 & 0.151 \\
\hline Thighs & 0.61 & 18 & 0.16 & 9 & 0.45 & 16 & 7 & 0.047 \\
\hline Lower legs & 0.36 & 12 & 0.03 & 2 & 0.33 & 11 & 1 & 0.003 * \\
\hline Soles of feet & 0.04 & 3 & 0.04 & 3 & 0.00 & 3 & 3 & 0.656 \\
\hline \multicolumn{9}{|c|}{ Dysplastic Moles } \\
\hline Total & 3.54 & 25 & 0.54 & 7 & 3.00 & 23 & 6 & $0.001 *$ \\
\hline Scalp & 0.00 & 2 & 0.00 & 0 & 0.00 & 2 & 0 & 0.250 \\
\hline Head \& neck & 0.14 & 7 & 0.00 & 0 & 0.14 & 0 & 0 & 1.000 \\
\hline Upper arms & 0.06 & 2 & 0.00 & 0 & 0.06 & 7 & $\mathbf{0}$ & $0.008 *$ \\
\hline Lower arms & 0.00 & 0 & 0.00 & 0 & 0.00 & 2 & $\mathbf{0}$ & 0.250 \\
\hline Palms & 0.00 & $\mathbf{0}$ & 0.00 & 0 & 0.00 & 0 & $\mathbf{0}$ & 1.000 \\
\hline Chest & 0.75 & 14 & 0.17 & 3 & 0.58 & 14 & 3 & $0.006 *$ \\
\hline Abdomen & 0.71 & 15 & 0.06 & 1 & 0.65 & 14 & 1 & $0.000 *$ \\
\hline Upper back & 1.14 & 16 & 0.19 & 6 & 0.96 & 16 & 6 & 0.026 \\
\hline Lower back & 0.58 & 15 & 0.09 & 2 & 0.49 & 14 & 2 & $0.002 *$ \\
\hline Buttocks & 0.04 & 3 & 0.01 & 1 & 0.03 & 3 & 1 & 0.313 \\
\hline Thighs & 0.10 & 5 & 0.00 & $\mathbf{0}$ & 0.10 & 5 & $\mathbf{0}$ & 0.031 \\
\hline Lower legs & 0.01 & 1 & 0.00 & $\mathbf{0}$ & 0.01 & 1 & 0 & 0.500 \\
\hline Soles of feet & 0.00 & $\mathbf{0}$ & 0.01 & 1 & -0.01 & 0 & 1 & 1.000 \\
\hline
\end{tabular}

* Indicates statistical significance at $p<0.01$ 
Table 30. Mole Count Summary Statistics for Invasive Cases and Matched Controls

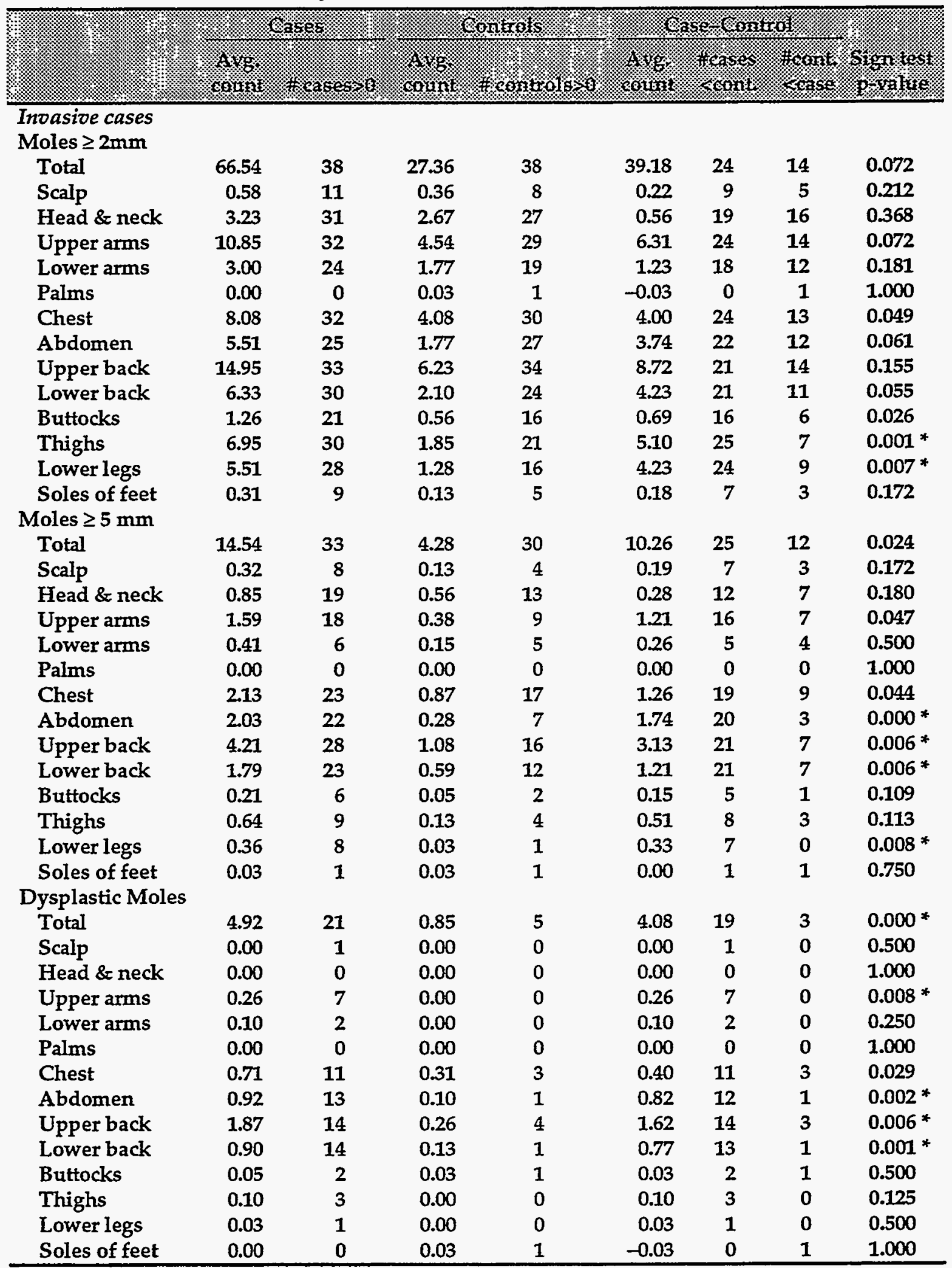

* Indicates statistical significance at $\mathrm{p}<0.01$ 


\begin{tabular}{|c|c|c|c|c|c|c|c|c|}
\hline $000^{\circ} \mathrm{L}$ & 0 & 0 & $00^{\circ} 0$ & 0 & $00^{\circ} 0$ & 0 & $00^{\circ} 0$ & 7әวf jo sə[oS \\
\hline $000^{\circ} \mathrm{L}$ & o & 0 & $00^{\circ} 0$ & 0 & $00 \% 0$ & 0 & $00^{\circ} 0$ & s8ిə[ \\
\hline OSZ० 0 & 0 & $z$ & OL*O & 0 & 000 & $\tau$ & OI:O & sપ8ిగ్L \\
\hline $00 S^{\circ} 0$ & $\mathbf{0}$ & I & $\varepsilon 0^{\circ} 0$ & 0 & 00.0 & I & $\varepsilon 0^{\circ} 0$ & sяpołng \\
\hline $0 S \angle{ }^{\circ} 0$ & I & I & $\varepsilon I^{*} 0$ & $\tau$ & $\varepsilon 0^{\circ} 0$ & $I$ & $\angle I^{*} O$ & Y्रPQ IәMO I \\
\hline $889^{\circ} 0$ & $\tau$ & $\tau$ & $\mathrm{OL}^{*} \mathrm{O}$ & $\tau$ & oro & $\tau$ & $0 Z^{\circ} 0$ & speq 1ədd $\Omega$ \\
\hline $0 s Z 0$ & $\mathbf{0}$ & $z$ & $\mathcal{E T}^{\circ} 0$ & 0 & $00^{\circ} 0$ & $\tau$ & $\varepsilon \mp \circ 0$ & uəuropqy \\
\hline SZT'O & 0 & $\varepsilon$ & $08^{\circ} 0$ & 0 & $00 \% 0$ & $\varepsilon$ & $08^{\circ} 0$ & $75 \partial 40$ \\
\hline $000^{\circ} \mathrm{I}$ & 0 & 0 & $00^{\circ} 0$ & 0 & $00 \% 0$ & 0 & $00^{\circ} 0$ & sured \\
\hline $000^{\circ} \mathrm{L}$ & 0 & 0 & $00^{\circ} 0$ & 0 & $00 \%$ & 0 & $00^{\circ} 0$ & sumre дәмот \\
\hline $000^{\circ} \mathrm{L}$ & 0 & 0 & $00^{\circ} 0$ & 0 & $00^{\circ} 0$ & 0 & $00^{\circ} 0$ & sumse xədd \\
\hline $000^{\circ} \mathrm{I}$ & 0 & 0 & $00^{\circ} 0$ & 0 & 000 & 0 & $00^{\circ} 0$ & Үрəu 2 реәH \\
\hline $00 S^{\circ} 0$ & 0 & I & $00^{\circ} 0$ & 0 & 000 & $\mathbf{I}$ & $00^{\circ} 0$ & dreos \\
\hline 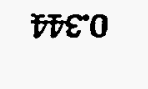 & $z$ & 五 & $09^{\circ} \mathrm{I}$ & $z$ & $\varepsilon I^{\circ} 0$ & 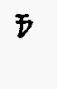 & $\varepsilon L^{\prime} \mathbf{L}$ & 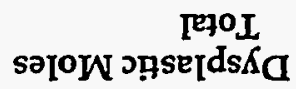 \\
\hline $889^{\circ} 0$ & $\tau$ & $\tau$ & $00^{\circ} 0$ & $\tau$ & $\angle 0^{\circ} 0$ & $z$ & $\angle 0^{\circ} 0$ & foaf jo səjos \\
\hline $88 \mathrm{~L}^{\circ} 0$ & I & $\mp$ & $\varepsilon \varepsilon$ & I & $80^{\circ} 0$ & $\varpi$ & $\angle \varepsilon^{\circ} 0$ & ร8วอ โว \\
\hline$\tau 6 \tau 0$ & $s$ & 8 & $L \varepsilon 0$ & $\mathbf{s}$ & $0 z^{\circ} 0$ & 6 & $\angle S^{\circ} 0$ & 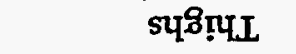 \\
\hline $009^{\circ} 0$ & $\varepsilon$ & 五 & $\angle I^{\circ} O$ & $\varepsilon$ & ot'o & $\varpi$ & $\angle Z{ }^{\circ} 0$ & sभpołng \\
\hline$\angle 8 \varepsilon^{\circ} 0$ & $\mathbf{s}$ & $\angle$ & $\varepsilon S^{\circ} 0$ & 9 & $0 \varepsilon^{* 0} 0$ & $\angle$ & $\varepsilon 8^{\circ} 0$ & Ү्रрq тәмо 7 \\
\hline $8 \varepsilon \angle{ }^{\circ} 0$ & $\tau I$ & OI & $\mathrm{OL}^{*} \tau$ & DI & $\varepsilon 0^{\circ} \mathrm{L}$ & $\varepsilon \tau$ & $\varepsilon I \cdot z$ & भрeq Iədd $\Omega$ \\
\hline $\cos ^{\circ} 0$ & 9 & $L$ & $\angle 0^{\circ} L$ & 9 & $\varepsilon Z^{\circ} 0$ & $\angle$ & $0 \varepsilon^{*} \Sigma$ & uəuropqy \\
\hline S6єొ0 & 9 & 8 & $\varepsilon 乙 \mathbf{L}$ & $L$ & $\varepsilon \boldsymbol{D D}^{\circ} 0$ & OI & $\angle 9^{\circ} \tau$ & ҰรวЧ० \\
\hline $000^{\circ} \mathrm{L}$ & 0 & 0 & $00^{\circ} 0$ & 0 & $00 \%$ & 0 & $00^{\circ} 0$ & surled \\
\hline $999^{\circ} 0$ & $\varepsilon$ & $\varepsilon$ & $\angle 0^{\circ} 0-$ & $\varepsilon$ & $0 z \cdot 0$ & $\varepsilon$ & $\varepsilon r^{\circ} 0$ & surxe IәMоT \\
\hline $060^{\circ} 0$ & $\Phi$ & OI & $\varepsilon 9^{\circ} 0$ & 4 & $\varepsilon \varepsilon^{* 0}$ & II & $\angle 6^{\circ} 0$ & suree xadd $\Omega$ \\
\hline $060^{\circ} 0$ & $\overline{7}$ & or & $\varepsilon E^{\circ} 0$ & $s$ & $0 z 0$ & II & $\varepsilon 9^{\circ} 0$ & Yุगəư 28 peəH \\
\hline $60 T^{\circ} 0$ & I & $\subseteq$ & $\varpi T^{\circ} 0$ & $\varepsilon$ & ot’o & 9 & $\varpi Z Z^{\circ}$ & dIEDS \\
\hline STF・0 & $\varepsilon \mathbf{I}$ & $\boldsymbol{S I}$ & $\varepsilon 6^{\circ} \subseteq$ & 现 & $\varepsilon \varepsilon^{*} \varepsilon$ & $\hbar \tau$ & $\angle I^{*} 6$ & $\begin{array}{c}\text { [E7OL } \\
\text { unu } s<\text { SO[OWN }\end{array}$ \\
\hline ZLI'O & $\varepsilon$ & $L$ & $\varepsilon \tau 0$ & $\Phi$ & $\varepsilon \tau^{\circ} 0$ & 8 & $\angle \varepsilon^{\circ} 0$ & 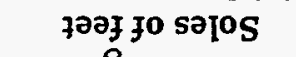 \\
\hline ยLO०O & $\mathbf{s}$ & $9 I$ & $\angle 6^{\circ} Z$ & ZI & $\varepsilon \tau^{\circ} \tau$ & $0 z$ & OZ'五 & ร8ిอ โวМо โ \\
\hline ICZ०0 & II & $9 I$ & $06^{\circ} \varepsilon$ & IZ & orz & Iz & $00^{\circ} 9$ & sપ8ฺฺL \\
\hline ఐてદా0 & 8 & II & $\varepsilon 0^{\circ} \mathrm{I}$ & $\varepsilon I$ & $\varepsilon S^{\circ} 0$ & sI & $\angle S^{\cdot} I$ & sypołng \\
\hline$\angle 90^{\circ} 0$ & $L$ & SI & $\mathrm{or}^{*} \varepsilon$ & $9 \mathrm{I}$ & $\angle S^{\circ} \tau$ & $\varepsilon \tau$ & $\angle 9^{\circ} \bar{T}$ & צ्रeq дәмо \\
\hline 9820 & ZI & $9 I$ & $08 \mathrm{Z}$ & $\mathfrak{S Z}$ & $\angle 9^{\circ} \mathrm{S}$ & $\angle z$ & $\angle 7^{\circ} 8$ & צ्रpq Iədd $\Omega$ \\
\hline $6 L T^{\circ} 0$ & II & $\varepsilon I$ & $\angle \tau \varepsilon$ & $8 I$ & $O S^{\circ} L$ & $8 I$ & $\angle L T$ & uวuropq \\
\hline ZEO॰O & 4 & $L I$ & $\angle S^{\circ} \varepsilon$ & $8 I$ & $09^{\circ} \mathrm{Z}$ & $\mathbf{s \tau}$ & $\angle I \cdot 9$ & $75 ว น ว$ \\
\hline $000^{\circ} \mathrm{L}$ & I & 0 & $\varepsilon 0^{\circ} 0^{-}$ & I & $\varepsilon 0^{\circ} 0$ & 0 & $00^{\circ} 0$ & surfed \\
\hline$\angle E 0^{\circ} 0$ & $L$ & $9 I$ & 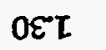 & $Z I$ & $\angle \varepsilon Z$ & oz & $\angle 9^{\circ} \varepsilon$ & surre IəMO $T$ \\
\hline $260^{\circ} 0$ & $\mathbf{O I}$ & $8 I$ & $O L^{\circ} \bar{T}$ & $\tau \tau$ & $\angle 6^{\circ} \varepsilon$ & $9 \tau$ & $\angle 9^{\circ} 8$ & surie radd $\Omega$ \\
\hline$z \varepsilon 0^{\circ} 0$ & $L$ & $L \mathbf{I}$ & $\angle \bar{T} Z$ & $\angle \mathrm{I}$ & $\varepsilon \Phi^{\bullet} I$ & $\sigma z$ & $00^{\circ} \bar{T}$ & भрәu भ реәH \\
\hline $060^{\circ} 0$ & $\bar{z}$ & $L$ & sटo & $\mathrm{s}$ & $\varepsilon \tau^{\circ} 0$ & 6 & $87^{\circ} 0$ & diess \\
\hline LZO'0 & 6 & IZ & $\varepsilon S^{\circ} 6 \tau$ & $0 \varepsilon$ & $\angle \bar{F}^{\circ} \varepsilon Z$ & $0 \varepsilon$ & $00^{\circ} \varepsilon \subseteq$ & 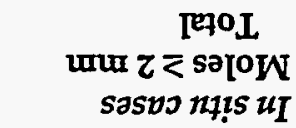 \\
\hline \% & 20.1. & wow & $(17070 \%$ & & 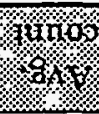 & & (3) & \\
\hline
\end{tabular}

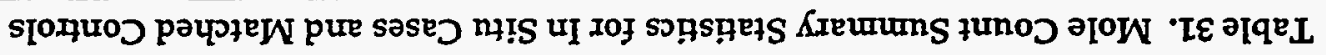


Table 32. Results of Applying Methods of Breslow \& Day to Mole Count Data

\begin{tabular}{|c|c|c|c|c|c|c|c|}
\hline$\frac{1}{17}$ & 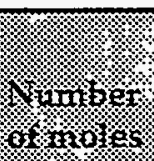 & א. & (1) ontirot & 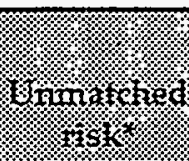 & 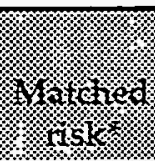 & (2) & 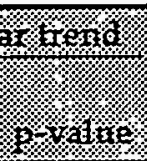 \\
\hline \multicolumn{8}{|c|}{ Total moles $\geq 2 \mathrm{~mm}$} \\
\hline 1 & 0 & 1 & 1 & 1.0 & & & \\
\hline 2 & $1-25$ & 27 & 46 & 0.6 & 1.0 & & \\
\hline 3 & $26-50$ & 19 & 14 & 1.4 & 2.6 & & \\
\hline 4 & $>50$ & 22 & 8 & 2.8 & 6.5 & 12.14 & 0.0005 \\
\hline \multicolumn{8}{|c|}{ Total moles $\geq 5 \mathrm{~mm}$} \\
\hline 1 & 0 & 12 & 15 & 1.0 & 1.0 & & \\
\hline 2 & $1-2$ & 16 & 24 & 0.8 & 0.9 & & \\
\hline 3 & $3-6$ & 11 & 20 & 0.7 & 0.8 & & \\
\hline 4 & $>6$ & 30 & 10 & 3.8 & 3.8 & 6.23 & 0.0125 \\
\hline \multicolumn{8}{|c|}{ Atypical moles } \\
\hline 1 & 0 & 44 & 62 & 1.0 & 1.0 & & \\
\hline 2 & $1-2$ & 6 & 5 & 1.7 & 2.5 & & \\
\hline 3 & $>2$ & 19 & 2 & 13.4 & 22.0 & 15.40 & 9E-05 \\
\hline
\end{tabular}

* Relative risk

Table 33. Correlations Among Mole Counts

\begin{tabular}{|c|c|c|c|}
\hline (4) & s.s. & 17oles & Writorer \\
\hline All moles & 1 & & \\
\hline Moles > $5 \mathrm{~mm}$ & 0.911 & 1 & \\
\hline Atypical moles & 0.796 & 0.872 & 1 \\
\hline \multicolumn{4}{|l|}{ Cases } \\
\hline All moles & 1 & & \\
\hline Moles > $5 \mathrm{~mm}$ & 0.915 & 1 & \\
\hline Atypical moles & 0.801 & 0.886 & 1 \\
\hline \multicolumn{4}{|l|}{ Controls } \\
\hline All moles & 1 & & \\
\hline Moles > $5 \mathrm{~mm}$ & 0.804 & 1 & \\
\hline Atypical moles & 0.633 & 0.683 & 1 \\
\hline
\end{tabular}


Table 34. Distribution of Family and Personal Medical History Examination Factors

\begin{tabular}{|c|c|c|c|c|c|c|c|}
\hline \multirow{3}{*}{$\frac{1}{4}$} & \multirow{2}{*}{$\frac{1 \%}{1 \%}$} & \multirow{2}{*}{ 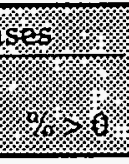 } & \multicolumn{2}{|c|}{. } & \multicolumn{2}{|c|}{ 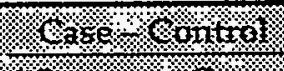 } & \multirow{2}{*}{ (1) } \\
\hline & & & : & $1 \%$ & \% & 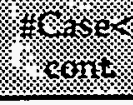 & \\
\hline & & & & & & & \\
\hline \multicolumn{8}{|l|}{ Family history } \\
\hline Number of moles & 28 & 41 & 8 & 12 & 27 & 6 & 0.001 \\
\hline Abnormal moles & 15 & 22 & 3 & 4 & 15 & 3 & 0.004 \\
\hline Dysplastic moles & 5 & 7 & 0 & 0 & $\mathbf{5}$ & 0 & 0.031 \\
\hline Previous mole excision & 9 & 13 & 4 & 6 & 9 & 4 & 0.133 \\
\hline Melanoma in family & 2 & 3 & 4 & 6 & $\mathbf{1}$ & 3 & 0.938 \\
\hline Precancer (nonmelanoma) & 9 & 13 & 8 & 12 & 8 & 7 & 0.500 \\
\hline Skin cancer & 17 & 25 & 13 & 19 & 13 & 9 & 0.262 \\
\hline \multicolumn{8}{|l|}{ Personal History } \\
\hline Dysplastic moles & 25 & 36 & 3 & 4 & 25 & 3 & 0.000 \\
\hline Previous mole excision & 29 & 42 & 14 & 20 & 23 & 8 & 0.005 \\
\hline Previous precancer (nonmelanoma) & 1 & 1 & 10 & 14 & 0 & 9 & 0.998 \\
\hline Previous skin cancer (nonmelanoma) & 6 & 9 & 9 & 13 & 9 & 6 & 0.304 \\
\hline \multirow{2}{*}{\multicolumn{8}{|c|}{$\begin{array}{l}\text { Invasive Cases } \\
\text { Family history }\end{array}$}} \\
\hline & & & & & & & \\
\hline Number of moles & 15 & 38 & 6 & 15 & 14 & 4 & 0.015 \\
\hline Abnormal moles & 10 & 26 & 3 & 8 & 10 & 3 & 0.046 \\
\hline Dysplastic moles & 3 & 8 & 0 & 0 & 3 & $\mathbf{0}$ & 0.125 \\
\hline Previous mole excision & 4 & 10 & 0 & 0 & 4 & $\mathbf{0}$ & 0.063 \\
\hline Melanoma in family & 2 & 5 & 2 & 5 & 1 & 1 & 0.750 \\
\hline Precancer (nonmelanoma) & 1 & 3 & 7 & 18 & 1 & 7 & 0.965 \\
\hline Skin cancer & 10 & 26 & 6 & 15 & 10 & 6 & 0.227 \\
\hline \multicolumn{8}{|l|}{ Personal History } \\
\hline Dysplastic moles & 13 & 33 & 2 & 5 & 13 & 2 & 0.004 \\
\hline Previous mole excision & 15 & 38 & 9 & 23 & 11 & 5 & 0.105 \\
\hline Previous precancer (nonmelanoma) & 1 & 3 & 6 & 15 & 0 & 5 & 0.969 \\
\hline Previous skin cancer (nonmelanoma) & 7 & 18 & 1 & 3 & 7 & 1 & 0.035 \\
\hline \multicolumn{8}{|l|}{ In situ casè } \\
\hline \multicolumn{8}{|l|}{ Family history } \\
\hline Number of moles & 13 & 43 & 2 & 7 & 13 & 2 & 0.004 \\
\hline Abnormal moles & 5 & 17 & 0 & 0 & 5 & 0 & 0.031 \\
\hline Dysplastic moles & 2 & 7 & $\mathbf{0}$ & 0 & 2 & 0 & 0.250 \\
\hline Previous mole excision & 5 & 17 & 4 & 13 & 5 & 4 & 0.500 \\
\hline Melanoma in family & 0 & 0 & 2 & 7 & 0 & 2 & 0.750 \\
\hline Precancer (nonmelanoma) & 8 & 27 & 1 & 3 & 7 & $\mathbf{0}$ & 0.008 \\
\hline Skin cancer & 7 & 23 & 7 & 23 & 3 & 3 & 0.656 \\
\hline \multicolumn{8}{|l|}{ Personal History } \\
\hline Dysplastic moles & 12 & 40 & 1 & 3 & 12 & 1 & 0.002 \\
\hline Previous mole excision & 14 & 47 & 5 & 17 & 12 & 3 & 0.018 \\
\hline Previous precancer (nonmelanoma) & 0 & 0 & 4 & 13 & 0 & 4 & 0.938 \\
\hline Previous skin cancer (nonmelanoma) & 2 & 7 & 5 & 17 & 2 & 5 & 0.938 \\
\hline
\end{tabular}


Table 35. Distribution of Skin Types Among Cases and Controls

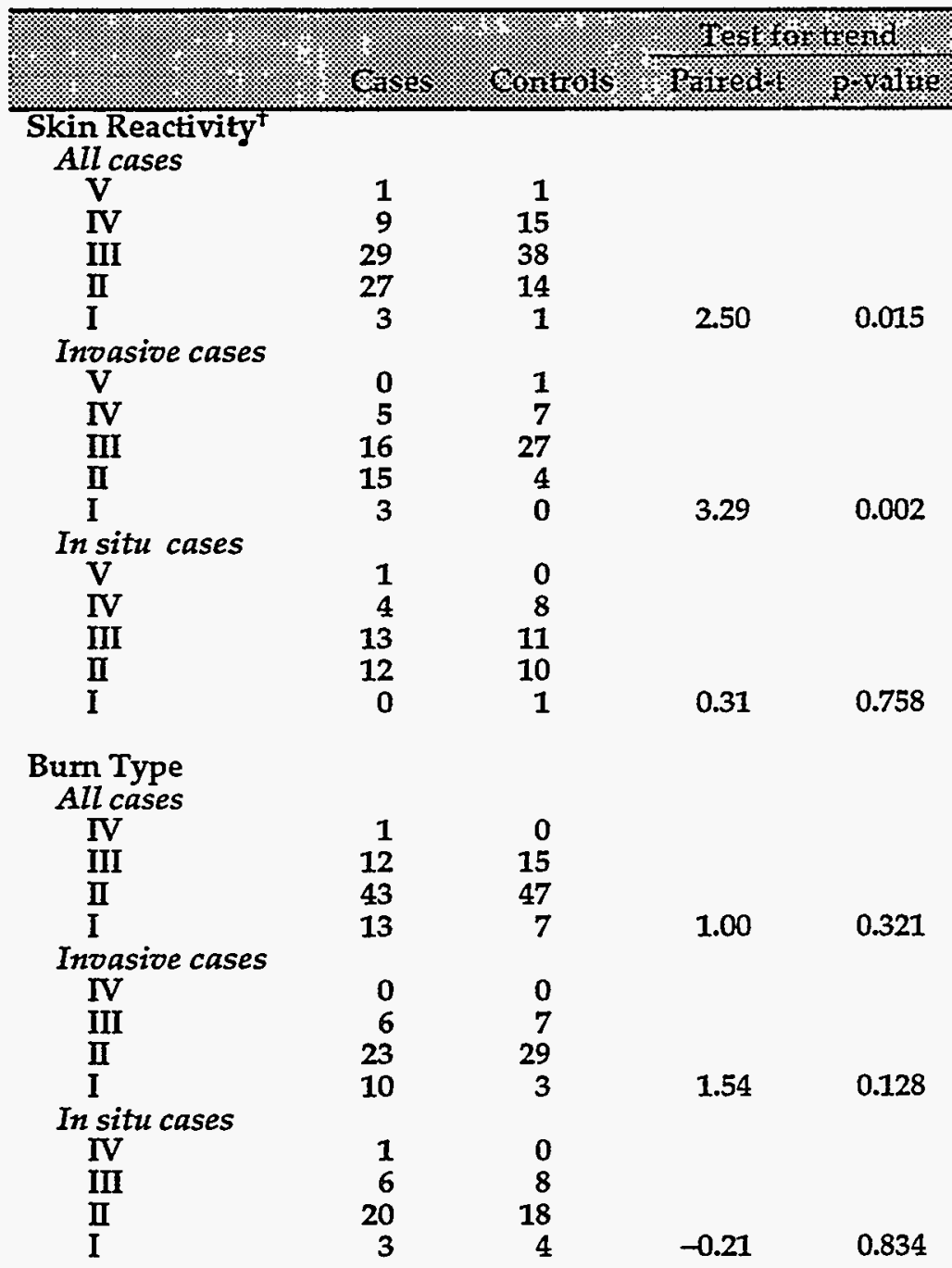

$\begin{array}{lrrll}\text { Tan Type } & & & & \\ \text { All cases } & & & & \\ \text { IV } & 1 & 2 & & \\ \text { III } & 23 & 49 & & \\ \text { II } & 40 & 18 & 4.67 & <0.001 \\ \text { I } & 5 & 0 & & \\ \text { Invasive cases } & & & & \\ \text { IV } & 12 & 1 & & \\ \text { III } & 23 & 5 & & \\ \text { II } & 4 & 0 & 5.64 & <0.001 \\ \text { I } & 1 & 1 & & \\ \text { In situ cases } & 1 & 16 & & \\ \text { IV } & 11 & 13 & & \\ \text { III } & 17 & 1 & 1.24 & 0.219 \\ \text { II } & 1 & 0 & \\ \text { I } & & \end{array}$

\footnotetext{
$f$ Ratings based on Fitzpatrick scale: I-always burn, never tan; II-usually burn, tan less than average; III-sometimes mild burn, $\tan$ about average; IV-rarely burn, $\tan$ more than average; V-never burn, always tan.
} 
Table 36. Summary of Results for Hair and Eye Color

\begin{tabular}{|c|c|c|c|c|}
\hline \multirow{2}{*}{$1.4 \%$} & \multirow{2}{*}{ 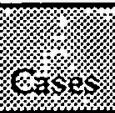 } & \multirow{2}{*}{ \% } & \multicolumn{2}{|c|}{ 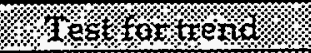 } \\
\hline & & & 3atuen & (1) \\
\hline \multicolumn{5}{|l|}{ Hair Color } \\
\hline \multicolumn{5}{|l|}{ All cases } \\
\hline Black & 1 & 5 & & \\
\hline Dark Brown & 11 & 20 & & \\
\hline Light Brown & 41 & 37 & & \\
\hline Red or Blond & 16 & 7 & 3.17 & 0.0023 \\
\hline \multicolumn{5}{|l|}{ Invasive cases } \\
\hline Black & $\mathbf{0}$ & 2 & & \\
\hline Dark Brown & 6 & 8 & & \\
\hline Light Brown & 21 & 26 & & \\
\hline Red or Blond & 12 & 3 & 3.52 & 0.0008 \\
\hline \multicolumn{5}{|l|}{ In situ cases } \\
\hline Black & 1 & 3 & & \\
\hline Dark Brown & 5 & 12 & & \\
\hline Light Brown & 20 & 11 & & \\
\hline Red or Blond & 4 & 4 & 2.77 & 0.0072 \\
\hline \multicolumn{5}{|l|}{ Eye Color } \\
\hline \multicolumn{5}{|l|}{ All cases } \\
\hline Brown & 12 & 13 & & \\
\hline Hazel & 18 & 18 & & \\
\hline Blue & 20 & 24 & & \\
\hline Green & 19 & 14 & 0.54 & 0.5939 \\
\hline \multicolumn{5}{|l|}{ Invasive cases } \\
\hline Brown & 6 & 7 & & \\
\hline Hazel & 7 & 12 & & \\
\hline Blue & 13 & 13 & & \\
\hline Green & 13 & .7 & 1.81 & 0.0743 \\
\hline \multicolumn{5}{|l|}{ In situ cases } \\
\hline Brown & 6 & 6 & & \\
\hline Hazel & 11 & 6 & & \\
\hline Blue & 7 & 11 & & \\
\hline Green & 6 & 7 & -1.03 & 0.3046 \\
\hline
\end{tabular}


Table 37. Results of Conditional Logistic Regression on Exam Factors

\begin{tabular}{|c|c|c|c|c|}
\hline 6.7. & 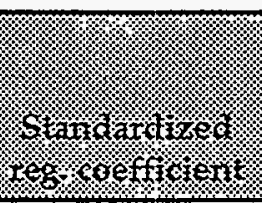 & : & 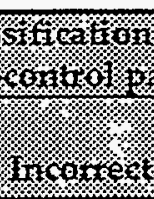 & : \\
\hline \multicolumn{5}{|l|}{ All cases } \\
\hline Tan type & 3.67 & & & \\
\hline$\geq 2 \mathrm{~mm}$ moles & 3.35 & 49 & 11 & 9 \\
\hline \multicolumn{5}{|l|}{ Invasive cases } \\
\hline Tan type & 2.47 & & & \\
\hline Dysplastic moles & 2.39 & 33 & 1 & 5 \\
\hline \multicolumn{5}{|l|}{ In situ cases } \\
\hline Family History (number of moles) & 2.43 & & & \\
\hline Hair color & 1.83 & 21 & 4 & 5 \\
\hline
\end{tabular}


Table 38. Occupational Factors

\begin{tabular}{|c|c|c|c|c|c|c|c|c|c|c|c|c|}
\hline \% & \%x. & (montrou & $\frac{1}{46 x}$ & $\frac{18}{4.93}$ & 1f & $\frac{51 \mathrm{me}}{10}$ & $\frac{1}{1.1}$ & $\frac{1}{4}$ & $\frac{519}{19}$ & ivisi & 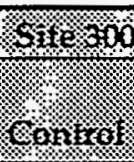 & \%.\% \\
\hline Overall & All ca & ses & & & & & & & & & & \\
\hline \multirow[t]{3}{*}{ Assessment } & $\begin{array}{c}1.20 \\
\text { Invas }\end{array}$ & $\begin{array}{c}1.28 \\
\text { ive cases }\end{array}$ & 0.82 & 1.14 & 1.28 & 0.97 & 1.41 & 1.28 & 0.07 & 1.45 & 1.41 & 0.33 \\
\hline & $\begin{array}{c}1.31 \\
\text { In situ }\end{array}$ & $\begin{array}{c}1.31 \\
1 \text { cases }\end{array}$ & 0.50 & 1.15 & 1.26 & 0.87 & 1.46 & 1.26 & 0.03 & 1.44 & 1.46 & 0.58 \\
\hline & 1.07 & 1.23 & 0.97 & 1.13 & 1.30 & 0.93 & 1.33 & 1.30 & 0.41 & 1.47 & 1.33 & 0.21 \\
\hline \multirow[t]{4}{*}{ LLNL } & All ca & & & & & & & & & & & \\
\hline & $\begin{array}{c}1.16 \\
\text { Invas }\end{array}$ & $\begin{array}{l}1.23 \\
\text { ive cases }\end{array}$ & 0.82 & 1.12 & 1.22 & 0.95 & 1.38 & 1.22 & 0.03 & 1.45 & 1.41 & 0.33 \\
\hline & $\begin{array}{l}1.23 \\
\text { In sity }\end{array}$ & $\begin{array}{c}1.28 \\
\text { cases }\end{array}$ & 0.66 & 1.10 & 1.23 & 0.92 & 1.41 & 1.26 & 0.08 & 1.44 & 1.46 & 0.58 \\
\hline & 1.07 & 1.17 & 0.91 & 1.13 & 1.20 & 0.79 & 1.33 & 1.17 & 0.10 & 1.47 & 1.33 & 0.21 \\
\hline \multirow[t]{4}{*}{ Non-LLNL } & All ca & & & & & & & & & & & \\
\hline & $\begin{array}{l}1.06 \\
\text { Invas }\end{array}$ & $\begin{array}{c}1.12 \\
\text { ive cases }\end{array}$ & 0.87 & 1.03 & 1.06 & 0.76 & 1.04 & 1.10 & 0.86 & 1.01 & 1.03 & 0.72 \\
\hline & $\begin{array}{l}1.10 \\
\text { In situ }\end{array}$ & $\begin{array}{l}1.10 \\
\text { cases }\end{array}$ & 0.50 & 1.05 & 1.03 & 0.28 & 1.08 & 1.05 & 0.33 & 1.03 & 1.03 & 0.50 \\
\hline & 1.00 & 1.13 & 0.98 & 1.00 & 1.10 & 0.91 & 1.00 & 1.17 & 0.95 & 1.00 & 1.03 & 0.84 \\
\hline & All ca & & & & & & & & & & & \\
\hline \multirow[t]{3}{*}{ Period A } & $\begin{array}{l}1.20 \\
\text { Invas }\end{array}$ & $\begin{array}{l}1.28 \\
\text { ive cases }\end{array}$ & 0.82 & 1.14 & 1.28 & 0.97 & 1.29 & 1.19 & 0.09 & 1.32 & 1.25 & 0.19 \\
\hline & $\begin{array}{c}1.31 \\
\text { In situ }\end{array}$ & $\begin{array}{c}1.31 \\
\text { cases }\end{array}$ & 0.50 & 1.15 & 1.26 & 0.87 & 1.28 & 1.21 & 0.19 & 1.26 & 1.38 & 0.89 \\
\hline & 1.07 & 1.23 & 0.97 & 1.13 & 1.30 & 0.93 & 1.30 & 1.17 & 0.16 & 1.40 & 1.07 & 0.01 \\
\hline Time & All ca. & & & & & & & & & & & \\
\hline \multirow[t]{3}{*}{ Period B } & $\begin{array}{c}1.10 \\
\text { Invasi }\end{array}$ & $\begin{array}{l}1.07 \\
\text { be cases }\end{array}$ & 0.34 & 1.01 & 1.00 & 0.16 & 1.20 & 1.12 & 0.10 & 1.29 & 1.33 & 0.68 \\
\hline & $\begin{array}{c}1.15 \\
\text { In situ }\end{array}$ & $\begin{array}{c}1.10 \\
\text { cases }\end{array}$ & 0.33 & 1.03 & 1.00 & 0.16 & 1.21 & 1.10 & 0.13 & 1.31 & 1.36 & 0.65 \\
\hline & 1.03 & 1.03 & 0.50 & 1.00 & 1.00 & 0.50 & 1.20 & 1.13 & 0.27 & 1.27 & 1.30 & 0.60 \\
\hline
\end{tabular}


Table 38. Occupational Factors (continued)

\begin{tabular}{|c|c|c|c|c|c|c|c|c|c|c|c|c|}
\hline \multirow{4}{*}{ 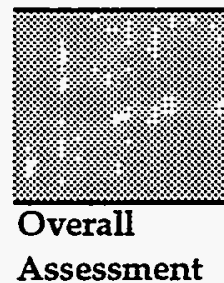 } & \multirow{2}{*}{\multicolumn{3}{|c|}{ in }} & \multicolumn{3}{|c|}{ i } & \multicolumn{3}{|c|}{ 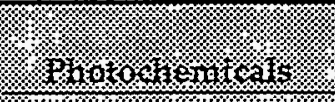 } & \multicolumn{3}{|c|}{ 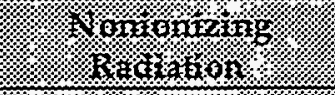 } \\
\hline & & & & 4 & \% & : & $\sqrt{1}$ & (8.0.7.t. & (17) & (x) & 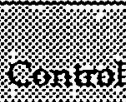 & \% \\
\hline & \multicolumn{12}{|c|}{ All cases } \\
\hline & 1.15 & 1.22 & 0.92 & 1.41 & 1.46 & 0.71 & 1.21 & 1.06 & 0.81 & 1.54 & 1.54 & 0.50 \\
\hline & \multicolumn{12}{|c|}{ Invasive cases } \\
\hline & 1.10 & 1.36 & 0.99 & 1.36 & 1.56 & 0.88 & 1.21 & 1.06 & 0.82 & 1.41 & 1.56 & 0.84 \\
\hline & \multicolumn{12}{|c|}{ In situ cases } \\
\hline & 1.23 & 1.08 & 0.21 & 1.47 & 1.31 & 0.32 & 1.22 & 1.06 & 0.58 & 1.70 & 1.50 & 0.20 \\
\hline \multirow[t]{6}{*}{ LLNL } & \multicolumn{12}{|c|}{ All cases } \\
\hline & 1.14 & 1.18 & 0.85 & 1.35 & 1.46 & 0.85 & 1.10 & 1.05 & 0.87 & 1.43 & 1.49 & 0.68 \\
\hline & \multicolumn{12}{|c|}{ Invasive cases } \\
\hline & 1.10 & 1.28 & 0.96 & 1.31 & 1.56 & 0.94 & 1.11 & 1.04 & 0.74 & 1.26 & 1.49 & 0.96 \\
\hline & \multicolumn{12}{|c|}{ In situ cases } \\
\hline & 1.19 & 1.07 & 0.35 & 1.40 & 1.31 & 0.43 & 1.08 & 1.05 & 0.87 & 1.67 & 1.50 & 0.24 \\
\hline \multirow[t]{6}{*}{ Non-LLNL } & \multicolumn{12}{|c|}{ All cases } \\
\hline & 1.10 & 1.15 & 0.75 & 1.35 & 1.43 & $0.76^{\circ}$ & 1.10 & 1.02 & 0.69 & 1.32 & 1.28 & 0.35 \\
\hline & \multicolumn{12}{|c|}{ Invasive cases } \\
\hline & 1.08 & 1.21 & 0.93 & 1.31 & 1.51 & 0.90 & 1.07 & 1.00 & 0.50 & 1.33 & 1.31 & 0.43 \\
\hline & \multicolumn{12}{|c|}{ In situ cases } \\
\hline & 1.13 & 1.07 & 0.29 & 1.40 & 1.31 & 0.36 & 1.13 & 1.05 & 0.75 & 1.30 & 1.23 & 0.34 \\
\hline Time & \multicolumn{12}{|c|}{ All cases } \\
\hline \multirow[t]{5}{*}{ Period A } & 1.14 & 1.20 & 0.88 & 1.33 & 1.43 & 0.83 & 1.16 & 1.05 & 0.91 & 1.42 & 1.45 & 0.59 \\
\hline & \multicolumn{12}{|c|}{ Invasioe cases } \\
\hline & 1.09 & 1.33 & 0.99 & 1.23 & 1.56 & 0.99 & 1.15 & 1.05 & 0.96 & 1.31 & 1.56 & 0.97 \\
\hline & \multicolumn{12}{|c|}{ In situ cases } \\
\hline & 1.23 & 1.07 & 0.11 & $1.4 \%$ & 1.24 & 0.20 & 1.18 & 1.05 & 0.50 & $1.5 \%$ & 1.30 & 0.11 \\
\hline Time & \multicolumn{12}{|c|}{ All cases } \\
\hline \multirow[t]{5}{*}{ Period B } & 1.07 & 1.17 & 0.88 & 1.33 & 1.42 & 0.77 & 1.10 & 1.00 & 0.61 & 1.39 & 1.41 & 0.55 \\
\hline & \multicolumn{12}{|c|}{ Inoasioe cases } \\
\hline & \multirow{2}{*}{\multicolumn{2}{|c|}{$\begin{array}{l}1.04 \\
\text { In situ cases }\end{array}$}} & 0.99 & 1.28 & 1.51 & 0.93 & 1.11 & 1.00 & 0.62 & 1.28 & 1.33 & 0.64 \\
\hline & & & & & & & & & - & & & \\
\hline & 1.13 & 1.06 & 0.22 & 1.40 & 1.30 & 0.29 & 1.08 & 1.00 & 0.50 & 1.53 & 1.50 & 0.44 \\
\hline
\end{tabular}


Table 39. Words Used By Case-Control Pairs with Sign Test 2-sided p-values $<0.05$

\begin{tabular}{|c|c|c|c|c|c|c|}
\hline 4rord: & $\frac{8}{8}$ & 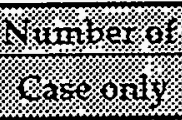 & 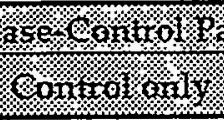 & 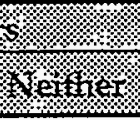 & ling & (ivi, \\
\hline Bioassay & 8 & 4 & 38 & 8 & 0.11 & $6 \mathrm{E}-08$ \\
\hline Therapy & $\mathbf{0}$ & 3 & 29 & 26 & 0.10 & $3 E-06$ \\
\hline Printer & 10 & 5 & 33 & 10 & 0.15 & $4 \mathrm{E}-06$ \\
\hline Allergy & 2 & 4 & 25 & 27 & 0.16 & 0.0001 \\
\hline Kerosene & 1 & 1 & 15 & 41 & 0.07 & 0.0005 \\
\hline Lithography & 0 & 11 & 0 & 47 & $\infty$ & 0.0010 \\
\hline Printer & 12 & 7 & 25 & 14 & 0.28 & 0.0021 \\
\hline Laser & 19 & 6 & 21 & 12 & 0.29 & 0.0059 \\
\hline Islands & 2 & 2 & 13 & 41 & 0.15 & 0.0074 \\
\hline Copper & 1 & 5 & 18 & 34 & 0.28 & 0.0106 \\
\hline Volatile & 47 & 1 & 10 & 0 & 0.10 & 0.0117 \\
\hline Radar & 14 & 7 & 21 & 16 & 0.33 & 0.0125 \\
\hline Metal & 12 & 7 & 21 & 18 & 0.33 & 0.0125 \\
\hline Booties & 7 & 14 & 3 & 34 & 4.67 & 0.0127 \\
\hline Oscilloscope & 2 & 2 & 12 & 42 & 0.17 & 0.0129 \\
\hline Helium & 1 & 2 & 12 & 43 & 0.17 & 0.0129 \\
\hline Dissolver & 2 & 0 & 7 & 49 & 0.00 & 0.0156 \\
\hline Cars & 2 & 4 & 15 & 37 & 0.27 & 0.0192 \\
\hline Nonionizing & 3 & 3 & 13 & 39 & 0.23 & 0.0213 \\
\hline Antenna & 3 & 9 & 1 & 45 & 9.00 & 0.0215 \\
\hline Electron & 1 & 9 & 1 & 47 & 9.00 & 0.0215 \\
\hline Nuclear & 48 & 1 & 9 & 0 & 0.11 & 0.0215 \\
\hline Neon & 0 & 1 & 9 & 48 & 0.11 & 0.0215 \\
\hline Woodworking & 2 & 2 & 11 & 43 & 0.18 & 0.0225 \\
\hline Octopus & 0 & 2 & 11 & 45 & 0.18 & 0.0225 \\
\hline Herbicide & 30 & 18 & 6 & 4 & 3.00 & 0.0227 \\
\hline Polaroid & 34 & 5 & 16 & 3 & 0.31 & 0.0266 \\
\hline Device & 7 & 5 & 16 & 30 & 0.31 & 0.0266 \\
\hline Sports & 1 & 5 & 16 & 36 & 0.31 & 0.0266 \\
\hline Beryllium & 8 & 6 & 17 & 27 & 0.35 & 0.0347 \\
\hline Ionizing & 0 & 10 & 2 & 46 & 5.00 & 0.0386 \\
\hline Cutting & 1 & 7 & 18 & 32 & 0.39 & 0.0433 \\
\hline Monitor & 1 & 13 & 4 & 40 & 3.25 & 0.0490 \\
\hline Detectors & 2 & 4 & 13 & 39 & 0.31 & 0.0490 \\
\hline
\end{tabular}


Table 40. Occupational Exposures to Agents

\begin{tabular}{|c|c|c|}
\hline & $3 \%$ & 8 (1) \\
\hline I & 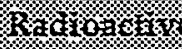 & 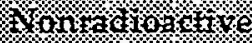 \\
\hline Case only & 15 & 4 \\
\hline Control only & 17 & 6 \\
\hline Both & 22 & 54 \\
\hline Neither & 15 & 5 \\
\hline
\end{tabular}

Table 41. Number of Radioactive Agents with Exposure

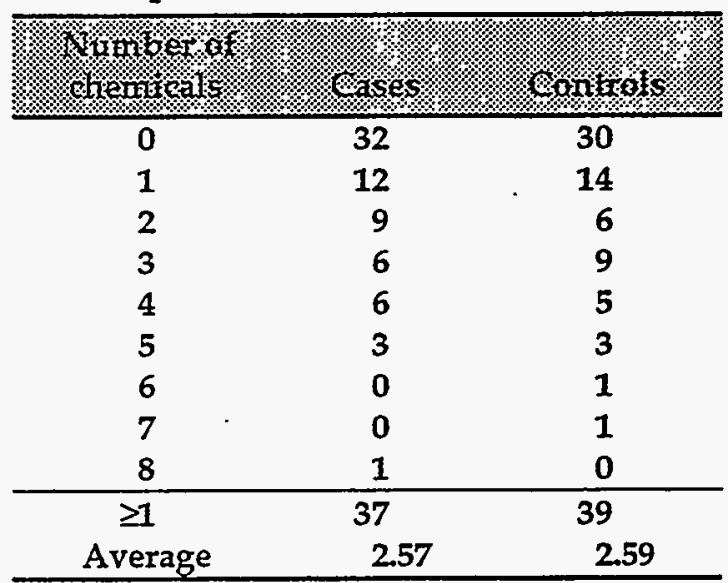

Table 42. Number of Nonradioactive Agents with Exposure

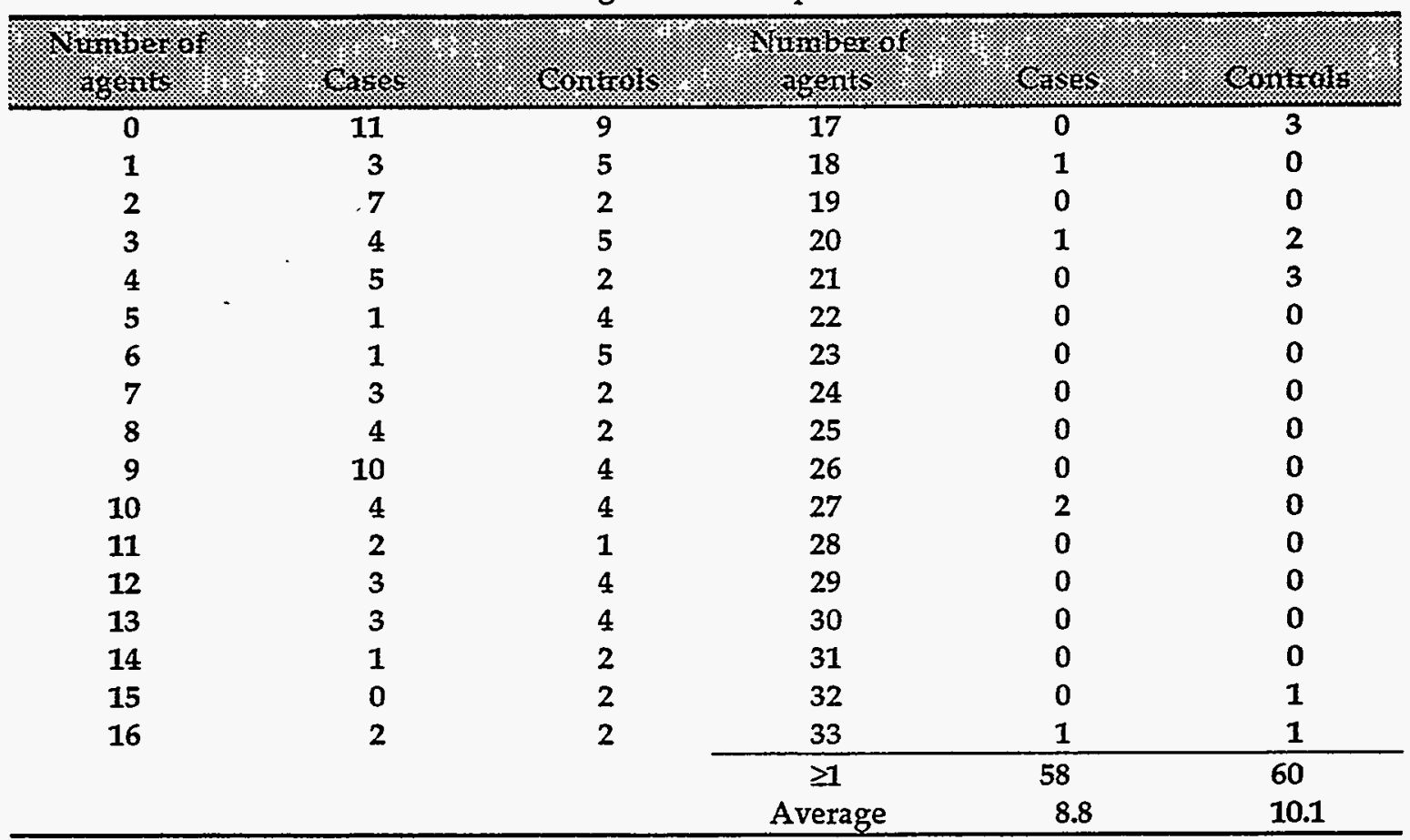


Table 43. Exposure to Most Frequently Mentioned Agents

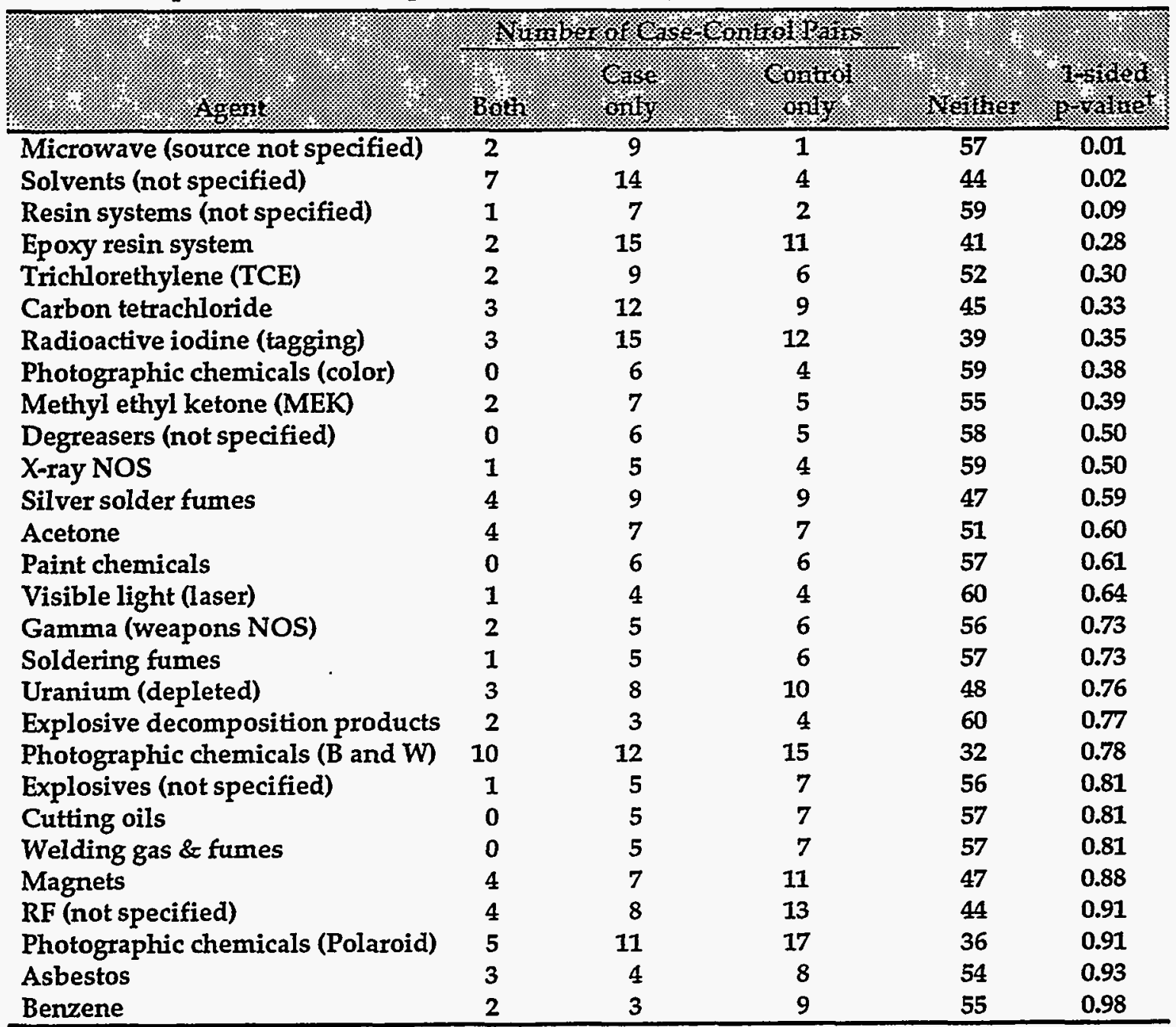

$t$ Based on sign test 
Table 43a. Exposure to Agent Groupings

\begin{tabular}{|c|c|c|c|c|c|}
\hline 4. & $\frac{1}{1601}$ & (1) & 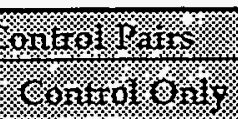 & yon & 19: \\
\hline Alcohols & 0 & 14 & 5 & 50 & 0.03 \\
\hline Microwave & 2 & 10 & 3 & 54 & 0.05 \\
\hline Chemicals identified by use & 4 & 11 & 5 & 49 & 0.11 \\
\hline Resin or major component & 11 & 15 & 9 & 34 & 0.15 \\
\hline Solvent & 8 & 14 & 9 & 38 & 0.20 \\
\hline Ketones & 5 & 14 & 10 & 40 & 0.27 \\
\hline Radioactive plutonium & 3 & 15 & 12 & 38 & 0.29 \\
\hline Pesticides & 0 & 8 & 5 & 56 & 0.29 \\
\hline Chlorinated hydrocarbons & 10 & 17 & 13 & 29 & 0.29 \\
\hline Miscellaneous chemicals & 6 & 19 & 15 & 29 & 0.30 \\
\hline Accelerator & $\mathbf{0}$ & 6 & 4 & 59 & 0.38 \\
\hline Gamma & 8 & 10 & 8 & 43 & 0.41 \\
\hline Photographic chemicals & 21 & 15 & 15 & 18 & 0.57 \\
\hline Explosive chemicals & 5 & 10 & 10 & 44 & 0.59 \\
\hline Gases & 2 & 9 & 9 & 49 & 0.59 \\
\hline UV & 1 & 7 & 8 & 53 & 0.70 \\
\hline Dielectric compounds & 1 & 6 & 7 & 55 & 0.71 \\
\hline X-ray & 3 & 5 & 6 & 55 & 0.73 \\
\hline Neutron & 1 & 4 & 5 & 59 & 0.75 \\
\hline Lubricoolants in machining & 1 & 7 & 9 & 52 & 0.77 \\
\hline Soldering and welding effluents & 3 & 7 & 9 & 50 & 0.77 \\
\hline Magnetic field & 5 & 8 & 11 & 45 & 0.82 \\
\hline $\begin{array}{l}\text { Hydrocarbon fuels, greases, and } \\
\text { products }\end{array}$ & 8 & 12 & 16 & 33 & 0.83 \\
\hline Mineral acids & 1 & 3 & 5 & 60 & 0.86 \\
\hline Computer paper chemicals & 1 & 4 & 7 & 57 & 0.89 \\
\hline Laser & 2 & 6 & 10 & 51 & 0.89 \\
\hline Metal with special toxicity & 10 & 12 & 18 & 29 & 0.90 \\
\hline Metals and metalloids & 3 & 10 & 16 & 40 & 0.92 \\
\hline Dyes & $\mathbf{0}$ & 4 & 8 & 57 & 0.93 \\
\hline Airborne particulate or aerosol & 6 & 7 & 13 & 43 & 0.94 \\
\hline RF & 4 & 8 & 15 & 42 & 0.95 \\
\hline Biological products & $\mathbf{0}$ & 4 & 10 & 55 & 0.97 \\
\hline Benzene \& compounds & 2 & 3 & 9 & 55 & 0.98 \\
\hline Fission fragments & 3 & 3 & 9 & 54 & 0.98 \\
\hline
\end{tabular}


Table 44. Number of Agents Mentioned During Interview

\begin{tabular}{|c|c|c|}
\hline 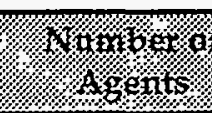 & 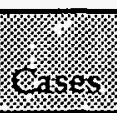 & 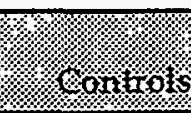 \\
\hline $0-4$ & 3 & 3 \\
\hline $5-9$ & 9 & 8 \\
\hline $10-14$ & 9 & 5 \\
\hline 15-19 & 7 & 8 \\
\hline $20-24$ & 10 & 11 \\
\hline $25-29$ & 3 & 8 \\
\hline $30-34$ & 6 & 8 \\
\hline 35-39 & 6 & 9 \\
\hline $40-44$ & 4 & 1 \\
\hline $45-49$ & 2 & 1 \\
\hline $50-54$ & 1 & 2 \\
\hline 55-59 & 1 & 0 \\
\hline $60-64$ & 0 & 0 \\
\hline $65-69$ & 0 & 0 \\
\hline $70-74$ & 0 & 0 \\
\hline $75-79$ & 0 & 0 \\
\hline$>75$ & 1 & 1 \\
\hline Total & 62 & 65 \\
\hline Avg. & 23.6 & 24.5 \\
\hline Med. & 22 & 23 \\
\hline SD & 15.6 & 14 \\
\hline Min. & 4 & 4 \\
\hline Max. & 82 & 85 \\
\hline
\end{tabular}

Table 45. Occupational Skin Exposures and Exposures to Skin Irritants

\begin{tabular}{|c|c|c|c|c|c|}
\hline 1. & K1) & 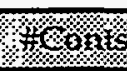 & 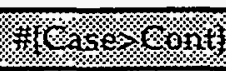 & merse ront & T) \\
\hline \multicolumn{6}{|c|}{ Skin exposure to any chemical } \\
\hline All cases & 39 & 48 & 6 & 15 & 0.99 \\
\hline Invasive cases & 21 & 29 & 2 & 10 & 1.00 \\
\hline In situ cases & 18 & 19 & 4 & 5 & 0.75 \\
\hline \multicolumn{6}{|c|}{ Exposure to skin irritants } \\
\hline All cases & 41 & 46 & 11 & 16 & 0.88 \\
\hline Invasive cases & 20 & 29 & 3 & 12 & 1.00 \\
\hline In situ cases & 21 & 17 & 8 & 4 & 0.19 \\
\hline
\end{tabular}

+ Based on one-sided sign test 
Table 46. Distribution of Total ${ }^{\dagger}$ Ionizing Radiation

\begin{tabular}{|c|c|c|c|}
\hline 1. & 6,85 & S & (6) \\
\hline 0 rem & 0 & 28 & 27 \\
\hline .001 to .05 & 1 & 9 & 10 \\
\hline .051 to .25 & 2 & 12 & 13 \\
\hline .251 to 1 & 3 & 10 & 7 \\
\hline 1.01 to 5 & 4 & 8 & 9 \\
\hline$>5 \mathrm{rem}$ & 5 & 2 & 3 \\
\hline Avg. dose & & 0.76 & 0.71 \\
\hline
\end{tabular}

$\dagger$ Total includes gamma, neutron, tritium, skin, and hand doses

Table 48. Distribution of Whole Body Dose-Time Period A

\begin{tabular}{|c|c|c|}
\hline 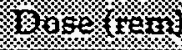 & . & govity \\
\hline 0 rem & 43 & 38 \\
\hline .001 to .05 & 5 & 5 \\
\hline .051 to .25 & 4 & 11 \\
\hline .251 to 1 & 8 & 3 \\
\hline 1.01 to 5 & 7 & 9 \\
\hline$>5 \mathrm{rem}$ & 2 & 3 \\
\hline Avg. dose & 0.43 & 0.48 \\
\hline
\end{tabular}

Table 50. Distribution of Total Dose-Time Period A

\begin{tabular}{|c|c|c|}
\hline 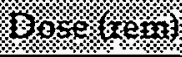 & r.s.ses & rantrols \\
\hline 0 rem & 41 & 38 \\
\hline .001 to .05 & 5 & 5 \\
\hline .051 to .25 & 5 & 10 \\
\hline .251 to 1 & 9 & 4 \\
\hline 1.01 to 5 & 7 & 9 \\
\hline$>5 \mathrm{rem}$ & 2 & 3 \\
\hline Avg. dose & 0.49 & 0.52 \\
\hline
\end{tabular}

Table 47. Distribution of Whole Body ${ }^{\dagger}$ Ionizing Radiation

\begin{tabular}{|c|c|c|}
\hline orose & S4s & \% \\
\hline $0 \mathrm{rem}$ & 30 & 27 \\
\hline .001 to .05 & 9 & 11 \\
\hline .051 to .25 & 12 & 13 \\
\hline .251 to 1 & 8 & 6 \\
\hline 1.01 to 5 & 8 & 9 \\
\hline$>5$ rem & 2 & 3 \\
\hline Avg. dose & 0.61 & 0.60 \\
\hline
\end{tabular}

+ Total includes gamma, neutron, and tritium doses

Table 49. Distribution of Whole Body Dose-Time Period B

\begin{tabular}{|c|c|c|}
\hline Tyoro frenti & (6.) & $1004\}$ \\
\hline 0 rem & 41 & 40 \\
\hline .001 to .05 & 10 & 17 \\
\hline .051 to .25 & 10 & 6 \\
\hline .251 to 1 & 7 & 5 \\
\hline 1.01 to 5 & 0 & 1 \\
\hline$>5 \mathrm{rem}$ & 1 & 0 \\
\hline Avg. dose & 0.18 & 0.12 \\
\hline
\end{tabular}




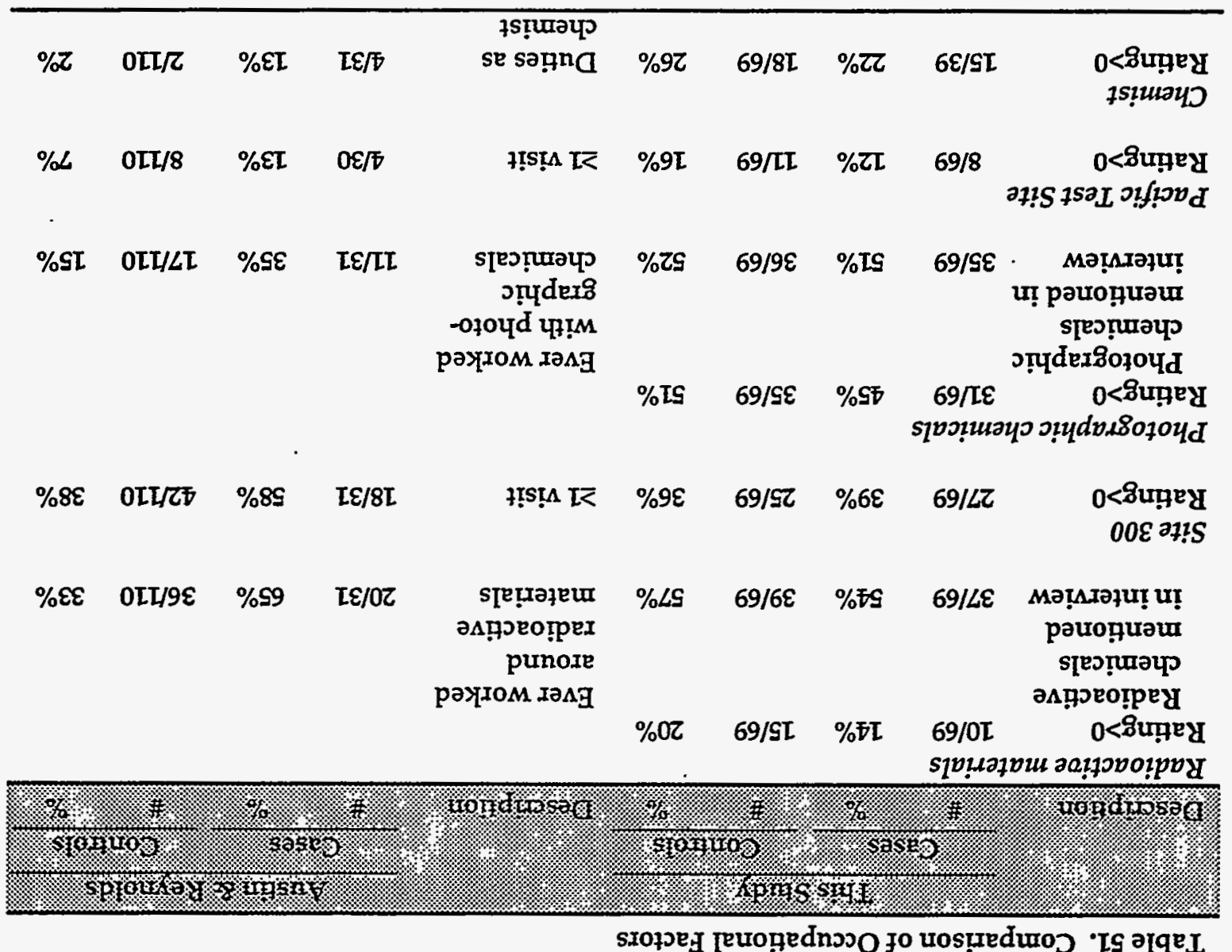


Table 52. Regression of Occupational

Factors on Start Year and Years of

Education

\begin{tabular}{lrr}
\hline & & \\
Ionizing Radiation & & \\
Start year & -0.027 & $<.0001$ \\
Education & 0.001 & 0.940 \\
& & \\
Site 300 & & \\
Start year & -0.023 & $<.0001$ \\
Education & 0.019 & 0.200 \\
& & \\
Photographic & & \\
chemicals & & \\
Start year & -0.016 & 0.007 \\
Education & 0.041 & 0.023 \\
& & \\
Pacific Test Site & & \\
Start year & -0.030 & $<.0001$ \\
Education & 0.039 & 0.004 \\
& & \\
Chemist & & \\
Start year & -0.013 & 0.070 \\
Education & 0.065 & 0.003 \\
\hline
\end{tabular}

+ Coefficient shows decrease (or increase) in rating score per year.

Table 53. Power to Detect Significant Risk Factors

\begin{tabular}{|c|c|c|c|c|c|c|}
\hline (1) & Evolosed & 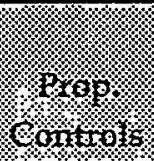 & 4 rading & (2) & ofour & : \\
\hline Radioactive materials & 0.65 & 0.33 & 3.8 & 0.95 & 0.95 & 0.91 \\
\hline Site 300 & 0.58 & 0.38 & 2.3 & 0.64 & 0.77 & 0.56 \\
\hline Photographic chemicals & 0.35 & 0.15 & 3.1 & 0.78 & 0.87 & 0.67 \\
\hline Pacific Test Site & 0.13 & 0.07 & 2.0 & 0.31 & 0.32 & 0.22 \\
\hline Chemist duties & 0.13 & 0.02 & 7.3 & 0.76 & 0.81 & 0.60 \\
\hline
\end{tabular}

* Austin \& Reynolds case-control study 
Table 54. Comparison of Results for Subsets of Cases

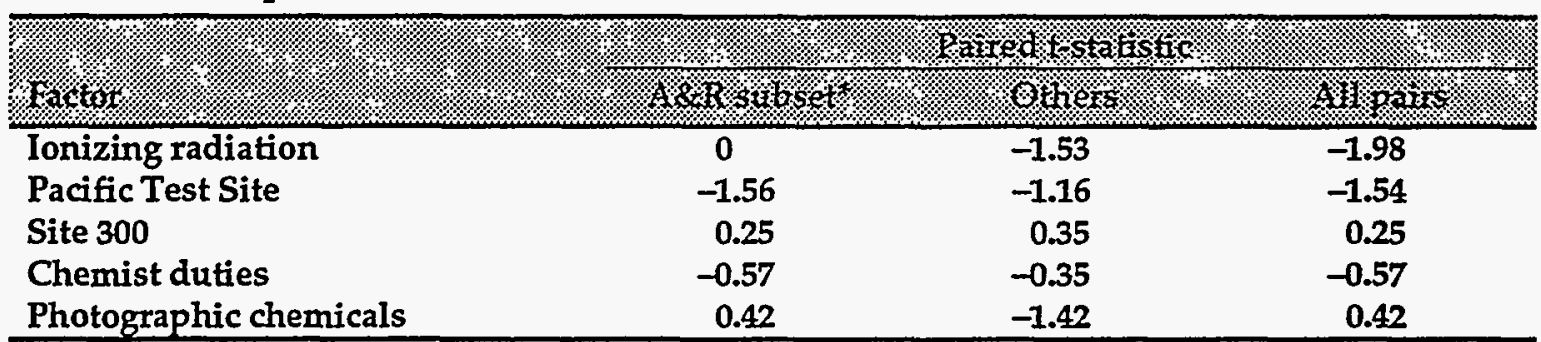

* Austin \& Reynolds case-control study

Table 55, Comparison of Results with Different Matching Criteria

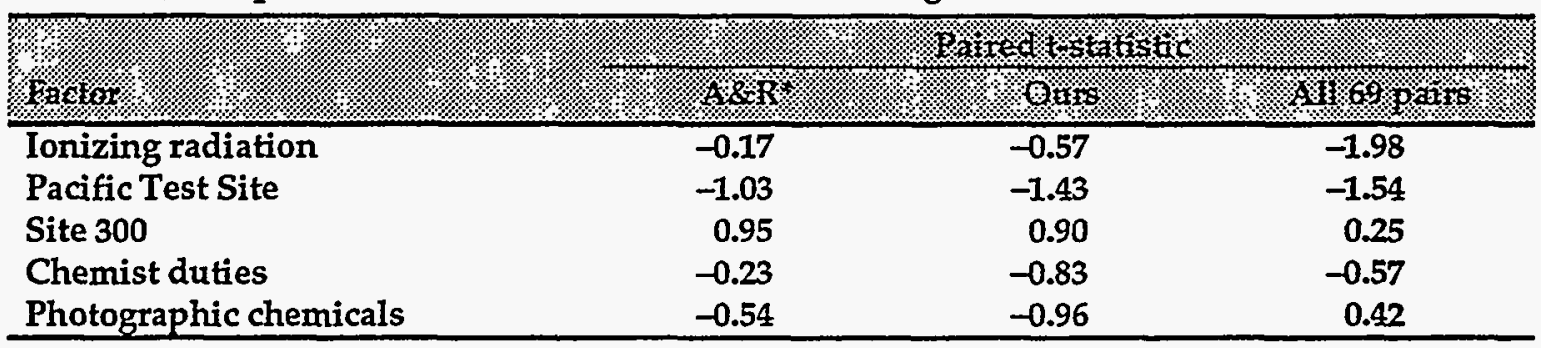

* Austin \& Reynolds case-control study

Table 56. Effect of Adjusting for Sex Mismatch

\begin{tabular}{|c|c|c|}
\hline If & \% & Whater \\
\hline Radioactive materials & 0.70 & \\
\hline Site $\mathbf{3 0 0}$ & 1.19 & \\
\hline Photographic chemicals & 0.83 & \\
\hline Pacific Test Site & 0.39 & \\
\hline Chemist duties & 0.89 & \\
\hline
\end{tabular}




\section{Figures}

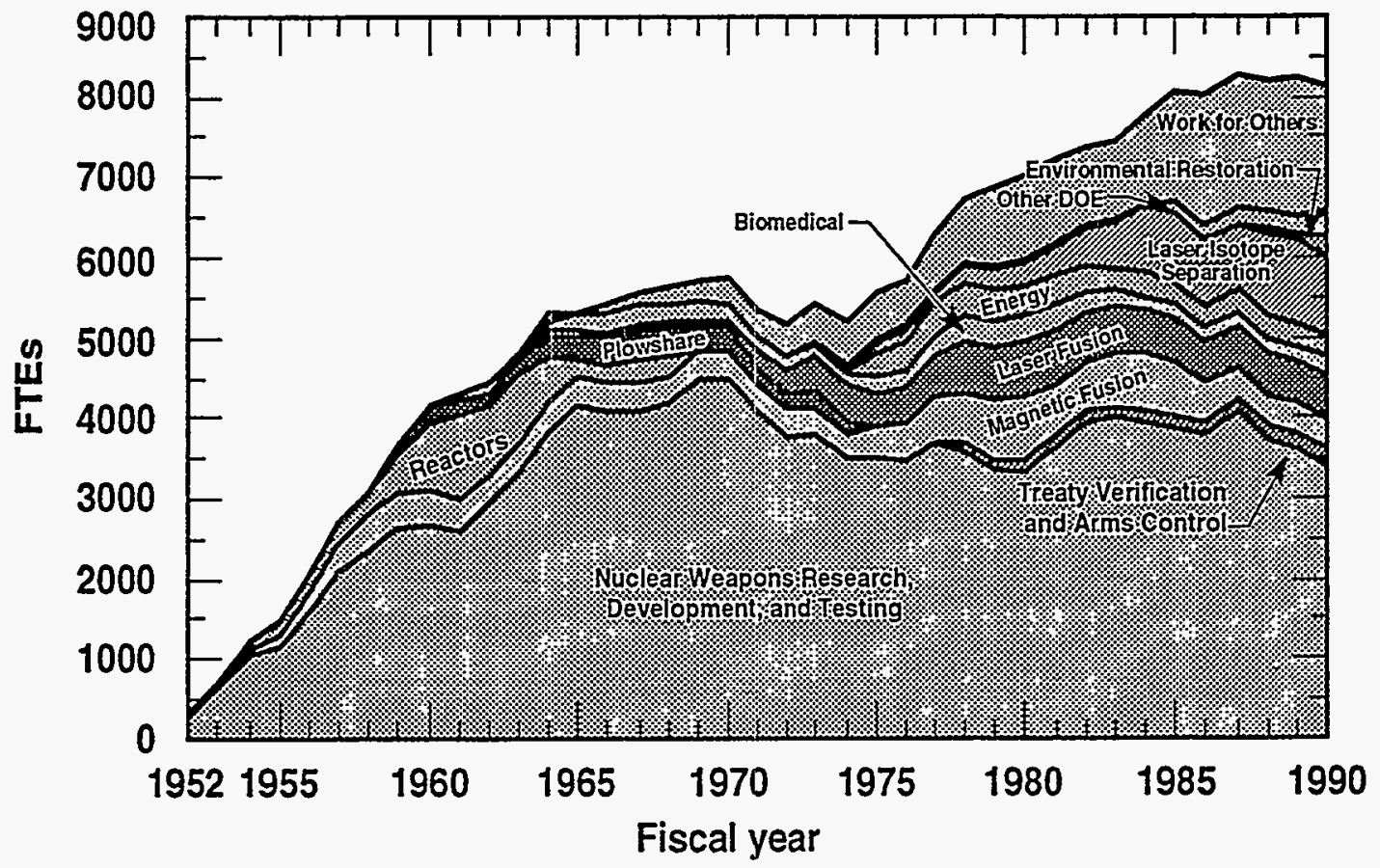

Figure 1. LLNL Staffing History 


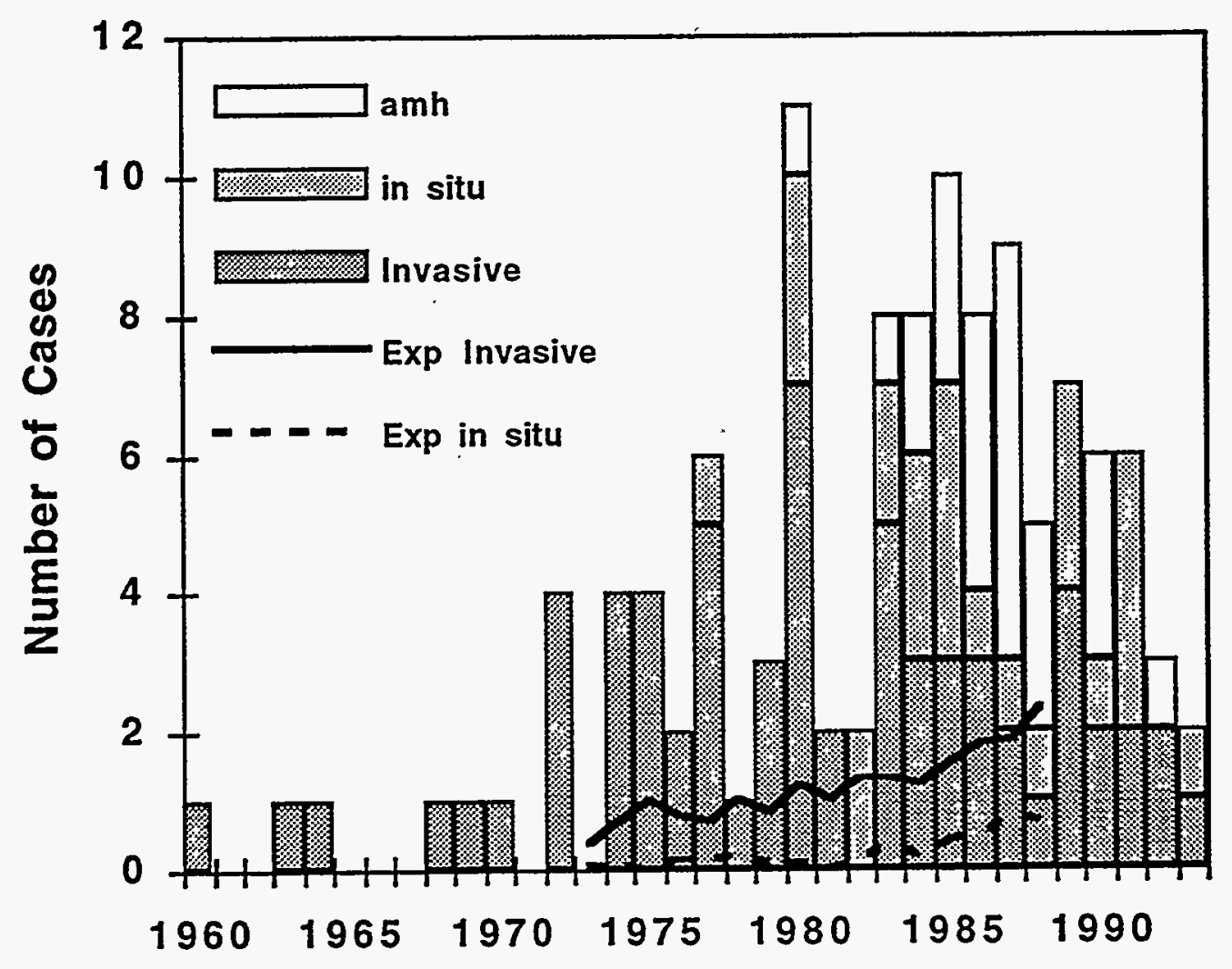

Figure 2. Cases by Year Chart 


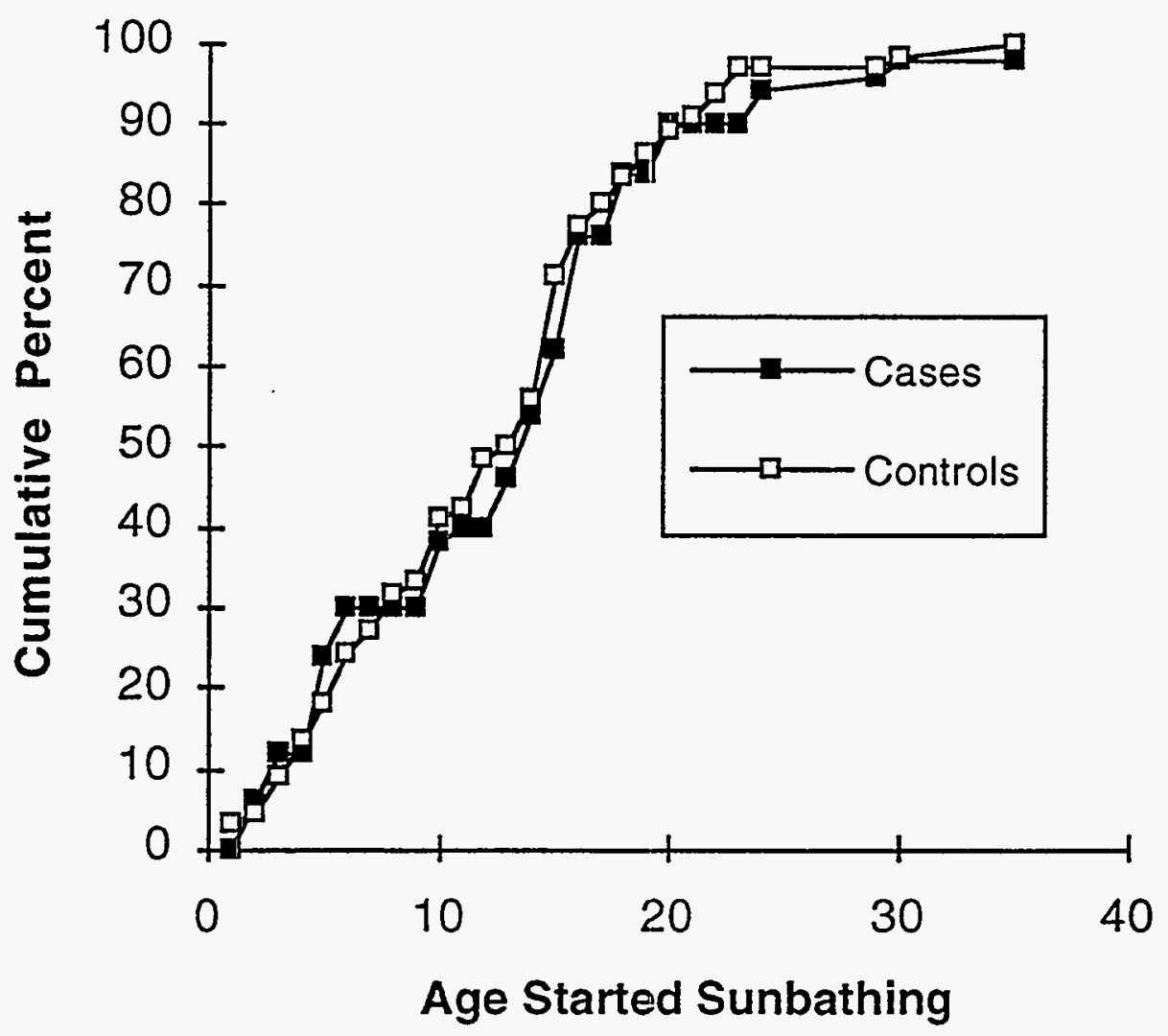

Figure 3. Cumulative Distribution of Cases and Controls for Sunbathing Start Age 

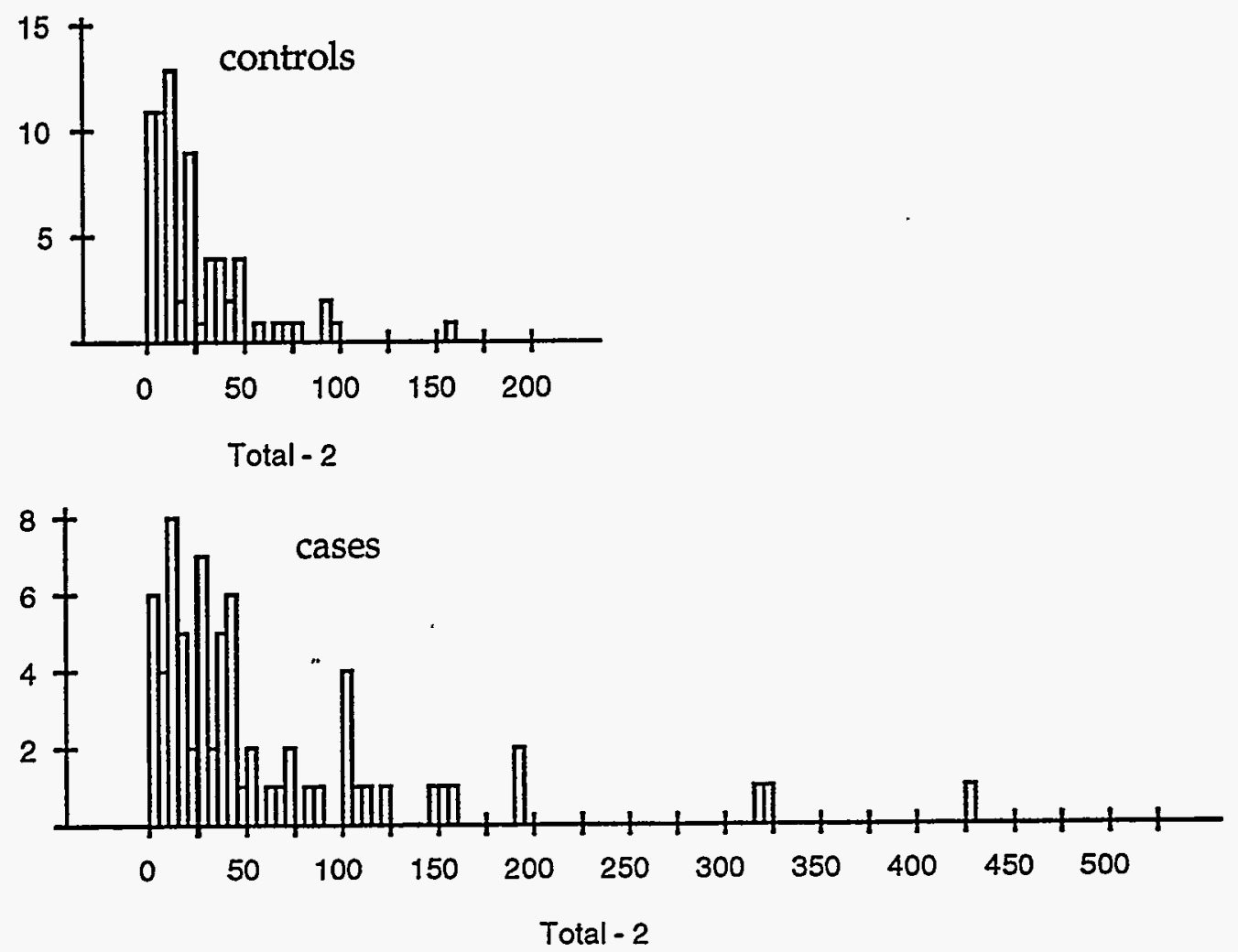

.Figure 4. Distribution of Counts of $\geq 2 \mathrm{~mm}$ Moles

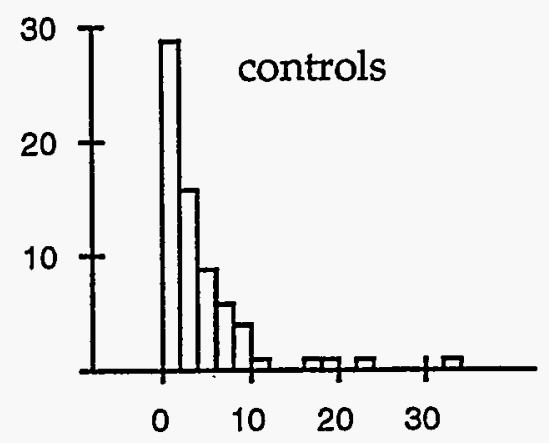

Total - 5

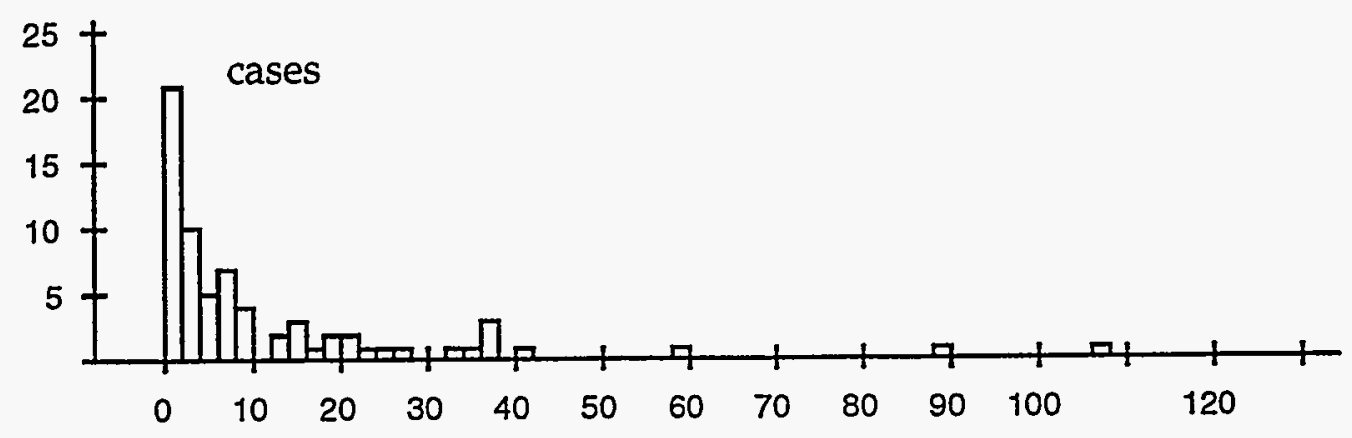

Total - 5

Figure 5. Distribution of Counts of $\geq 5 \mathrm{~mm}$ Moles 

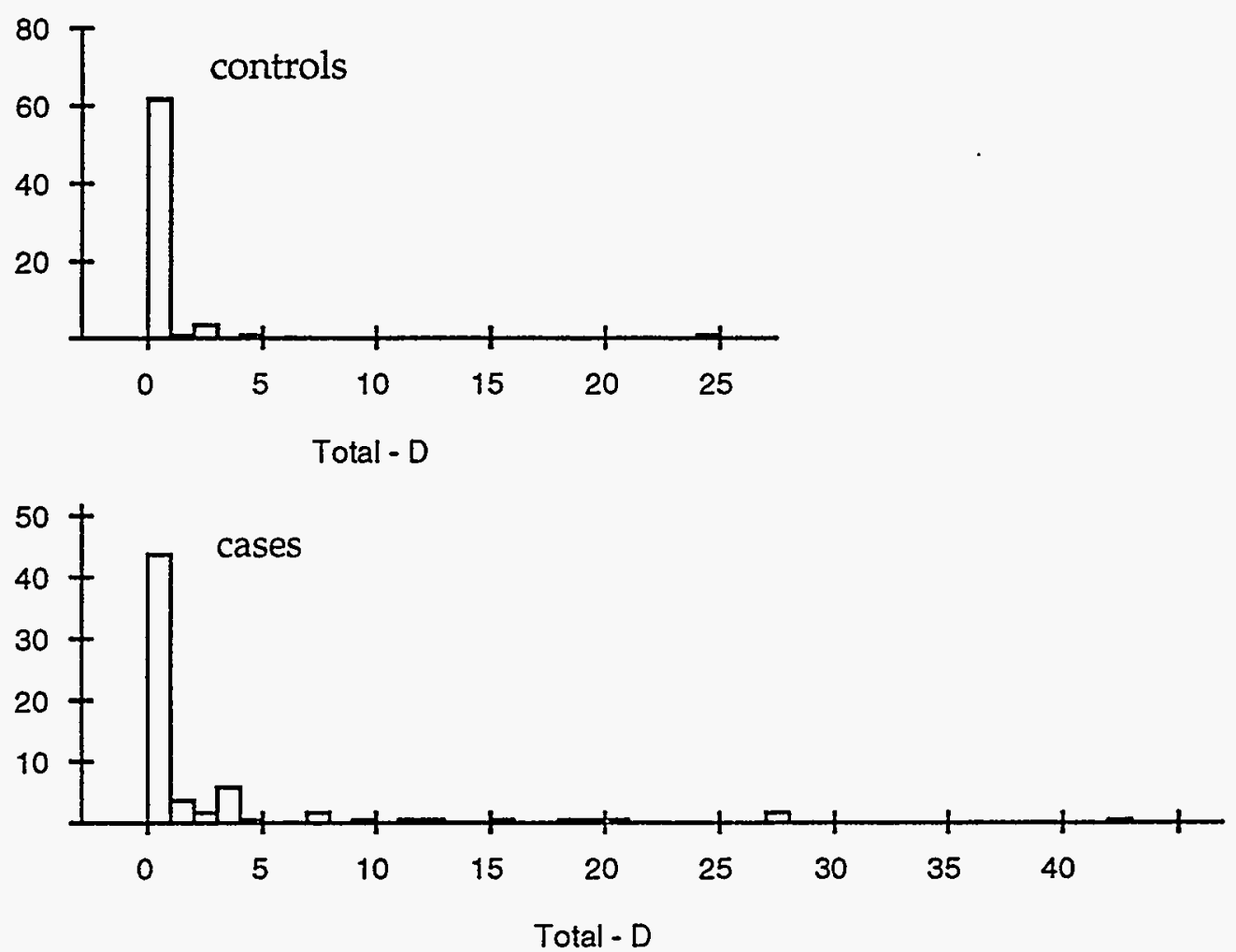

Figure 6. Distribution of Counts of Dysplastic Moles

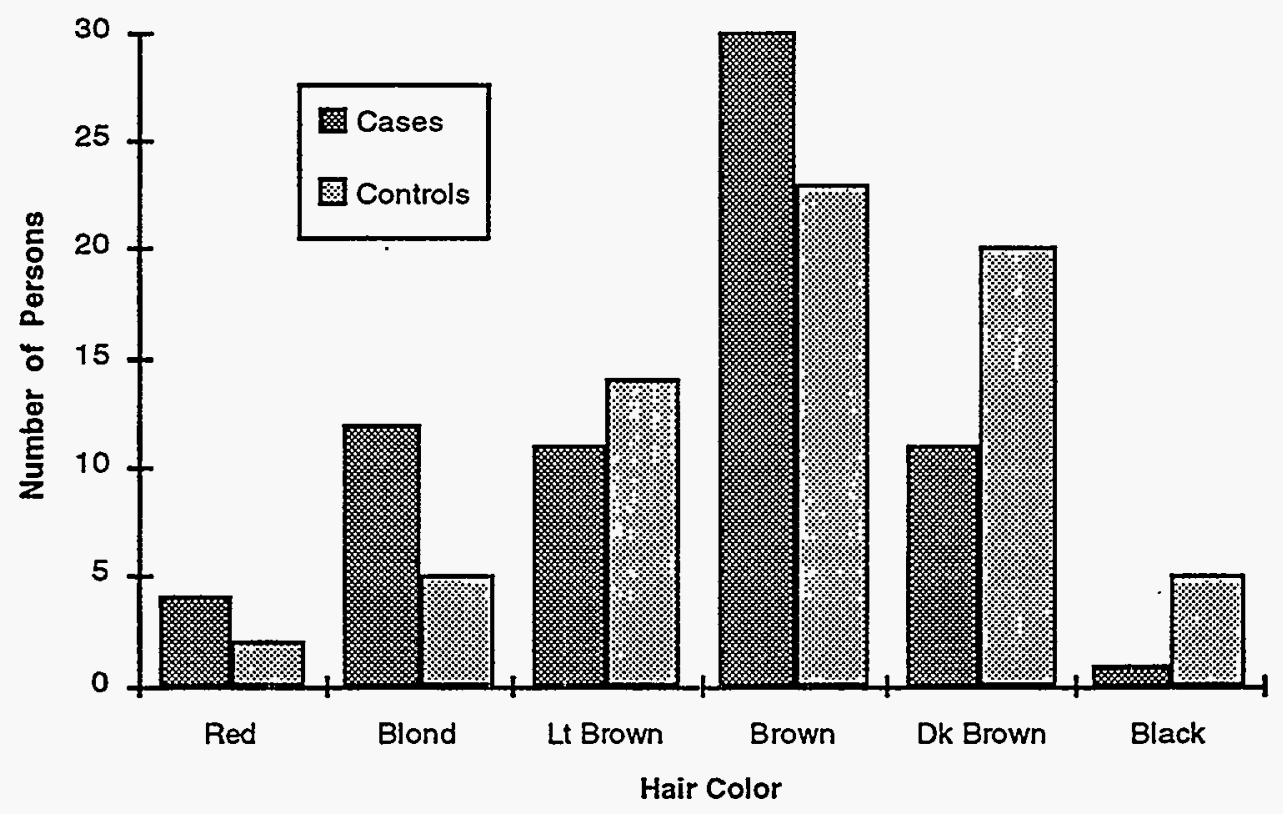

Figure 7. Distribution of Hair Color among Cases and Controls 


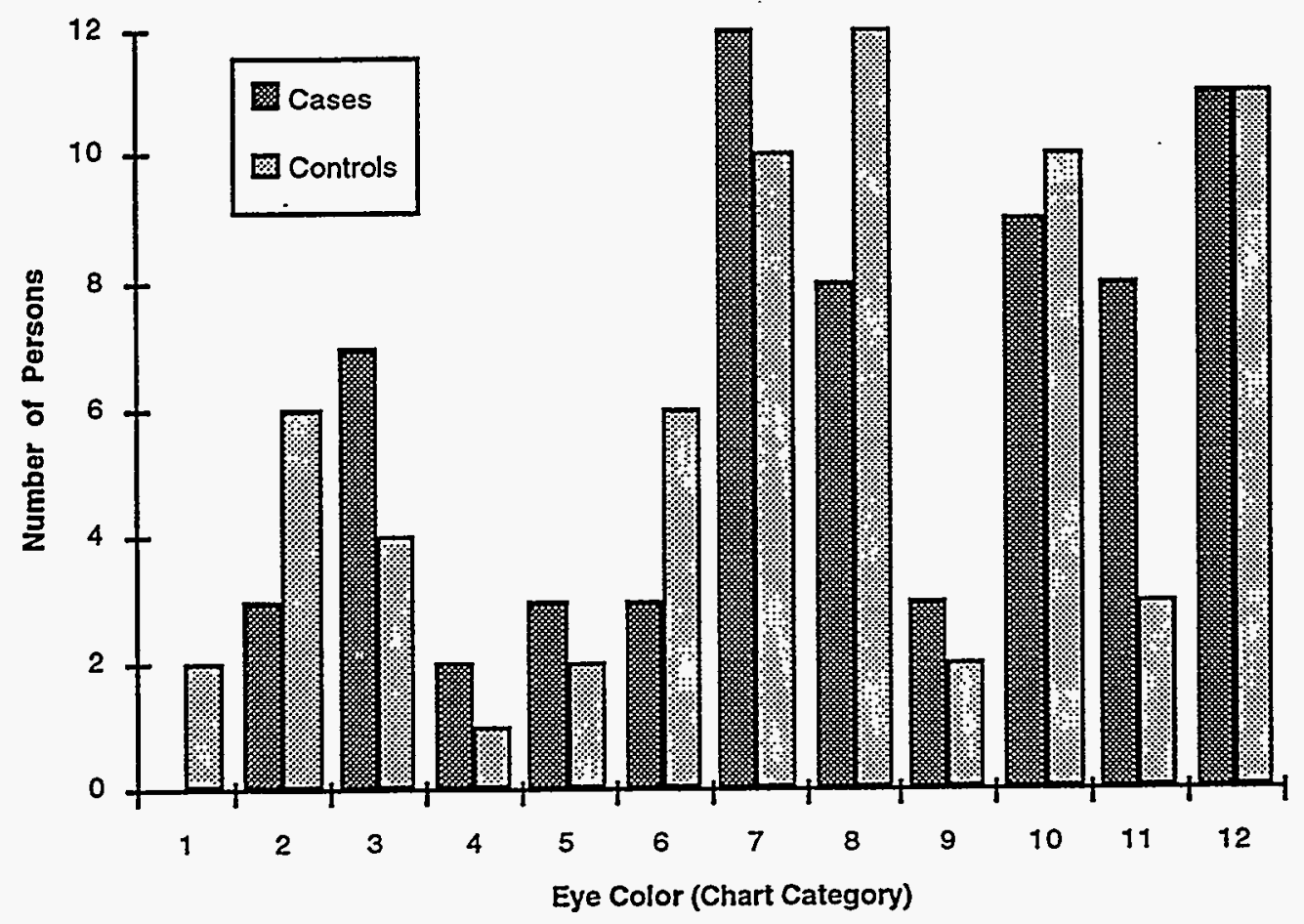

Figure 8. Distribution of Eye Color among Cases and Controls 


\section{Appendices}

Appendix A-Consent to Act as Human Subject

Appendix B-Exposure Checklist

Appendices A, B, C, and D of this checklist are selected versions of Laboratory Safety documents and were used to facilitate recall by the interviewees of any possible exposures they may have received.

Appendix C-Constitutional Factors Questionnaire 


\title{
UNIVERSITY OF CALIFORNIA \\ LAWRENCE LUERMORE NATIONAL LABORATORY
}

Consent to Act as a Human Subject

\author{
LLNL Institutional Review Board \\ Approval Number: 86P-101 \\ Approval Dates $11 / 19 / 85,11 / 25 / 86,3 / 14 / 88,3 / 27 / 89$
}

Workplace Investigation for Melanoma Risk Factors

Subject's Name:

Date:

1. I hereby authorize $\mathrm{H}$. Wade Patterson and/or David Discher to obtain from me questionnaire data concerning my medical history, work experience, lifestyle, residential history, and other relevant information, and to conduct an interview with me that will probe, to the extent deemed necessary, my workplace experiences at LLNL and elsewhere. I understand that the interview may be recorded stenographically for the pupose of accurate record maintenance, and that I will have an opportunity to review the transcript and correct it, if necessary.

2. I understand that the purpose of this investigation is to obtain comprehensive information on possible workplace exposures or other factors that could contribute to the apparent increased diagnosis rate of malignant melanoma at LLNL.

3. I understand that the reason for my selection for this project is either that I am a melanoma case* or I match such a person on the basis of age, sex, time at the Laboratory, and educational degree. Persons selected as matches shall not have a diagnosis of melanoma as defined in Attachment A.

4. I understand that all the information I provide will be protected as medically confidential. It will be made available to Health Services staff assigned to the project and to members of the Melanoma Investigation Task Group who are involved in the investigation. To the extent possible it will be worked with in coded form with my name removed. No use of the information, other than that required for evaluating possible contributory factors to melanoma incidence, will be made.

5. I understand that any possible risks and discomiorts that may result from the procedure(s) are considered unlikely but include the possibility of psychological discomfort associated with detailed discussion of past activities and the remote chance of inadvertent release of confidential information.

6. Since this activity does not involve medical treatment, there is no alternative procedure which might be advantageous to me.

Subject's Initials

\footnotetext{
"See Attachment A: Broad Interpretation of "Melanoma." Interviow consent tom
} 
7. I further understand that this study may result in no direct benefit to me but it may contribute to the understanding of the possible causes of melanoma and to making the work environment at LLNL as safe as possible, and may therefore be of some benefit to individuals in the future.

8. I understand that Dr. David Discher and/or Mr. Patterson will answer any inquiries I may have at any time concerning the procedures and/or investigation.

9. Any publication arising from this study will be made without specific reference to my name.

10. I recognize that my participation in this investigation is entirely voluntary and I may refuse to participate or may withdraw at any time without jeopardy. Owing to the scientific nature of the study, the investigator may in his absolute discretion terminate the procedures and/or investigations at any time.

11. I acknowledge the receipt of a signed copy of this consent form and the LLNL Experimental Subjects Bill of Rights.

12. Dr. David Discher, an employee of the University of California, Lawrence Livermore National Laboratory, is responsible for the conduct of the investigation in which I am to participate. This research is sponsored by the Lawrence Livermore National Laboratory solely for increasing the understanding of the apparent increase in melanoma among LLNL employees.

13. I understand that if I have any complaints or concerns about the procedures, I may address them to Dr. Barton L. Gledhill, Chairman of the Institutional Review Board, in person, by telephone, or in writing. Dr. Gledhill can be reached at (415) 422-3883, L-452, Lawrence Livermore National Laboratory, P.O. Box 5507, Livermore, California 94550.

Subject's Signature:

Date:

Witness' Signature:

Date: 


\section{ATTACHMENT A \\ BROAD INTERPRETATION OF "MELANOMA"}

In the various research study forms (consent forms, questionnaires, and letters or memos) we have used the terms "malignant melanoma" and melanoma" in numerous instances. Wherever either of these terms appear we intend to be referring to the presence of a biopsied skin lesion which is a member of a broad family of diagnosed medical conditions ranging from:

(1) melanoma precursor lesion (a lesion which strictly speaking is not defined or recognized as a true malignant lesion by most pathologists).

(2) an early lesion with all the criteria of a true malignancy but at a superficial level of penetration.

(3) to a true malignant melanoma at an advanced level of malignancy.

All persons reading statements and answering questions where the terms "malignant melanoma" or "melanoma" appear should recognize our intended broad interpretation for these diagnostic terms. 


\section{EXPERIMENTAL SUBJECT'S BILL OF RIGHTS}

The management and staff of the University of California, Lawrence Livermore National Laboratory, wish you to know:

Any person who is requested to consent to participate as a subject in a research study involving a medical experiment, or who is requested to consent on behalf of another, has the right to:

1. Be informed of the nature and purpose of the experiment.

2. Be given an explanation of the procedures to be followed in the medical experiment, and any drug or device to be utilized.

3. Be given a description of any attendant discomforts and risks reasonably to be expected from the experiment, if applicable.

4. Be given an explanation of any benefits to the subject reasonably to be expected from the experiment, if applicable.

5. Be given a disclosure of any appropriate alternative procedures, drugs or devices that might be advantageous to the subject, and their relative risks and benefits.

6. Be informed of the avenues of medical treatment, if any, available to the subject after the experiment, if complications should arise.

7. Be given the opportunity to ask any questions concerning the experiment or the procedures involved.

8. Be instructed that consent to participate in the medical experiment may be withdrawn at any time and the subject may discontinue participation in the medical experiment without prejudice.

9. Be given a copy of the signed and dated written consent form.

10. Be given the opportunity to decide to consent or not to consent to a medical experiment without the intervention of any. element of force, fraud, deceit, duress, coercion, or undue influence on the subject's decision.

If at any time you have any questions regarding a research study, the researcher or his/her assistant will be glad to answer them. You may also seek assistance from the Institutional Review Board which was established for the protection of volunteers in research projects. The Chairman of that Board, Dr. Barton L. Gledhill, may be reached by calling (415) 422-3883, from 8:00 a.m. until 5:00 p.m., Monday through Friday, or writing to the Institutional Review Board, L-452, Lawrence Livermore National Laboratory, P.O. Box 5507, Livermore, CA 94550. 


\title{
Exposure Checklist
}

\section{INSTRUCTIONS}

Please review the following pages. The checklist is intended to assist you in recall and in organizing your thought prior to your interview. It is organized in the following sections:

\author{
-POSSIBLE EXPOSURES \\ CHEMICAL \\ PHYSICAL \\ BIOLOGIC \\ ANY UNUSUAL EXPLSURES \\ -PROGRAMS/PROJECTS/SHOTS \\ -LLNL WORK HISTORY \\ -APPENDICIES A-D
}

We also request that you reflect on tour WORK HISTORY at places of employment other than LLNL and consider exposures in college and graduate or trade school.

Please give some consideration to the following with respect to all exposures prior to your diagnosis of melanoma:

-Duration of Typical/accumulated exposure

-Part(s)L of body and route(s) of entry

- Level of exposure (rough estimate/?data) 
Name:

Date:

\section{POSSIBLE EXPOSURES}

\section{- $\quad$ CHEMICAL}

Carcinogens; for more details see Appendix A

Photogenically; for more details see Appendix B

Thermal/paralyses products (Teflon, fire test cell exposures)

Cutting oils/other oil mists and oil skin contactant

Computer print outs

Polychlorinated biphenyls (PCBs)

Explosives and mock explosives; for more details see Appendix C

Diesel and nondiesel fuels and associated solvents

Toxic gases

Compressed air or other gases

Paint chemicals, solvents, degreasers

Skin protective creams

Asbestos, sandblasting materials, and other airborne dusts

Welding fumes and associated gases/vapors, soldering, brazing

Beryllium/uranium

Epoxy, polyurethane, polyester and other resin systems

Moca, adiprene, adhesives, plasticizers

Dyes and solvents associated with lasers

Toxic metals

Coal and its by-products

Plating and etching solutions

Wood dust

lon exchange resins (contaminants)

Hydrides (Lithium, Beryllium, Arsenic, Phosphouous, etc.)

Shielding blocks (metals, concrete, boron)

Rare earth elements (Yttrium, Neodynium, etc.)

Chlorinated solvents, methyl chloroform, perchlorethylene

Boranes

Carbon black

Pesticides/herbicides 
Name:

-PHYSICAL

Date:

Radioisotopes (Specify physical-chemical)

External ionizing radiation sources (specify type)

Ultraviolet light (specifically high exposure generators, such as mercury vapor lamps)

Magnetic flux

Microwave

Lasers

Radio frequency sources RF furnaces, for example)

Flash tubes

\section{-BIOLOGIC}

-Cocci exposure (skin findings for Valley Fever)

Fecal contaminated sewage

\section{ANY UNUSUAL EXPOSURES}

Packing/unpacking hazardous materials

Reactors (nuclear, chemical, etc.)

Waste handling

Animal handling

Water cooling tower effluent

Explosions

Spills/releases

Fires (controlled or uncontrolled)

Required emergency use of respirators/clothing, etc.

Use of Glove Boxes

From chemical synthesis

Stemming operations at NTÍ; for more details see Appendix D

Shot Canister Liner Mix (231); for more details see Appendix D 
Name:

Date:

\section{PROGRAMS/ PROJECT/SHOTS}

Please circle the items that pertain to you.

Weapons

Sherwood --.. CTR -..- MFE

Rover (Reactor for spare flight)

R-Division/Pluto - Ram Jet Beo/U

Tory $2 \mathrm{~A}$ and $2 \mathrm{C}$

Plowshare/weapons tests

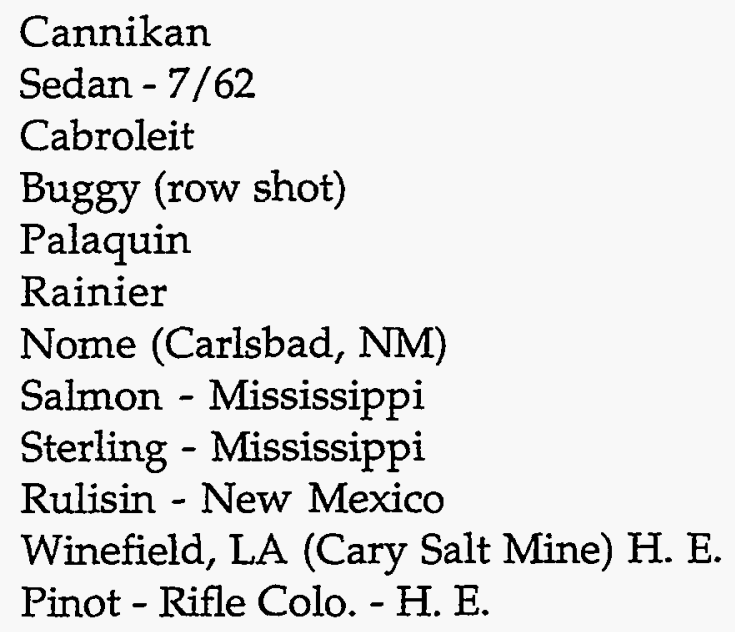

Cannikan

Sedan $-7 / 62$

Cabroleit

Buggy (row shot)

Palaquin

Rainier

Nome (Carlsbad, NM)

Salmon - Mississippi

Sterling - Mississippi

Rulisin - New Mexico

Winefield, LA (Cary Salt Mine) H. E.

Pinot - Rifle Colo. - H. E.

BioMed - Fallout studies/chemical carcinogens

Computations

\section{ENERGY PROGRAMS}

Coal Gasification

Oil Shale

Salton Sea (hot brine)

Laser Program

Chemistry

Physics

Lasers 


\section{LLNL WORK HISTORY}

\section{Review of Homework}

- Chronological list of assignments

(Tasks, duties, responsibilities)

- Locations (Building and room numbers for each assignment)

- $\quad$ Field exercises

- Names of events

- Atmospheric release as it relates to assignment

- Recovery operations as it relates to assignment

- Work at other AEC/ERDA/DOE facilities

- $\quad$ Site 300/NTS/Salton Sea/ The Gysers /Pacific Islands and other off-site assignments

- Normal work schedules (for each assignment)

- Indoor vs. outdoor time (for each assignment)

- Areas of specialization

- List of publications, UCRL reports, technical notes, etc.

- Supervisors and co-workers (for each assignment) 


\section{Appendix A}

\section{Carcinogen Clàssifications January 1985}

\section{Listed by substance:}

\begin{tabular}{|c|c|c|c|}
\hline Substance & Category & Substance & Category \\
\hline 2-Acetylaminofluorene & I & cis-Dichlorodiamine platimum II $^{d}$ & II \\
\hline Acridine and its derivatives & & 2,7, Dinitrofluorene $^{d}$ & II \\
\hline (includes Acridine Orange) $^{d}$ & II & 4-Dimethylaminoazobenzene ${ }^{2}$ & I \\
\hline Acriflavine ${ }^{d}$ & II & 7,12-Dimethylbenzanthracene ${ }^{c}$ & I \\
\hline 2-Actinomycin $D^{c}$ & I & 9,10-Dimethy1-1,2-benzanthracene & I \\
\hline Acrylonitrile & III & Dimethyl carbamylchloride $e^{b, c}$ & I \\
\hline Aflatoxins ${ }^{c}$ & I & 1,1-Dimethylhydrazine ${ }^{b}$ & II \\
\hline 2-Aminoanthracene ${ }^{d}$ & II & Ethidium bromide (and congeners) ${ }^{d}$ & II \\
\hline 9-Aminocridine & II & Ethylene dibromide ${ }^{b}$ & II \\
\hline 4-Aminodiphenyl (p-Xenylamine) ${ }^{2, b}$ & I & Ethylene oxide $^{b}$ & III \\
\hline 2-Amino fluorene & II & Ethionine $^{d}$ & II \\
\hline 2-Aminopurine ${ }^{d}$ & II & Ethyleneimine $e^{2}$ & I \\
\hline 3-Amino $1,2,4$-triazole ${ }^{b}$ & II & 5-Fluorouracil ${ }^{d}$ & II \\
\hline Amitrole $e^{b}$ & II & Formaldehyde ${ }^{b}$ & III \\
\hline Anthracene $^{d}$ & II & Hexachlorobutadiene ${ }^{b}$ & II \\
\hline Antimony trioxide production ${ }^{b}$. & II & Hexamethylphosphoramide ${ }^{b}$ & II \\
\hline Arsenic ${ }^{b}$ & II & Hydrazine ${ }^{b}$ & II \\
\hline Arsenic trioxide production ${ }^{b}$ & II & Hydrazine sulfated & II \\
\hline Asbestos ${ }^{2, b}$ & III & 8-Hydroxyquinoline $\mathrm{e}^{c}$ & III \\
\hline Azaserine $^{d}$ & II & ICR $170^{d}$ & II \\
\hline Benz(a)anthracene $e^{e}$ & I & ICR $191^{d}$ & II \\
\hline Benzidine $e^{2, b}$ & I & Imidazolidinethione ${ }^{d}$ & II \\
\hline Benzo(a)pyrene ${ }^{b, c}$ & I & $4,4^{\prime}-$ Methylene bis (s-chloroaniline) ${ }^{2}$ & I \\
\hline Beryllium ${ }^{b}$ & III & Methyl chloromethyl ether ${ }^{2}$ & I \\
\hline Benzene $^{b}$ & III & $4,4^{\prime}$-Methylene dianiline $e^{b}$ & II \\
\hline Bromobenzanthracene $^{c}$ & I & Methyl hydrazine ${ }^{b}$ & II \\
\hline 5-Bromo-deoxyuridine ${ }^{d}$ & II & Methyl iodide ${ }^{b}$ & III \\
\hline 1,3-Butadiene $e^{b}$ & III & 4-Methoxy-2-Naphthylamine ${ }^{d}$ & II \\
\hline Chrysene $^{b \cdot c}$ & I & $\alpha$-Naphthylamine ${ }^{2}$ & I \\
\hline bis-Chloromethyl ether ${ }^{2, b}$ & I & $\beta$-Naphthylamine $e^{2, b}$ & I \\
\hline Cadmium oxide production ${ }^{b}$ & II & N-Butyl-N-(4-hydroxy-butyl) & \\
\hline Carbon tetrachloride ${ }^{b}$ & III & ritrosoamine or $B B N^{d}$ & II \\
\hline Chloroform ${ }^{b}$ & III & Nitrogen mustard ${ }^{d}$ & II \\
\hline Chromomycin $\mathrm{A}-3^{\mathrm{d}}$ & II & $\mathrm{N}$-Nitrosodimethylamine $\mathrm{e}^{2, \mathrm{~b}}$ & I \\
\hline Colchicine $^{d}$ & II & 2-Nitropropane ${ }^{b}$ & III \\
\hline Chromates of lead, and zinc as $\mathrm{Cr}^{b}$ & II & N-phenyl-beta-napthylamine (skin) ${ }^{b, c}$ & I \\
\hline Cyanogen bromide $^{d}$ & II & Phenylhydrazine ${ }^{b}$ & III \\
\hline Cyclophosphamide $^{d}$ & II & Phenathrene $^{d}$ & II \\
\hline Cytosar $(A a-C)^{d}$ & II & Picene $^{d}$ & II \\
\hline Decarbamoyl mitomycin $C^{d}$ & II & Platinum sulfate $^{d}$ & II \\
\hline \multirow{2}{*}{$\begin{array}{l}\text { Dibenz(a,c)anthracene, and Dibenz } \\
(a, h) a n t h r a c e n e^{r}\end{array}$} & & P-Nitrosodiphenylamine ${ }^{d}$ & II \\
\hline & I & Porfiromycin $^{d}$ & II \\
\hline Dibromo-3-chloropropane ${ }^{r}$ & II & Propane sultone $\mathrm{e}^{\mathrm{b} . c}$ & I \\
\hline 2,2 Dichloro-N-Methyldiethylamine ${ }^{d}$ & II & $\beta_{\text {-propriolactone }}^{b}$ & I \\
\hline 3,3-Dichlorobenzidine (and its salts) & I & Propyleneimine $b$ & III \\
\hline
\end{tabular}


OSHA-PEL OT

\begin{tabular}{|c|c|}
\hline & $\begin{array}{l}\text { N-Butyl-N-(4-hydroxy-butyl) } \\
\text { nitrosoamine or } \mathrm{BBN}^{\mathrm{d}}\end{array}$ \\
\hline 0.5 ppm-skin & Nitrogen mustard $d^{d}$ \\
\hline \multirow[t]{2}{*}{0.1 ppm-skin } & N-Nitrosodiphenylamine \\
\hline & Phenanthrene $^{d}$ \\
\hline \multirow[t]{3}{*}{-skin } & Picene $^{d}$ \\
\hline & Platinum sulfate $^{d}$ \\
\hline & P-Nitrosodiphenylamine ${ }^{d}$ \\
\hline $0.02 \mathrm{ppm}$ & Porfiromycin ${ }^{d}$ \\
\hline -skin & Pyrene ${ }^{\delta}$ \\
\hline \multirow[t]{4}{*}{0.1 ppm,-skin } & Quercitin $^{d}$ \\
\hline & Quinoline, 4-nitro, 1-oxide ${ }^{d}$ \\
\hline & $\begin{array}{l}\text { Tetra-ethylthiuram disulfide } \\
\text { (disulfiram) }\end{array}$ \\
\hline & Thiourea $^{e}$ \\
\hline $\begin{array}{l}0.1 \mathrm{ppm} \\
\text { c } 0.2 \mathrm{ppm} \text {,-skin }\end{array}$ & $\begin{array}{l}\text { TRP-P- } 1 \text { and TRP-P-2 and other } \\
\text { heterocyclic food mutagens }{ }^{5}\end{array}$ \\
\hline
\end{tabular}

cis-Dichlorodiamine Platinum II $^{\mathrm{d}}$

2,7, Dinitrofluorene ${ }^{d}$

1,1-Dimethylhydrazine ${ }^{b}$.

Dimethyl sulfate ${ }^{b}$

Ethidium bromide (and congeners)

Ethylene dibromide ${ }^{b}$

Ethionine $^{d}$

5-Fluorouracil ${ }^{d}$

Hexachlorobutadien $e^{b}$

Hexamethylphosphoramide ${ }^{b}$

Hydrazine $^{b}$

Hydrazine sulfate ${ }^{d}$

ICR $170^{d}$

ICR $191^{\mathrm{d}}$

Imidaolidinethione $^{d}$

4,4'-Methylene dianiline ${ }^{6}$

Methyl hydrazine ${ }^{b}$

4-Methoxy-2-naphthylamine ${ }^{d}$
N-Butyl-N-(4-hydroxy-butyl)

Nitrogen mustard ${ }^{d}$

N-Nitrosodiphenylamine

Phenanthrene $^{d}$

Picene $^{d}$

Platinum sulfate

P-Nitrosodiphenylamine ${ }^{d}$

Porfiromycin ${ }^{d}$

Quinoline, 4-nitro, 1-oxide ${ }^{d}$

Tetra-ethylthiuram disulfide

"OSHA list.

"TLV list and documentation.

- Documented by Industrial Hygiene Group.

"Classification is still subject to review.

\section{Category III}

(Carcinogenic substances of low potency)

OSHA-PEL or ACGIH-TLV (if estab.)

Substance

Substance

2 ppm

Acrylonitrile ${ }^{b}$

Asbestos ${ }^{2, b}$

See Supp. 21.19

Beryllium $^{b}$

See Supp. 21.10

1,3-Butadiene ${ }^{b}$

$10 \mathrm{ppm}$

Benzene $^{b}$

Carbon tetrachloride ${ }^{b}$

Chloroform ${ }^{b}$

$10 \mathrm{ppm}$

5 ppm - skin

Ethylene oxide ${ }^{b}$

Formaldehyde ${ }^{b}$

$10 \mathrm{ppm}$

$1 \mathrm{ppm}$

1 ppm
Methyl iodide ${ }^{b}$

2-Nitropropane ${ }^{b}$

o-Toluidine, p-Toluidine, m-Toluidine ${ }^{b}$

Phenylhydrazine ${ }^{b}$

Propyleneimine ${ }^{b}$

Vinyl bromide

Vinyl chloride ${ }^{b}$

Vinyl cyclohexene dioxide
OSHA-PEL or ACGIH-TLV (if estab.)

2 ppm - skin $10 \mathrm{ppm}$

2 ppm - skin

5 ppm - skin

2 ppm - skin

5 ppm

5 ppm

8-Hydroxyquinoline

"OSHA list.

"TLV list and documentation.

- Documented by Industrial Hygiene Group.

"Classification is still subject to review. 


\section{APPENDIX B}

\section{Photographic Chemicals}

- Did you routinely work with photographic chemicals?

- Did your hands/arms come in direct contact with photographic chemicals?

- Did you work in areas where you could just smell the photographic chemical odor?

- What kind of photographic chemicals did you work with?

Black and white ( $B \& W$ )

Color

Polaroid

- Did B\&W activities involve print development or film development?

- Did color activities involve, E-3, E-4, E-5 or E-6 development process?

- Did your activities involve B\&W Polaroid photos?

How many photos did you treat per day with the acetic acid applicator?

Did you do anything else with the Polaroid system?

- Did you carry out any photolithography work? 
EXPLOSIVES

Table 3-1. Pure explosive compounds.

\begin{tabular}{|c|c|c|c|}
\hline Materiala & Chemical nameb & Other designations & Color \\
\hline AN & Armonium nitrate & & Clear \\
\hline$A P$ & Amonium perchlorate & & White \\
\hline BTF & $\begin{array}{l}\text { Benzotris }[1,2,5] \text { oxadiazole. } \\
\text { 1,4,7-trioxide }\end{array}$ & $\begin{array}{l}\text { Benzotrifuroxan; } \\
\text { Hexanitrosobenzene; } \\
\text { Benzotrifurazan- } \\
\text { N-oxide }\end{array}$ & Buff \\
\hline DATB & $\begin{array}{l}2,4,6-\text { Irinitro-1,3- } \\
\text { benzenediamine }\end{array}$ & $\begin{array}{l}\text { 1,3-Diamino-2,4,6- } \\
\text { trinitrobenzene }\end{array}$ & Yellow \\
\hline DEGN & $\begin{array}{l}2,2^{4} \text {-Oxybisethanol, } \\
\text { dinitrate }\end{array}$ & $\begin{array}{l}\text { Diethylene glycol } \\
\text { dinitrate; } \\
\text { Dinitrodiglycol }\end{array}$ & cleer \\
\hline DIPAM & $\begin{array}{l}2,2^{\prime}, 4,4^{\prime}, 6,6^{\prime} \text {-Hexanitro- } \\
{[1,1 \text {-biphenyl]-3,3'-diamine }}\end{array}$ & $\begin{array}{l}3,3^{\prime}-\text { - imino } \\
2,2^{\prime}, 4,4^{\prime}, 6,6^{\prime}- \\
\text { Hexanitrobiphenyl; } \\
\text { Hexanitrodipheny } 1 \\
\text { amine hexite; } \\
\text { Dipicraride }\end{array}$ & - \\
\hline DNPA & 2,2-Dinitropropyl acrylate & & off-white \\
\hline EDNP & Ethyl 4,4-dinitropentanoete & $\begin{array}{l}\text { Ethyl } 4,4- \\
\text { dinitrovalerate }\end{array}$ & Yellow \\
\hline Explosive D & Amonium picrate & Dunnite & Yellow/red \\
\hline PEPO & $\begin{array}{l}1,1 \text { '-[Yethylenebis (oxy) ]bis- } \\
\text { [2-fluoro-2,2-dinitroethane] }\end{array}$ & $\begin{array}{l}\text { Bis(2-fluoro-2,2- } \\
\text { dinitroethyl) foral }\end{array}$ & Strav \\
\hline
\end{tabular}




\section{SAMES AND FORYILATIONS}

Thas section consists of Tables 3-1 chrough 3-6, which 1 ist the names and formulations of the various materials for which aata are reported in this handbook. The high explosive (4) compositions are arranged by major component in Table $3-6$.

Table 3-1. Pure explosive compounds.

\begin{tabular}{|c|c|c|c|}
\hline Materiala & Chemical nameb & Other designations & Color \\
\hline AN & Amonium nitrate & & Clear \\
\hline AP & Amonium perchlorate & & White \\
\hline BTF & $\begin{array}{l}\text { Benzotris }[1,2,5] \text { oxadiazole, } \\
1,4,7 \text {-trioxide }\end{array}$ & $\begin{array}{l}\text { Benzotrifuroxan; } \\
\text { Hexanitrosobenzene; } \\
\text { Benzotrifurazan- } \\
\text { N-oxide }\end{array}$ & Buff \\
\hline DATB & $\begin{array}{l}2,4,6-\text { Trinitro-1,3- } \\
\text { benzenediamine }\end{array}$ & $\begin{array}{l}\text { 1,3-Diamino-2,4,6- } \\
\text { trinitrobenzene }\end{array}$ & Yellow \\
\hline DEGN & $\begin{array}{l}2,2^{\prime} \text {-oxybisethanol, } \\
\text { dinitrate }\end{array}$ & $\begin{array}{l}\text { Diethylene glycol } \\
\text { dinitrate; } \\
\text { Dinitrodiglycol }\end{array}$ & Cleat \\
\hline DIPAM & $\begin{array}{l}2,2^{\prime}, 4,4^{\prime}, 6,6^{\prime}-\text { Hexanitro- } \\
{\left[1,1^{-}-\text {bipheny }^{\prime}\right]-3,3^{\prime} \text {-diamine }}\end{array}$ & $\begin{array}{l}3,3^{\prime}-\text { Diamino } \\
2,2^{\prime}, 4,4^{\prime}, 6,6^{\prime}- \\
\text { Bexanitrobipheny } 1 \text {; } \\
\text { Hexanitrodipheny } 1 \\
\text { amine hexite; } \\
\text { Dipicramide }\end{array}$ & - \\
\hline DNPA & 2,2-Dinitropropyl acrylate & & off-white \\
\hline EDNP & Ethyl 4,4-dinitropentanoate & $\begin{array}{l}\text { Ethyl } 4,4- \\
\text { dinitrovalerate }\end{array}$ & Yellow \\
\hline Explosive D & Ammonium picrate & Dunnite & Yellow/red \\
\hline FERO & $\begin{array}{l}\text { 1,1'-[ Hethylenebis(oxy)]bis- } \\
{[2-\text { fluoro-2,2-dinitroethane] }}\end{array}$ & $\begin{array}{l}\text { Bis(2-Eluoro-2,2- } \\
\text { dinitroethyl) formal }\end{array}$ & Straw \\
\hline
\end{tabular}


Table 3-1. Pure explosive compounds. (Continued)

\begin{tabular}{|c|c|c|c|}
\hline Materiala & Chemical nameb & Other designations & Color \\
\hline RDX & $\begin{array}{l}\text { Hexahydro-l,3,5-trinitro- } \\
1,3,5-t r i a z i n e\end{array}$ & $\begin{array}{l}\text { 1,3,5-Irunitro-1,3,5- } \\
\text { triazacyciohexane } \\
\text { Cyclotrimethylene } \\
\text { trinitramine; } \\
\text { Hexogen; Cyclonite; } \\
\text { Gh; T4; 1,3,5- } \\
\text { Irinitrotrimethylene- } \\
\text { triamine }\end{array}$ & White \\
\hline IACOT & $\begin{array}{l}2,4,8,10-\text { Tetranitro-sh-benzo- } \\
\text { triazolo- }[2,1-a] \text {-benzo- } \\
\text { triazol-6-ium, hydroxide, } \\
\text { inner salt. }\end{array}$ & $\begin{array}{l}\text { Tetranitrodibenzo- } \\
1,3 a, 4,6 a- \\
\text { tetrazapentalene }\end{array}$ & $\begin{array}{l}\text { Red- } \\
\text { orange }\end{array}$ \\
\hline IATB & $\begin{array}{l}2,4,6 \text {-Trinitro- } 1,3,5 \text {-benzene- } \\
\text { triamine }\end{array}$ & $\begin{array}{l}1,3,5-\text { Triamino- } 2,4,6- \\
\text { trinitrobenzene }\end{array}$ & $\begin{array}{l}\text { Bright } \\
\text { yellow }\end{array}$ \\
\hline Tetryl & $\begin{array}{l}\text { N-Methyl-N, } 2,4,6 \text {-tetranitro- } \\
\text { benzenamine }\end{array}$ & $\begin{array}{l}\text { 2,4,6-Trinitropheny } 1- \\
\text { methylnitramine; } \\
\text { N-methyl-\$,2,4,6- } \\
\text { tetranitroaniline; } \\
\text { Tetranitromethyl- } \\
\text { aniline; Pyronite; CE }\end{array}$ & Yellow/buff \\
\hline TNM & Tetranitromethane & & Clear \\
\hline TNT & $\begin{array}{l}\text { 2-Methy } 1-1,3,5 \text {-trinitro- } \\
\text { benzene }\end{array}$ & $\begin{array}{l}2,4,6-\text { Trinitrotoluene- } \\
\text { Trotyl; T; Tolit }\end{array}$ & $\begin{array}{l}\text { Buff/ } \\
\text { brown }\end{array}$ \\
\hline
\end{tabular}

a Properties of these materials are sumnarized in the data sheets (Section IV).

b The chemical names are listed in the Chemical Abstracts Index Guide (American Chemical Society, Columbus, $\mathrm{OH}, 1977+$ ).

C Nitrocellulose is not, strictly speaking, a single chemical compound. Different grades are commercially available; the grade denotes the degree of nitration. For this handbook, we cite data, where possible, that is characteristic of lacquer-grade nitrocellulose (12.0\% N) and guncotton (13.35\% $\mathrm{N}, \mathrm{min})$. Lacquer-grade nitrocellulose is not an explosive but an energy-contributing plastic binder in PBX-9404. The maximum possible nitration is $14.14 \%$. 
Table 3-3. Plastic-bonded explosives: names and formulaticns.

\begin{tabular}{|c|c|c|c|c|}
\hline \multirow[b]{2}{*}{ Explosivea } & \multirow[b]{2}{*}{ Othet designations } & \multicolumn{2}{|c|}{ Formulation } & \multirow[b]{2}{*}{ Color } \\
\hline & & Ingredient & $w t z$ & \\
\hline $2 x-04-1$ & P BHV $-85 / 15$ & $\begin{array}{l}\operatorname{Hix} \\
\text { Viton } A\end{array}$ & $\begin{array}{l}85 \\
15\end{array}$ & Yellow \\
\hline $2 x-07-2$ & $R X-04-B A$ & $\begin{array}{l}\operatorname{Hrx} \\
\text { Viton } A\end{array}$ & $\begin{array}{l}90 \\
10\end{array}$ & Orange \\
\hline$L x-09-0$ & $R X-09-C B$ & $\begin{array}{l}\text { HMX } \\
\text { PDNPA } \\
\text { FEFO }\end{array}$ & $\begin{array}{l}93 \\
4.6 \\
2.4\end{array}$ & Purple \\
\hline $2 x-09-1$ & & $\begin{array}{l}\text { HIX } \\
\text { PDNPA } \\
\text { FEEO }\end{array}$ & $\begin{array}{r}93.3 \\
4.4 \\
2.3\end{array}$ & Purple \\
\hline $2 x-10-0$ & $R X-04-D E$ & $\begin{array}{l}\text { Hix } \\
\text { Viton A }\end{array}$ & $\begin{array}{r}95 \\
5\end{array}$ & $\begin{array}{l}\text { Blue-green spots } \\
\text { on white }\end{array}$ \\
\hline $2 x-10-1$ & $R X-04-E A$ & $\begin{array}{l}\text { Hax } \\
\text { Viton A }\end{array}$ & $\begin{array}{r}94.5 \\
5.5\end{array}$ & $\begin{array}{l}\text { Blue-green spots } \\
\text { on white }\end{array}$ \\
\hline$L X-11-0$ & $R X-04-P I$ & $\begin{array}{l}\text { Hux } \\
\text { Viton A }\end{array}$ & $\begin{array}{l}80 \\
20\end{array}$ & White \\
\hline $2 x-14-0$ & $R X-04-E Q$ & $\begin{array}{l}\text { HaX } \\
\text { Estane } \\
\text { S702-P1 }\end{array}$ & $\begin{array}{r}95.5 \\
4.5\end{array}$ & $\begin{array}{l}\text { Violet spots } \\
\text { on white }\end{array}$ \\
\hline $2 x-15$ & $R X-28-A S$ & $\begin{array}{l}\text { Bus-I } \\
\text { Re1-R } 800\end{array}$ & $\begin{array}{r}95 \\
5\end{array}$ & Beige \\
\hline $2 x-16$ & $R X-15-A D$ & $\begin{array}{l}\text { PETN } \\
\text { FPC } 461\end{array}$ & $\begin{array}{r}96 \\
4\end{array}$ & White \\
\hline $2 x-17-0$ & $R X-03-B B$ & $\begin{array}{l}\text { TATB } \\
\text { Rel-I } 800\end{array}$ & $\begin{array}{r}92.5 \\
7.5\end{array}$ & Yellow \\
\hline$P B X-9007$ & PBX-9007 Type B & $\begin{array}{l}\text { RDX } \\
\text { Polystyrene } \\
\text { DOP } \\
\text { Rosin }\end{array}$ & $\begin{array}{l}90 \\
9.1 \\
0.5 \\
0.4\end{array}$ & $\begin{array}{l}\text { White or mottled } \\
\text { grayb }\end{array}$ \\
\hline PBX -9010 & & $\begin{array}{l}\mathrm{RDX} \\
\text { Rel-P } 3700\end{array}$ & $\begin{array}{l}90 \\
10\end{array}$ & White \\
\hline
\end{tabular}


Table 3-4. Miscellaneous explosives: names and formulations.

\begin{tabular}{|c|c|c|c|c|}
\hline \multirow[b]{2}{*}{ Explosive } & \multirow[b]{2}{*}{ Orher designations } & \multicolumn{2}{|l|}{ Formulation } & \multirow[b]{2}{*}{ Color } \\
\hline & & Ingredient & wt\% & \\
\hline Black Powder & Black gunpowoet & $\begin{array}{l}\mathrm{KNO}_{3} \\
\text { Charcosl } \\
\text { Sulfur }\end{array}$ & $\begin{array}{l}75 \\
15 \\
10\end{array}$ & Gray to black \\
\hline Comp $c-3$ & & $\begin{array}{l}\text { RDX } \\
\text { TNT } \\
\text { DNT } \\
\text { MNT } \\
\text { Tetryl } \\
\text { NC }\end{array}$ & $\begin{array}{r}77 \\
4 \\
10 \\
5 \\
3 \\
1\end{array}$ & Yellow \\
\hline Comp $c-4$ & Harrisite & $\begin{array}{l}\text { RDX } \\
\text { Di(2-ethylhexyl) } \\
\text { sebacate } \\
\text { Polyisobutylene } \\
\text { Motor oil }\end{array}$ & $\begin{array}{l}91 \\
5.3 \\
2.1 \\
1.6\end{array}$ & Light brown \\
\hline$E L-506 A$ & Detasheet & $\begin{array}{l}\text { PETH } \\
\text { Binder }\end{array}$ & $\begin{array}{l}85 \\
15\end{array}$ & Red \\
\hline$E L-506 C$ & Detasheet & $\begin{array}{l}\text { PETK } \\
\text { HC }(12.37 \mathrm{~N}) \\
\text { ATBC }\end{array}$ & $\begin{array}{r}63 \\
8 \\
29\end{array}$ & Olive \\
\hline$L X-01$ & $N T N, R X-01-M$ & $\begin{array}{l}\text { NM } \\
\text { TNM } \\
\text { 1-Nitropropane }\end{array}$ & $\begin{array}{l}51.7 \\
33.2 \\
15.1\end{array}$ & Clear \\
\hline $2 x-02-1$ & $\begin{array}{l}E L-506 L-3 \\
R X-02-A C\end{array}$ & $\begin{array}{l}\text { PETy } \\
\text { Butyl rubber } \\
\text { ATBC } \\
\text { Cab-O-Sil }\end{array}$ & $\begin{array}{r}73.5 \\
17.6 \\
6.9 \\
2.0\end{array}$ & Buff \\
\hline $2 x-08$ & $R X-02-A M$ & $\begin{array}{l}\text { PEIH } \\
\text { Sylgard } 182 \\
\text { Cab-a-Sil }\end{array}$ & $\begin{array}{r}63.7 \\
34.3 \\
2.0\end{array}$ & Blue \\
\hline $2 x-13$ & & $\begin{array}{l}\text { PETH } \\
\text { Sylgard } 182\end{array}$ & $\begin{array}{l}80 \\
20\end{array}$ & White \\
\hline
\end{tabular}


Tabie 3-5. Addatives and binders.

\begin{tabular}{|c|c|c|c|}
\hline Macerial & Chemical name & Other designations & Color \\
\hline BDNPA-F & $\begin{array}{l}\text { Bis(2,2-dinitropropyl) } \\
\text { acetal/bis(2,2-dinitro- } \\
\text { propyl) formal, 50/50 wtz }\end{array}$ & & Straw \\
\hline Cab-o-sil $\div-5$ & & $\begin{array}{l}\text { Amorphous silicon } \\
\text { oxide }\end{array}$ & White \\
\hline CEF & $\begin{array}{l}\text { Iris-B-chloroethyl- } \\
\text { phosphare }\end{array}$ & & Clear \\
\hline DOP & Di(2-ethylhexyl) phthalate & Dioctylphthalate & Clear \\
\hline Estane 5702-F1 & & $\begin{array}{l}\text { Polyurethane } \\
\text { solution sysrem }\end{array}$ & Light amber \\
\hline FPC 461 & $\begin{array}{l}\text { Vinyl chloride/chlorotri- } \\
\text { fluoroethylene copolymer, } \\
1.5: 1\end{array}$ & & White \\
\hline $\mathrm{Kel}-\mathrm{F} 800$ & $\begin{array}{l}\text { Chlorotrifluoroethylene/ } \\
\text { vinylidine fluoride } \\
\text { copolymer, } 3: 1\end{array}$ & & Off-white \\
\hline Polystyrene & & & Clear \\
\hline Sylgard 182 & - Poly(dimethylsiloxane) & Silicone resin & Light str2w \\
\hline Viton A & $\begin{array}{l}\text { Vinylidine fluoride/hexa- } \\
\text { fluoropropylene copolymer, } \\
60 / 40 \text { vi }\end{array}$ & & White \\
\hline
\end{tabular}

a Properties of these materials are summarized in the data sheets (Section IV). 
Table 3-6. Explosive compositions by major HE component. (Continued)

\begin{tabular}{|c|c|c|c|}
\hline Mejor & component (wtz) & Other constituents. (wt $x$ ) & Designation \\
\hline IATB & $\begin{array}{l}95 \\
92.5 \\
80\end{array}$ & $\begin{array}{l}\text { Kel-F } 8005 \\
\text { Kel-F } 8007.5 \\
\text { HyX } 15 \text { Kel-F } 8005\end{array}$ & $\begin{array}{l}\text { PBX }-9502 \\
L X-17-0 \\
P B X-9503\end{array}$ \\
\hline TNT & $\begin{array}{l}50 \\
40 \\
40\end{array}$ & $\begin{array}{l}\text { PETN } 50 \\
\text { AN } 40 \text { AI } 40 \\
\text { Boric acid } 60\end{array}$ & $\begin{array}{l}\text { Pentolite } 50 / 50 \\
\text { Minol-2 } \\
\text { Boracitol }\end{array}$ \\
\hline
\end{tabular}




\section{APPENDIX D}

TYPICAL STEMMING MIX USED AT NTS

Approx. Wt. $\%$

$\begin{array}{lll}\text { SD-696 } & 30 . & \text { Epoxy Resin } \\ \text { CP-524 } & 62 . & \text { Coal Tar } \\ \text { UCC-A-1100 } & 0.25 & \text { Hetting Agent (Silane) } \\ \text { Dion 3-900 } & 6 . & \text { Catalyst } \\ \text { DETA } & 2 . & \text { Catalyst }\end{array}$

Other Materials Used at Various Times

Local sand and gravel

Magnatite ore $\left(\mathrm{Fe}_{3} \mathrm{O}_{4}\right)$

Hot asphait and wax

"Gas Block" - similar to silicone rubber

Colemanite (boron mineral)

\section{Canister Liner Mix}

Similar to steming mixes but with Boron Carbide powder added. 


\section{CONSTITUTIONAL FACTORS QUESTIONNAIRE - 2}

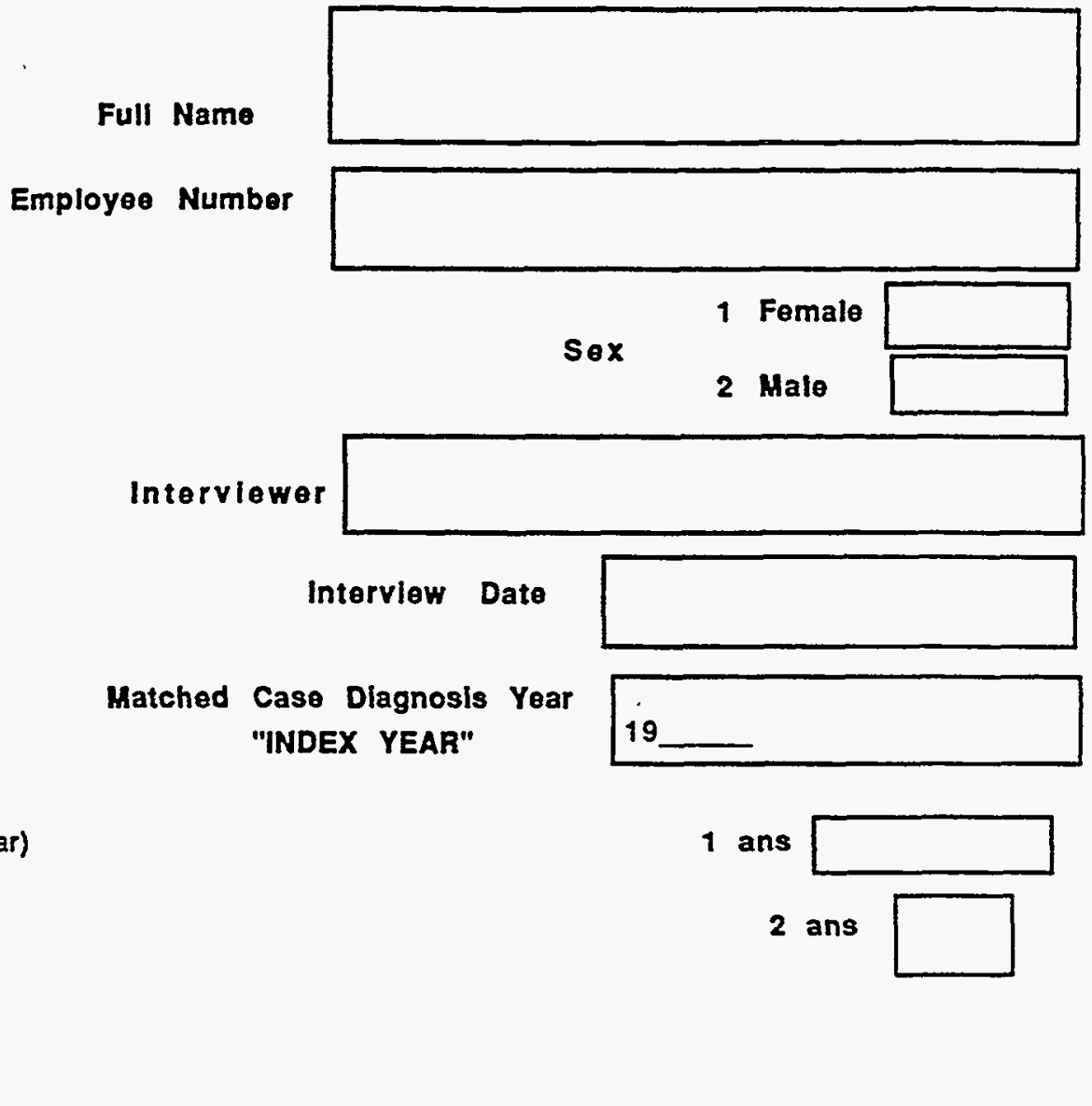

3 What is the ethnic origin of your grandparents on your mother's side? (N.B. Ethnic origin as distinct from birth place)
(0) English, Scottish, Welsh, Irish
(6) Asian
(1) Northern European
(7) Black
(2) Eastern European
(8) Other (please specify)
(3) Southern European
(4) Hispanic
(9) Unknown
(5) Native American (Indian, Eskimo)

3 ans Mother's father:

Mother's mother:

4 What is the ethnic origin of your grandparents on your father's side? (N.B. Ethnic origin as distinct from birth place)
(0) English, Scottish, Wolsh, Irish
(1) Northern European
(2) Eastern European
(3) Southern European
(4) Hispanic
(5) Native American (Indian, Eskimo)

\section{(6) Asian}

(7) Black

(8) Other (please spocify)

(9) Unknown

5 What is your current marital status?
(1) Married
(2) Widowed
(3) Divorced
(4) Separated
(5) Never married
(9) Unknown 
6 What was the highest grade or year of school that you completed?

$\begin{array}{ll}\text { Grade school } & (1)(2)(3)(4)(5)(6)(7)(8) \\ \text { High School } & (9)(10)(11)(12) \\ \text { College } & (13)(14)(15)(16) \\ \text { Graduate work } & (17+) \\ \text { MAMS } & (18) \\ \text { PhDMD } & (19) \\ \text { Unknown } & (99)\end{array}$

7 I am now going to ask you about the places you have lived.

A. Could you please tell me of all the places in which you have lived for more than a year, STARTING FROM WHEN YOU WERE BORN, working forward till now. If you have lived in the same place more than once, lease tell me about it.

B. In what year did you first live there?

C. In what year did you first move from there?

D. So for how long (years) did you live there?

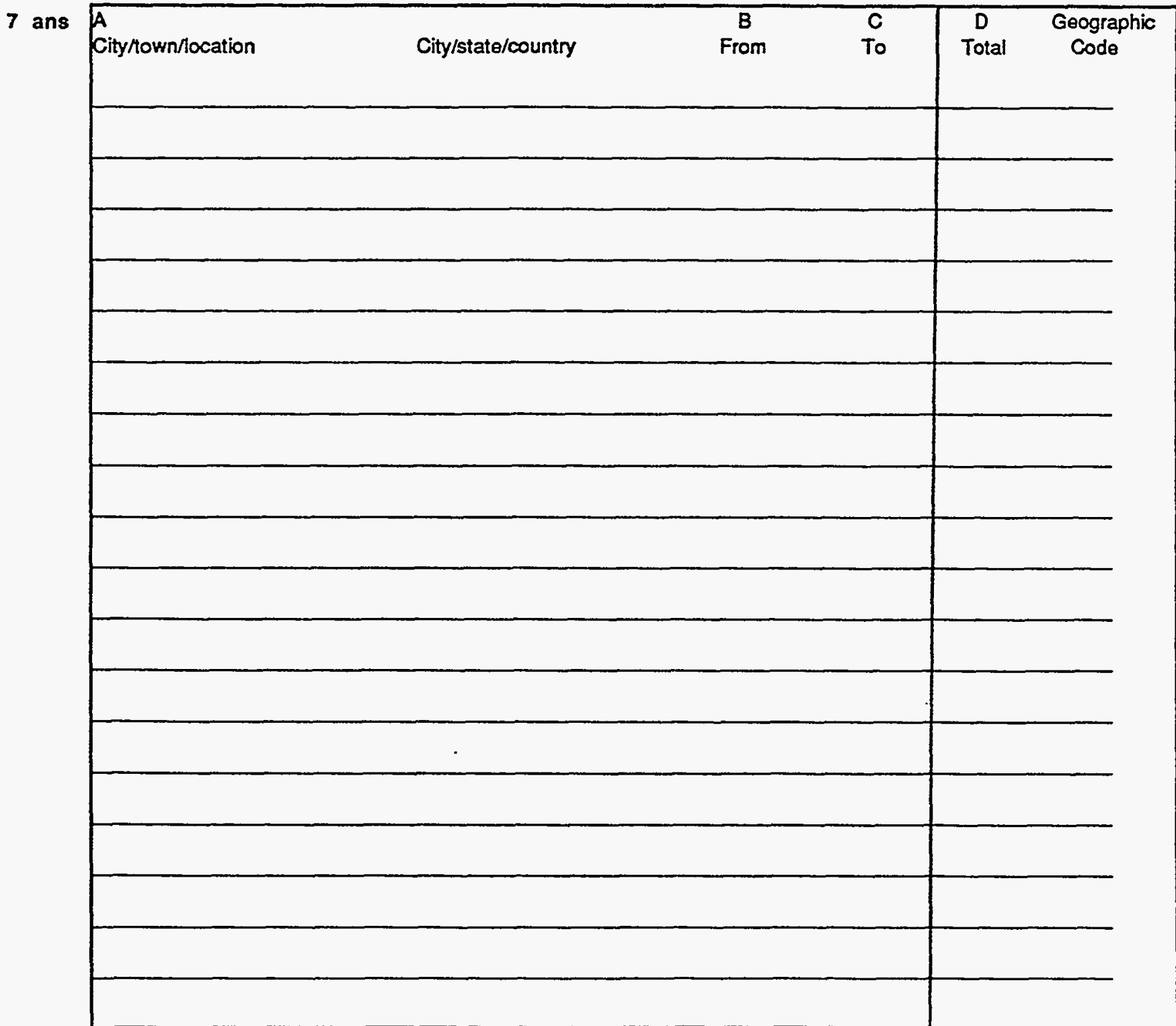


8 What color are your eyes?

8 ans
(1) Blue
(2) Green
(3) Gray
(4) Light brown, hazel
(5) Brown

9 What was your NATURAL hair color when you were 20 years old?

9 ans
(1) Blond
(2) Red
(3) Light brown
(4) Brown
(5) Black
(9) Uncertain

\section{SUNBURNS AND SUNTANS}

I am now going to ask you about the way your sun-exposed skin usually reacts to the sun. Consider what would happen if you used no sunscreen preparation and wore no special protective clothing.

10 What would happen if you had no tan and were to go out in the summer noonday sun for a half hour or so? Would you: (CARD 7)

(1) Usually burn with no tanning.

(2) Usually burn with little tanning.

(3) Usually burn with tanning.

(4) Usually tan with no burning.

(5) Nover burn or tan.

(9) Uncertain.

11 After your skin had been exposed to the sun for a few days, what would happen if you were to go out in the summer noonday sun for a half hour or so? Would you: (CARD 7)

(1) Usually burn with no tanning.

(2) Usually burn with little tanning.

(3) Usually burn with tanning.

(4) Usually $\tan$ with no burning.

(5) Never burn or tan.

(9) Uncertain.

\section{SUN EXPOSURE HABITS}

Now I would like to ask you about your outdoor recreation habits PRIOR TO 19

Of the following, which response best described you the year prior to 19 ?

12 (CARD 8)

(1) I got a fair amount of sun all year and tended to keep a tan the year round.

(2) I got a fair amount of sun during the summer months and tended to keep a tan for this part of the year.

(3) I went out in the sun occasionally and my tan faded and darkened repeatedly.

(4) I went out in the sun occasionally and usually burned but seldom tanned.

(5) I went out in the sun occasionally but not for long enough to get tanned or burned.

(6) When I was out in the sun I was protected by clothing and rarely did I get burned or tanned.

(7) I was seldom out in the sun and rarely did I get burned or tanned.

(9) Uncertain.

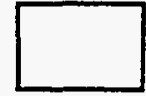


13 On average, throughout the year, how often did you lie out in the sun or sunbathe the year prior 19 ? (CARD 9)

(1) Never.

(2) 1-10 times.

(3) 11-20 times.

(4) 21-50 times.

(5) 51-100 times.

(6) More than 100 times.

(9) Uncertain.

14 Was there a time in your life prior to your diagnosis of melanoma when you sunbathed more frequently?

(1) Yes (If YES ask question 15)

(2) No (If NO skip to question 16)

(9) Uncertain

15 At what time of life prior to 19 did you sunbathe the most? (CARD 10)

(1) Elementary school

(2) High school

(3) Young adutt (up to 30 years)

(4) Adult (over 30 years)

(9) Uncertain or N/A

16 Prior to 19 did you ever indulge in sunbathing in order to obtain a suntan?

16 ans

(1) yes

(2) no (If NO go to question 17)

16.1 How old were you when you first began sunbathing?

16.1 ans

14 ans

15 ans
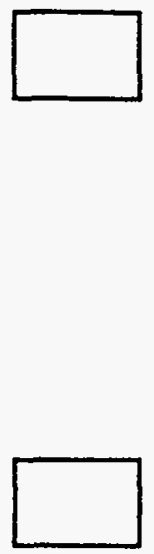
17 Prior to 19 how often had you visited a tanning salon?

(CARD 12)
(1) Never
(2) 1-10 times
(3) 11-25 times
(4) 26-50 times
(5) 51-100 times
(6) More than 100 times
(9) Uncertain

\section{SUNBURN EPISODES}

18 Prior to 19 _ how many sunburns, that actually caused blisters, do you recall during each of the following periods of your life?

\begin{tabular}{|c|l|l|l|l|}
\hline & ElementarySchool & High School & $\begin{array}{c}\text { (18-29) } \\
\text { Young Adult }\end{array}$ & $\begin{array}{c}\text { (30 \& older) } \\
\text { Adult }\end{array}$ \\
\hline (1) Non & & & & \\
\hline (2) $1-10$ & & & & \\
\hline (3) $11-20$ & & & & \\
\hline (4) $21-30$ & & & & \\
\hline (5) More than 30 & & & & \\
\hline (9) Uncertain & & & & \\
\hline
\end{tabular}

19 Prior to19__ had you EVER been sunburnt severely enough to cause peeling of your skin, i.e., pieces of dead skin that could be peeled off - not flaking?
(1) yes
(2) no (If NO, go to question 20)

19.1 How many times in your life has this occurred?

19.2 How old were you when this last occurred?

20 Prior to 19 had you ever been sunburnt so severely as to cause large blisters?

(1) yes

(2) no (If NO, go to question 21)

20.1 How many times in your life did this occur?

20.2 At what age did it last occur?
18 ans

Elom Sch
High Sch
Young Ad
Adult

19 ans

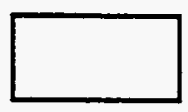

19.1 ans

19.2 ans

20 ans

20.1 ans

20.2 ans 
Prior to 19 how periods of your life?

\begin{tabular}{|l|l|l|l|l|}
\hline & ElementarySchool & High School & $\begin{array}{c}\text { (18-29) } \\
\text { Young Adult }\end{array}$ & $\begin{array}{c}\text { (30 \& older) } \\
\text { Adult }\end{array}$ \\
\hline (1) None & & & & \\
\hline (2) $1-10$ & & & & \\
\hline (3) 11-20 & & & & \\
\hline (4) 21-30 & & & & \\
\hline (5) More than 30 & & & & \\
\hline (9) Uncertain & & & & \\
\hline
\end{tabular}

22 Prior to 19 were you ever sunburnt so as to cause pain for two or more days?

(1) yes

(2) no (If NO, go to question 23)

HOW OFIEN DID THIS OCCUR....

22.1 During the last year prior to 19_?

22.2 During the year before last prior to 19

22.3 Altogether over the last ten years prior to 19 ? $?$ (Total number)

(If subject was younger than 30 years at the time of diagnosis, GO to question 22.5)

\subsection{Between your 15th and 25th birthdays? (Total number)}

22.5 As a child up to the age of ten? (Total number)

\section{FRECKLES THAT CHANGED WITH SUN EXPOSIJRE}

23 Now I want to ask you about freckles. I'd like you to think about your skin as a young adult, and I'm not interested in any freckles that appeared with ageing, but prior to 19 __. So, ignoring these did you have freckles that darkened and faded depending on the amount of sun exposure that you had?
(1) Yes
(2) No
(9) Uncertain

\section{SUNLIGHT REACTION PRIOR TO DIAGNOSIS.}

Now I would like to ask how your skin reacted to sunlight prior to 19

24

Prior to 19 if your skin was exposed to strong sunlight for the first time in summer for one hour, would you ... . (GIVE CARD D)

(1) Get a severe sunburn with blistering?

(2) Have a painful sunburn for a few days followed by peeling?

(3) Get mildly burnt followed by some degree of tanning?

(4) Go brown without any sunburn?

(9) Uncertain
21

ans

Elem Sch

High Sch

Young Ad

Adult

22 ans

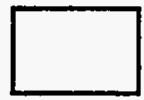

22.1 ans

22.2 ans

22.3 ans

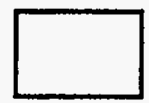

22.4 ans

22.5 ans

23

ans

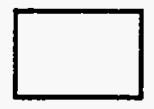

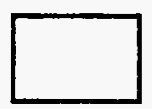


NamelNumber

25 Prior to 19 after repeated and prolonged exposure to sunlight would your skin

become ...

(GIVE CARD E)

(1) Very brown and deeply tanned?

(2) Moderately tanned?

(3) Only mildly tanned due to a tendency to peel?

(4) Oniy freckled or no suntan at all?

(9) Uncertain

\section{OUTDOOR PASTIMES}

This is a list of common outdoor pastimes. (GIVE CARD B). Please tell me the names of any of these or similar activities which you have undertaken on at least ten occasions in any one year prior to 19 sunset.

For each pastime:

(A) Between what ages did you take part in that activity?

(B) And in what season of the year?
(1) summer
(2) winter
(3) other or mixed
(9) unknown

(C) How often would you have taken part in it?

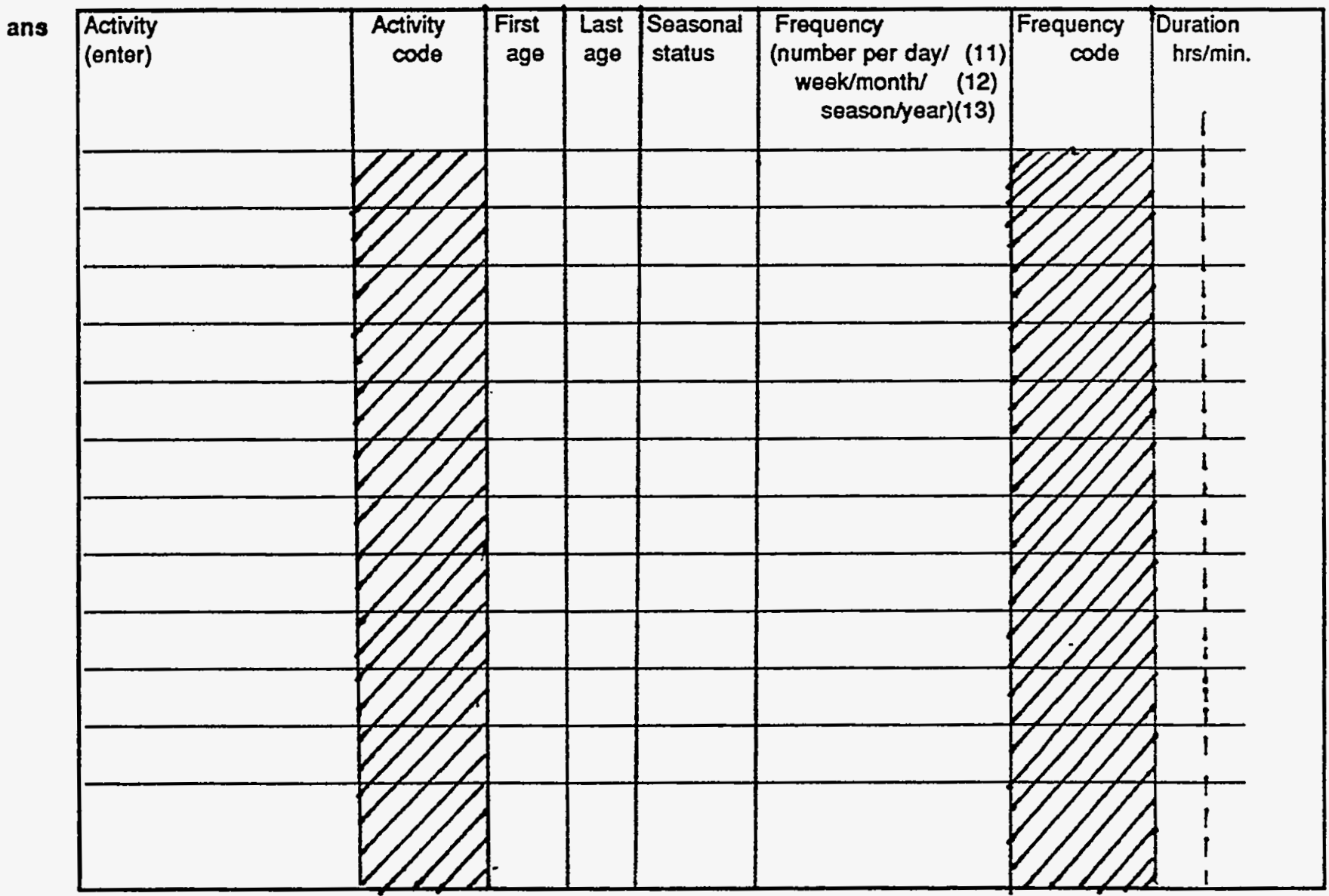




\section{MEDICATION}

27 Have you ever taken tablets to improve skin tanning such as Trisoralen, Oxsoralen or Meladinine for any reason?

(1) yes
(2) no (If NO, ask question 28)

27.1 What was the reason?

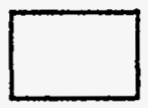

\section{FAMILY \& PERSONAL SKIN CANCER HISTORY}

Please answer all of the following questions UP TO THE PRESENT TIME.

28 Have you had any skin cancers in the past?
(1) yes
(2) no (If NO, ask question 29)

28.1 Beginning with the most recent, please tell me about all the SKIN CANCERS you have had, WHERE each was on your body, THE YEAR IN WHICH IT WAS REMOVED, and THE TYPE OF CANCER IT WAS (precancers not included).

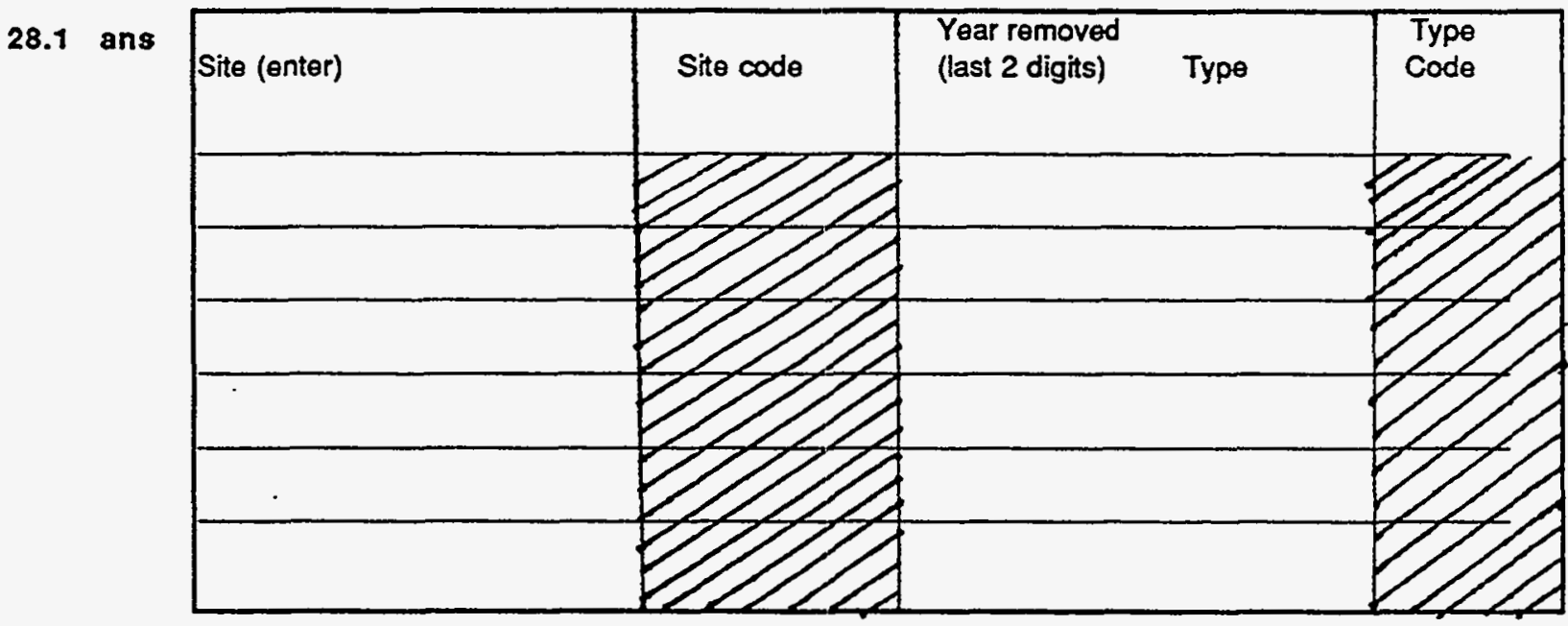

29 Please tell me any of your blood relatives who have had molanoma. By blood relatives I mean persons who are directly related to you, that is, not by marriage.

\begin{tabular}{|l}
\hline Relative \\
\hline \\
\hline \\
\hline
\end{tabular}


30 Have you ever had a mole removed from your skin?

(1) yes

(2) no (lf NO, ask question 31)

30.1 Beginning with the first mole you ever had treated, please tell me where each was on your body, the year of treatment and what the doctor said it was.

30.1 ans

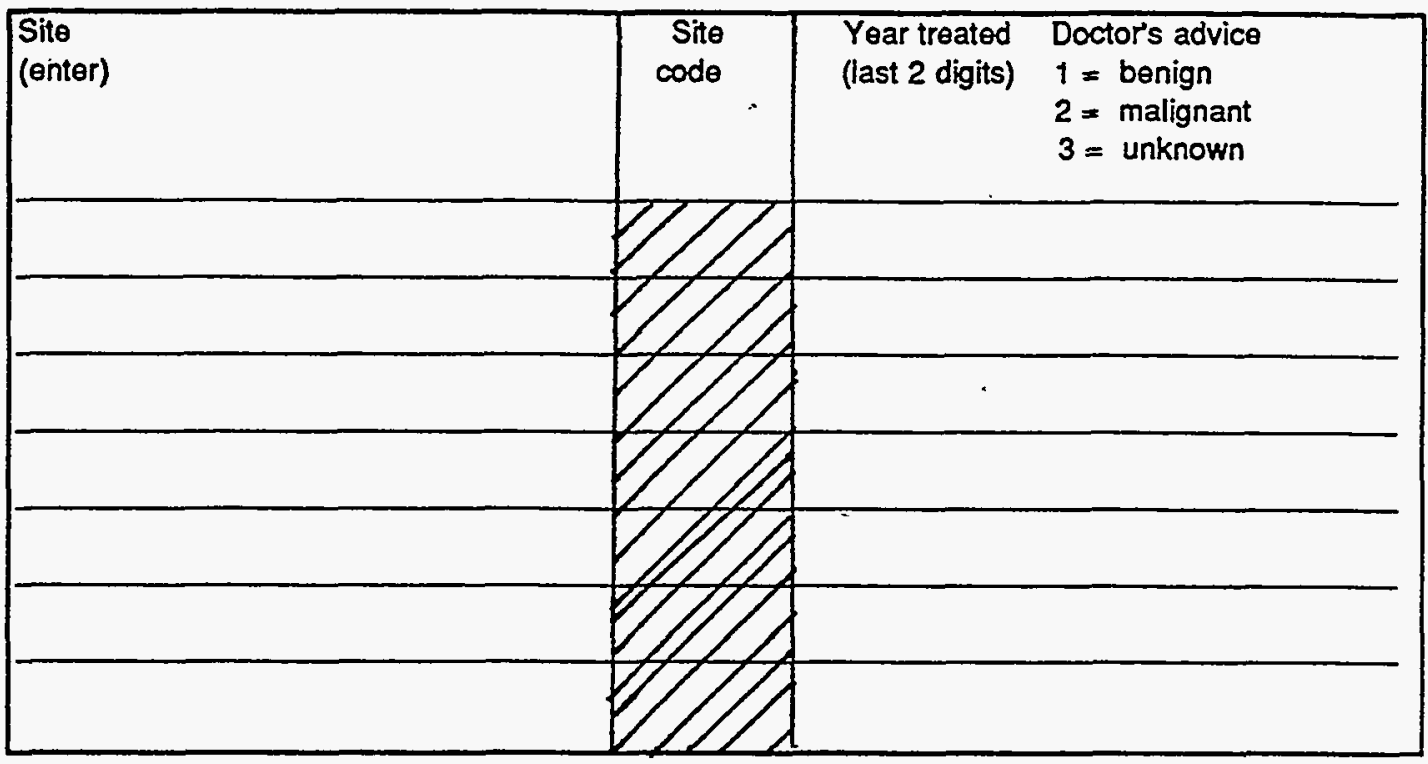

31 Please list any blood relatives who have large numbers of moles on their skin.

31 ans

\section{Relative}

\begin{tabular}{|}
\hline \\
\hline \\
\hline \\
\hline \\
\hline
\end{tabular}


32 Reliability of intormation as assessed by interviewer:
(1) Very good
(2) Good
(3) Fair
(4) Poor
(5) Very poor

33 ans

COMMENTS:

(2)

COMMENTS:

